Crossing the Threshold between Spatial Installation Art and Interior Architecture

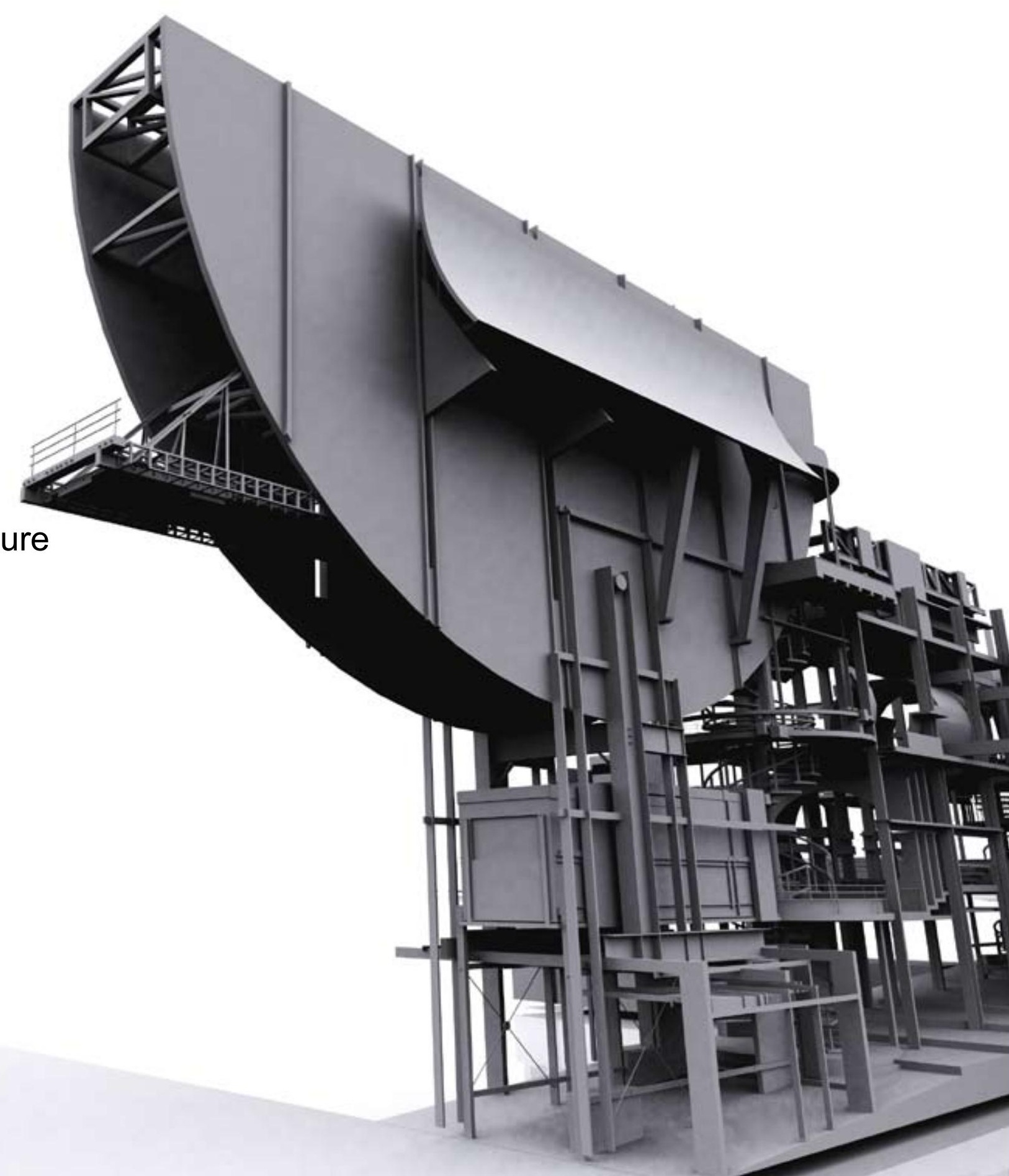





\section{Crossing the Threshold between}

Spatial Installation Art and Interior Architecture

by

Caley Wiki

A Thesis submitted in Partial fulfillment of the requirement for the degree of

Masters of Interior Architecture

at

Victoria University of Wellington

May 2011

Under the supervision of

Associate Professor Daniel K. Brown 



\section{ACKNOWLEDGMENTS}

I would like to express my deepest gratitude to my

supervisor, Daniel K. Brown for his support, guidance and expertise throughout this thesis. He has shown me great

leadership, understanding and the encouragement to move

forward from the beginning to the end of this thesis.

Also many thanks to Jack Thomas and Cissy Zhang. Both have shown me the greatest friendship and support since the beginning of this journey that we have taken together.

I am incredibly fortunate for the friendship of Jeremy Caird who has stood beside me throughout this thesis. I thank him for the caring, support and encouragement he shown me in the times when I needed it most.

Finally, I am forever gratefully to my family. My parents Richard and Dorothy, and to my Nana, for their endless support, love and encouragement to complete this degree. A special thanks for the confidence each has given me. I dedicate this thesis to them. 



\section{CONTENTS}

ABSTRACT

1. THESIS FORMAT

2. THEORETICAL ARGUMENT 15

I. Introduction 17

II. Background 19

III. Review of Practice 31

A. Spatial Installation Artists $\quad 31$

B. Architects 45

Definition

V Conclusion 55

$\begin{array}{ll}\text { VI Bibliography } & 57\end{array}$

3. SITE ASSESSMENT 65

Site Conditions 67

4. DESIGN INTERVENTION

Introduction 81

Final Design Intervention $\quad 79$

Design Analysis 104

Design Conlusion 133 


\section{ABSTRACT}

This thesis explores opportunities to challenge how the nature of spatial installation art might be conceived within the medium of habitable architecture. It explores how spatial installation can take a shift in spatial qualities from space that is occupied to space that is inhabited. It focuses specifically on precedents and opportunities for the use of architectural vocabulary along with materiality, context, ordering systems, and identities to engage the occupant with spatial experience that challenges the boundaries between art and interior architecture. The intent of this thesis is to investigate how such vocabularies can be applied to interior architecture in order to formulate architectural space that society actively interacts in and through. The macro approach embraces multi - functionality allowing freedom for the space to metamorphose when confronted with a new set of social demands by the inhabitant without the space actually needing to physically change.

The thesis investigates the threshold between the realms of conceptual spatial art and programmed habitable architectural space. It examines how an 'installation' can respond to multiple programmatic requirements and the requirements of habitation, as a means of redefining our presumptions of interior architecture. This thesis investigates the liminal boundaries defining a construction as a work of architecture versus a work of art by considering interio architecture as a vital transition between architecture and art.

As a site for this investigation the thesis explores 'interior architecture' opportunities along a pedestrian pathway in Wellington, one which is spatially contained by urban buildings on either side. The selection of this site for an investigation of interior architecture immediately challenges traditional presumptive boundaries between interior architecture, architecture, landscape architecture and urban planning. Such a site provides a critical vehicle for investigating the nature of program and habitability within a constructed installation space that crosses the boundaries into architecture. 
1 THESIS FORMAT 


\section{THESIS FORMAT}

This chapter is the introduction to the research. It outlines the focus and argument of each chapter of the thesis.

The objective of the research is to re-interpret programs held by interior architecture through the use of spatial

installation art as a medium to redefine the presumptive

boundaries of the disciplines. The structure of the thesis is comprised of the three following chapters. Firstly, chapter two

establishes a critical investigation of the existing conditions

of interior architecture and spatial installation art. Secondly, chapter three is a site analysis introducing the importance

of the chosen site in relation to achieving the design

objectives. Thirdly, chapter four is a design intervention that demonstrates the crossing of thresholds between spatial

installation art and interior architecture. 
Chapter One:

This chapter summaries the format and objectives of this thesis. It outlines the objectives of each of the following chapters.

Chapter Two:

This chapter is the theoretical argument that establishes the conditions of the thesis. It firstly establishes the background

of spatial installation art, how the discipline has come to create physical space that can be occupied through the use of architectural vocabulary. The chapter then analyses spatial installation artists who have engaged architectura vocabulary through form but whose space does not invite habitable program. It then moves to analyse architects whose architecture is removed from the conditions of its traditiona boundaries. The chapter finishes with a summary outlining the conditions of both spatial installation art and interior architecture, this creates the understanding for how the boundaries of each discipline can be crossed.
Chapter Three:

This chapter analyses the chosen site of Woodwood Street (a pedestrian walkway) for the design intervention. This chapter progresses from the investigation of the urban context: Wellington City down to the analysis of the conditions of the site itself and its surrounding buildings that contain the alleyway.

\section{Chapter Four:}

This is the final chapter of the thesis and shows the design conclusion that is the design intervention. It analyses how the design has become a piece of architecture that is driven by spatial installation art. It investigates how program enables habitability to become the defining characteristic of the design and how this is determined by the occupants of the space. The design intervention is expressed both as a piece of interior architecture and spatial installation art expressed through the poetics of space. 

THEORETICAL ARGUMENT 



\section{INTRODUCTION}

"When I look at the environment outside, you see how resistant architecture is to change. You see how resistant it is to those very ideas. We can think them out. We can create incredible things. And yet, at the end, it's so hard to change a wall. We applaud the well-mannered box. But to create a space that never existed is what interests me. To create something that has never been, a space that we have never entered except in our minds and in our spirits, and I think that is really what architecture is based on. Architecture is not based on concrete and steel and elements of the soil. It is based on wonder. And that wonder is really what has created the greatest cities, the greatest spaces that we have had. And I think that that is indeed what architecture is, it is a story."

The thesis began with a critical analysis of Daniel Libeskind's talk on ' 17 words of architectural inspiration' and his argument of architecture's need for change of the 'well mannered box' in order to create something new and unexpected. He suggests that architecture need not be constricted by the box or two presumptive walls. As an interior architect, the challenge of this thesis goes beyond Libeskind, to invite and evoke the entire city to become the presumptive environment within which interior architecture can be held.

This is a thesis investigating interior architecture from the point of view of applicable aspects of spatial installation art and how to challenge the presumptive boundaries between the two disciplines. The site for the investigation of the thesis is the alleyway of Woodward Street in Wellington, this provides an exterior urban space that can be treated as interior architecture or as a spatial installation. The thesis will begin with a summary of the history of the development of spatial installation art. The thesis will then present case studies where installation artists begin to cross the boundaries into the field of interior architecture. The thesis will then argue that by applying certain elements of program and habitability to spatial installation art, the qualities of both can become integrated and enhance the narrative nature of interior architecture. 


\section{BACKGROUND}

i. This section of the thesis explores the evolution of installation art, specifically how installation art has developed into the use of architectural vocabulary in spatial installations. It investigates how installation has been derived from the notion of manipulating two-dimensional space, the manipulation of objects including sculpture as well as the manipulation of architecture including interiors into three-dimensional space which is occupied as a spatial installation. The section shows both the development of installation as a spatial experience and the importance of the audience interaction and occupation of created spaces to complete a work.

The term 'Installation' within the world of art, at one stage was literally to distinguish an activity of the physical act of how a prefabricated work of art was exhibited. The idea of an art form being an activity is not far from the current meaning of the term 'installation art'. The term is a fairly new one, which now is a large movement that has progressed from this original meaning above. Installation art has developed to establish principles of relationships between numerous elements, forms, media, and contexts generating an extensive discipline. Its broad scope is established by this maturation from multiple disciplines, along with their histories, creating the use of multimedia and diverse culture in which it now sits. Installation art's general description is three-dimensional site-specific works, designed to transform space and the perception of space. This focus on space has created a movement away from other three-dimensional art forms such as sculpture, where the focus lies in form, into installation, where the focus is the manipulation of space and the creation of an experience revealed to the audience.

As installation art is closely related to and crosses the boundaries of other disciplines, it has gathered numerous related terms, i.e. site specific, public, environmental art works. It is also closely related to 'earth sculptures' and 'site works'. Site works are exterior works of art dealing with similar principles to that of installations. These are works that deal with subtraction, carving, rearranging and the placement of objects and space. This relationship to other disciplines and definitions embraces installations' contemporary stance in the art world as an all encompassing discipline.

The idea of an art form embracing multiple disciplines began as early as 1849 through Richard Wagner's concept Gesamtkunstwerk (total work of art), referring to his ideal of unifying all works of art. Originally concerned with uniting music, poetry, the visual arts and dance, it has since been applied to numerous entireties such as painting, sculpture, installations, and architecture, etc. Through this, installation art shifted the approach and thinking being taken by the realm of art demanding a new movement. Its position in the art world has grown to capture the audience within an experiential, spatial and visual response. Through its history it continued to establish itself away from fine arts through a shift in focus: "Installation is a shift from art as an object to art as process, from art as a 'thing' to be addressed, to art as something which occurs in the encounter between the onlooker and a set of stimuli." ${ }^{2}$ 
Futurism, a movement originating in the early 20th century, was another movement to explore art using every medium. It was similar to the qualities of Gesamtkunstwerk, both offering installation art possibilities for exploring of collaborative new techniques and media such as literature, film, sculpture, architecture. These could be applied together, or realised with a collaboration of the traditional, to create 'new' art.

In addition it explored the idea of using multiple disciplines and what they could offer art when the boundaries of their discipline met or crossed.

\section{A. Two-dimensional Development}

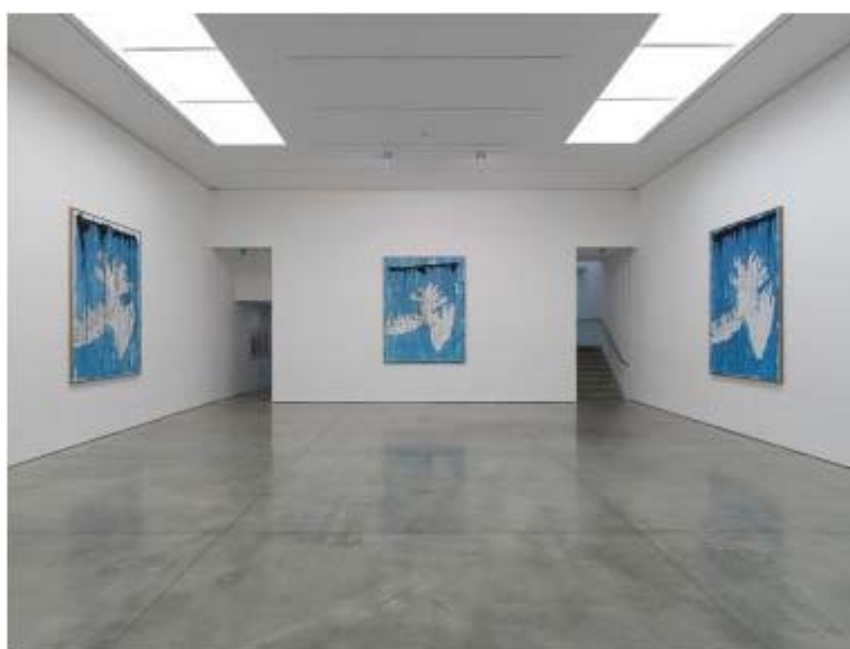

Figure 1 : Georg Baselitz "Between Eagles and Pioneers” Exhibition, 2011
Brian O'Doherty's paper in 1976 entitled 'Inside the White Cube: The Ideology of the Gallery Space' argues how the control galleries' spaces (the white cube) have construed the meaning of art housed within it. O'Doherty believes in the need to move beyond this space and involve the audience's experience and interpretation of art. He stated "there is no suggestion that the space within the picture is continuous with the space outside it." 3 These ideals have been developed through the manipulation of two-dimensiona space into three-dimensional art movements such as

Collage and Spatialism which helped evolve installation art in many ways. Collage began to alter a flat picture plane by the build up of elements that extruded out into the physical space of the exhibition. Artists used the processes of layers upon layers, often using mixed media to challenge the aesthetic of interior spaces by this extrusion of art out into the physical environment of the audience rather than flat twodimensional works. The movement 'Spatialism', founded by Lucio Fontana was outlined in his Manifesto blanco (White Manifest) published in 1946 and was embodied in his works of holed and slashed canvases of the 1950s. His slashed canvases moved space through and beyond the traditional picture plane. The movement aimed to "transcend the area of the canvas, or the volume of the statue, to assume further dimensions and become an integral part of architecture transmitted into the surrounding space and using new discoveries in science and technology." ${ }^{4}$ It was amongst the first to consider the idea of creating art that dealt with using and making space. Spatialism illustrated a necessity for a distinctive spatial art form, by exploring the use of new media and technologies. It embodied a union not seen before to create unity between fine arts and science. Fontana intended the integration of colour, sound, space, movement, and time into this new type of art. His ideals were influential in the foundation of spatial installations, for he was one of the first to promote the idea of art as a gesture or an event 


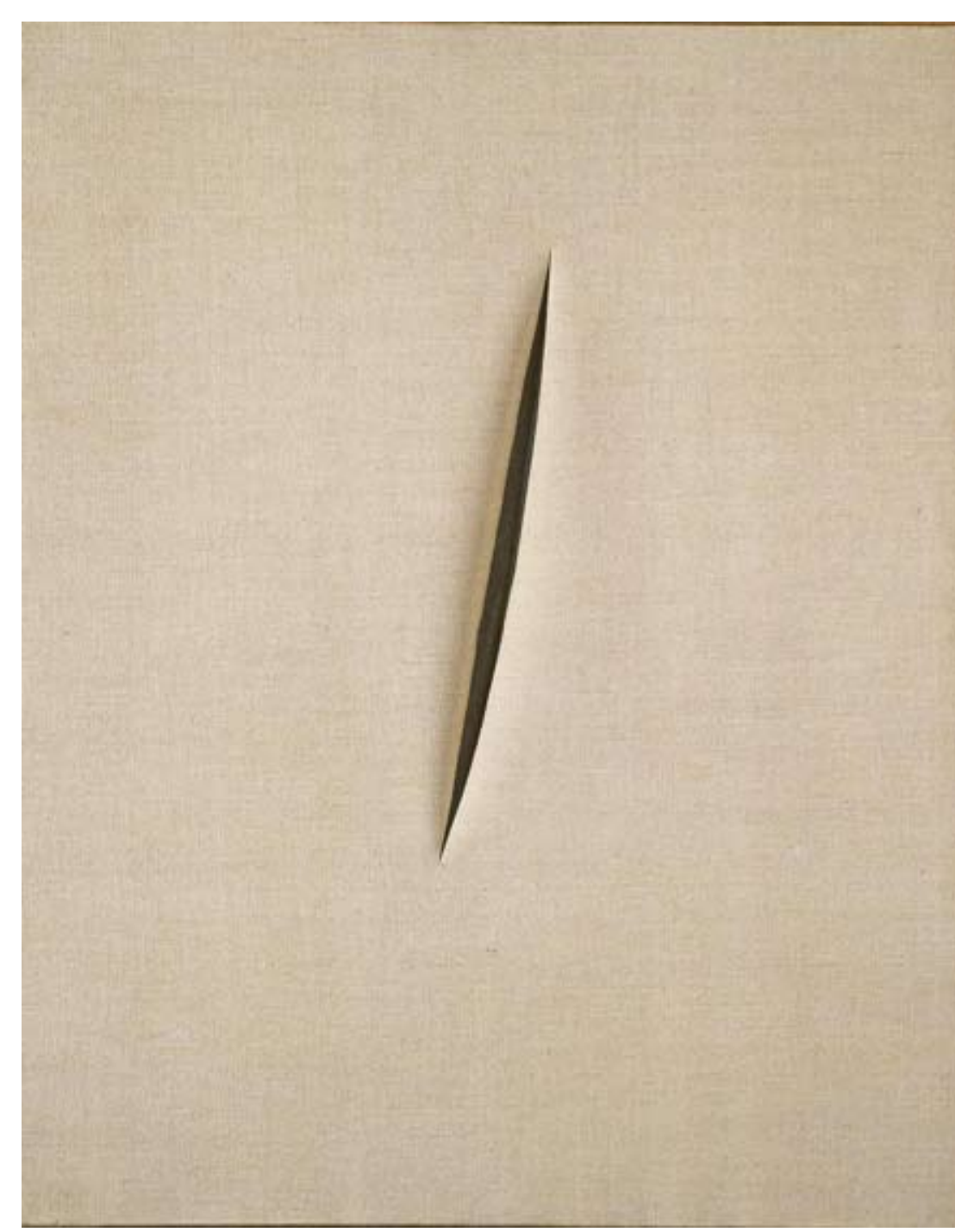

Figure 12: Lucio Fontana, “Spatial Concept: Expectations",1960 rather than as the creation of an enduring physical work.

Spatial installations have maintained this throughout their development, generating art that is more than form but rather involved in the creation of space, narrative or event.

\section{B. Three-dimensional Development}

Three-dimensional art movements such as Found Art and Sculpture largely influenced installation art as a spatial medium. The exploration of space in installations has been developed by a progression from 'Found Art' (art created from found objects that are not normally considered art). Marcel Duchamp was an artist who originated Found Art by challenging these boundaries of space and art, calling his works 'readymade'. His first work entitled 'Bicycle Wheel' was in 1913 followed by his controversial work 'Fountain' in 1917. Duchamp chose his objects on their 'visual indifference' or 'no aesthetic emotion'. ${ }^{5}$ Like many new and unconventional ideas that push the boundaries, many of his works of art were dismissed by the art world at the time, only to be accepted and considered innovative and boundary pushing at a later date. The works began to create an exploration of real space, with real objects and real form. Found Art explored a progressive concept of placing common objects within a gallery space to challenge what could be considered and accepted as an artwork. It intended the audience to contemplate and reflect on the object in a new and unfimiliar context, considering its meaning within a new context. Often the found objects were modified in some form, either with other found objects or by repositioning, joining or tilting the objects. 


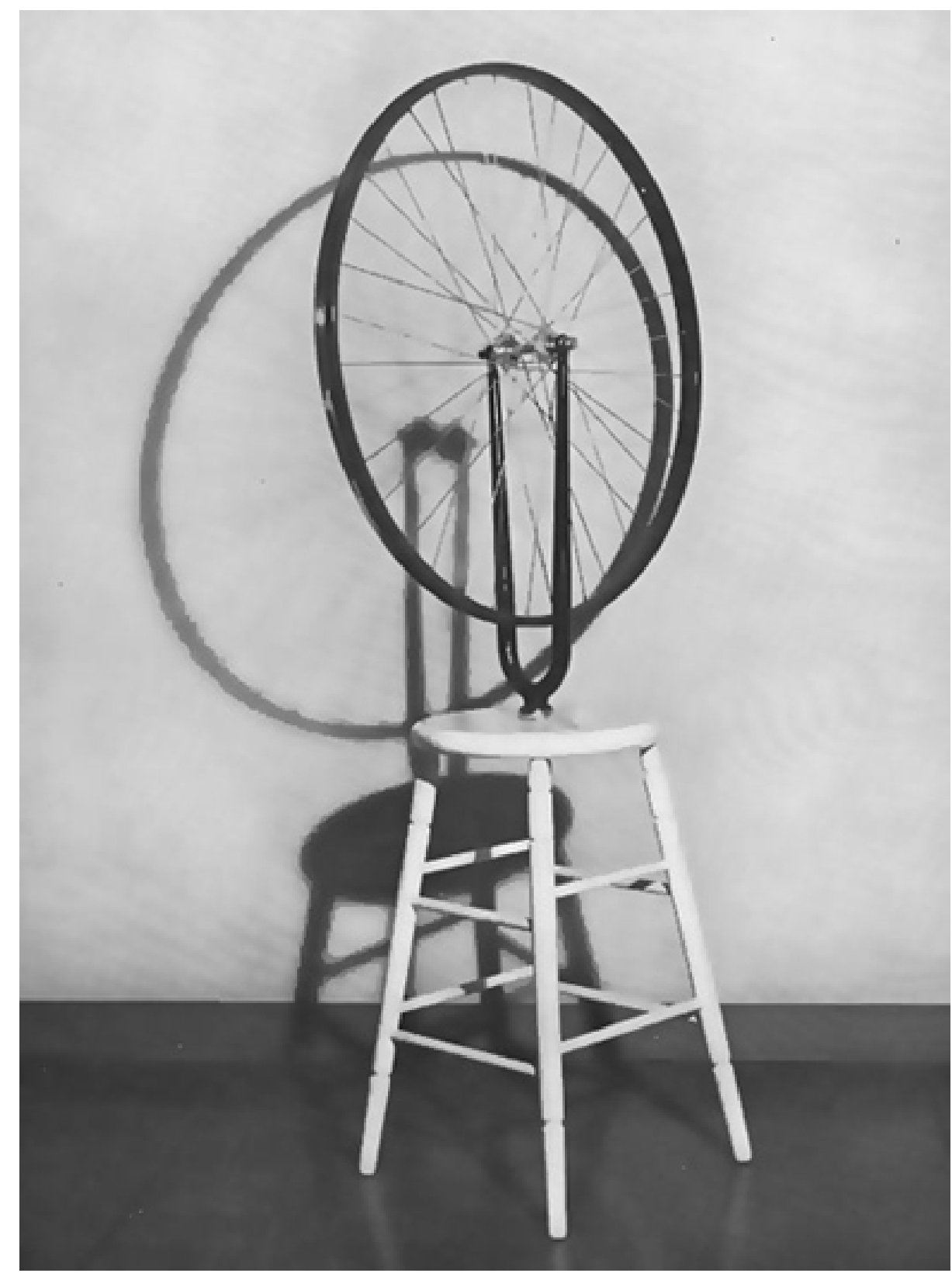

Figure 3: Marcel Duchamp, 'Bicycle Wheel' 1913 


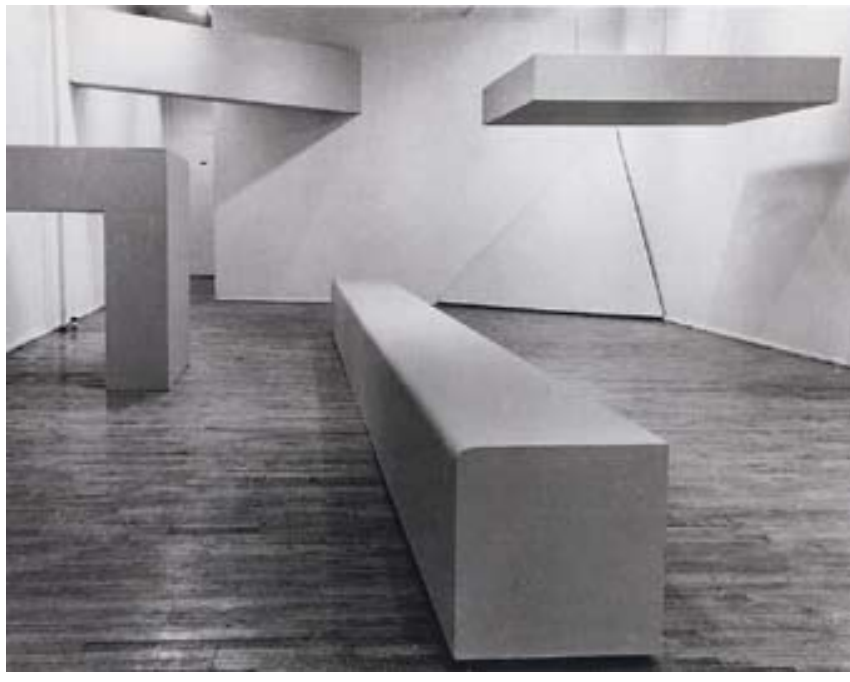

Figure 4: Robert Morris, installation in the Green Gallery, 1964

Robert Morris's 'Notes on Sculpture' in 1966 explored minimalist sculpture and the continuation of the involvement of the audience with an object, as they can exist, in one physical space - a hugely influential idea in the development of spatial installation art where the focus is to create spatial experience the audience can occupy. Morris suggested this created minimalist sculpture work as a function in the audience's 'field of vision'. He claimed that: "The object is but one of the terms in the newer aesthetic... because one's awareness of oneself existing in the same space as the work is stronger than in previous work." 6 These same views have been applied and then furthered by spatial installation art, as the audience plays a part in the meaning and completion of the artwork itself, but also through their physical act of entering the space created by an artwork. It is through this creation of space that one can enter that spatial installation took a shift away from sculpture as a three-dimensional art

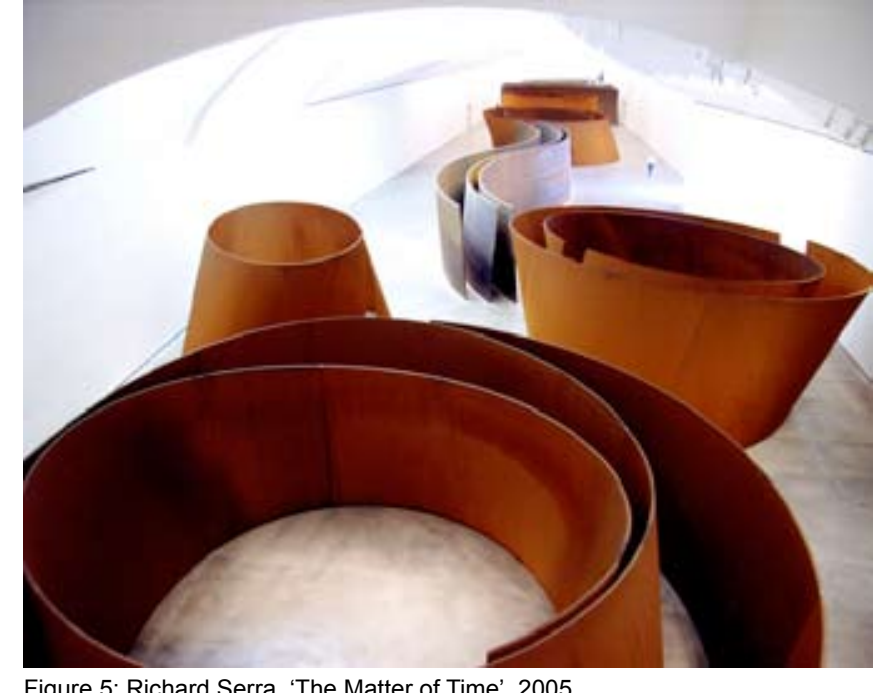

Figure 5: Richard Serra, 'The Matter of Time', 2005

form. The form was no longer an object viewed from the exterior but a spatial experience for one to enter.

Richard Serra is an artist that embraces minimalism's ideals and the creation of space through his installation art. From 1966 onwards Serra has been known for his large scale, site specific works; his works created accentuated materiality and space. He believed that each viewer created the installation and space for themselves by occupying the work, generated by their connection with the sculpture and context as they moved around the forms. He designed with the idea of the site, object and audience being equal parts to the artwork. Also during the 1960s Donald Judd removed his works from the term 'sculpture' and termed his art 'threedimensional work'. This was to suggest how these works of art had taken a direct shift away from the origins of art forms such as sculpture and found art. ${ }^{7}$ Judd's work instead paid 


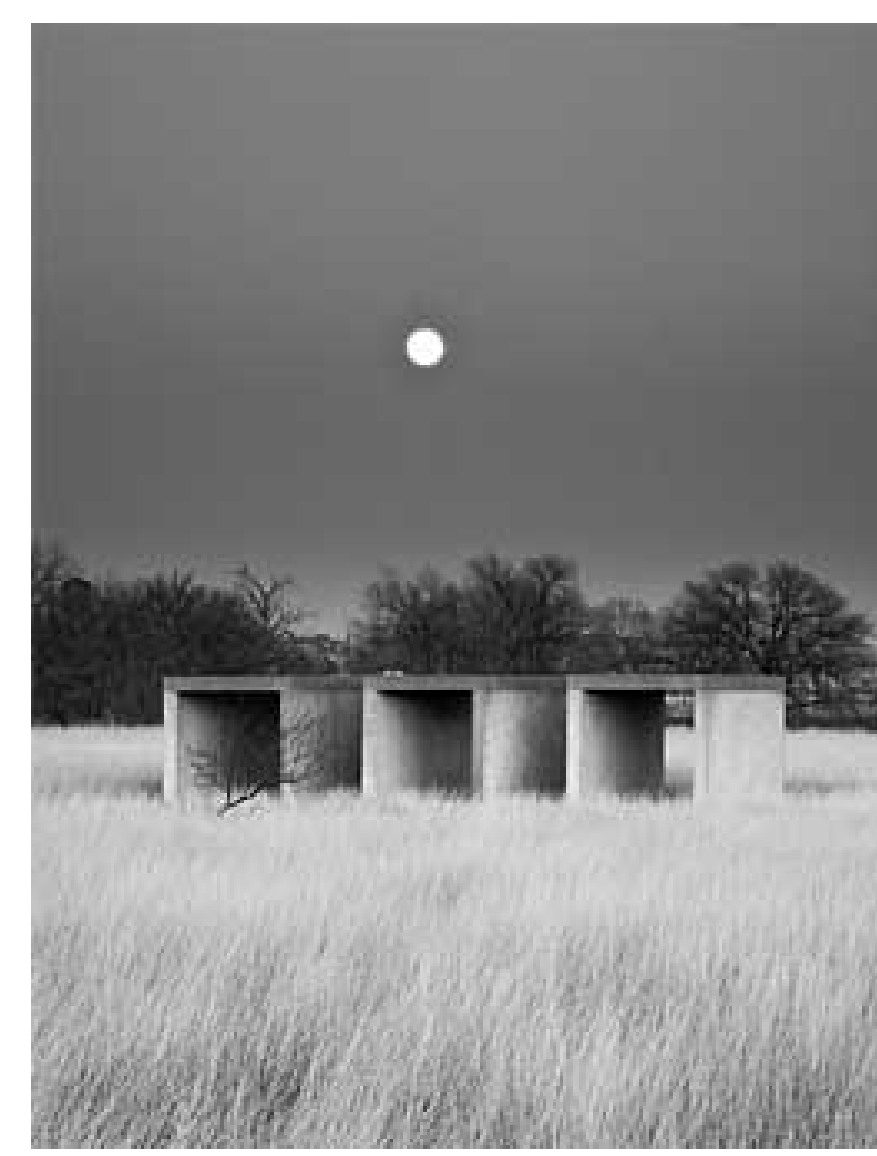

Figure 6: Donald Judd, "Untitled" 1980-1984

particular attention to the relationship between the object, the viewer, the space and its environment. His 'untitled' freestanding concrete works at The Chinati Foundation introduced architectural vocabulary into his work such as order, repetition and hierarchy; he explored these systems in architectural formulations of space, where the relationship between object and context created new space.

An artist that had a large influence over the progression of spatial installation art as an active physical space was Allan Kaprow. In 1957 Kaprow developed the terms "Environment" and the "Happening" which were literal discoveries of

activities that took place within art. These dealt with the art form of performance, actions, event, context and situation. The intention of "Happenings" was to create a performance in art. The works were focusing on eliminating the boundaries between the artwork and the audience, involving the audience within the artwork and eliminating the boundaries of the gallery walls, moving beyond them to the outside. The "Environments" were often works that filled a space, and / or enveloped the room. These works also relied heavily on the involvement of the audience, offering them a chance to occupy the art itself, to enter a new space created solely by the work itself. The audience often had to make choices on how to interact with the work, i.e. which pathway to take. These conceptual ideals were the predecessor of the "Happenings" and eventually "Happenings" were embraced within the art world. Kaprow created a bond in his works with the environment and audience. They were able to discover the art work for themselves as they moved through the narrative. This freedom Kaprow believed was essential as the 'environments' changed and altered with how the audience found themselves within an environment and discovered this narrative. This began the shift from 'art as an object to art as a process'. ${ }^{8}$ Kaprow considered art as experimental and that the nature of the environment that an artwork existed within played a fundamental role in the meaning of the work. This in turn shaped a need to involve and respond to the environment. This set of principles created early spatial installations which were to discover the 'environment' and 





to create an understanding of the surrounding in which the audience stood.

"Performance is the replacement of the word happening, or event, or activity, which we used in those days to refer to a number of somewhat, related kind of real time events. What's called installation today is the child of what used to be called before the happenings, and environments."

\section{Architectural Transformation}

The transformation of architectural space for the creation of a spatial installation began in one of the earliest works, now classified as an installation, by Kurt Schwitter sometime between 1919 and 1923 up until the mid 1930's. The work titled 'Merzbau' no longer exists as it was destroyed in the British air raids in 1943. 'Merzbau' was constructed and spread to numerous rooms within his house, over a number of years. Schwitter invented the term 'Merz' which he applied to all his works including poetry, collage, paintings, and constructions. 'Merzbau' was no exception and fell under this category. The installation was unfinished as it was continuously growing and changing as Schwitter saw fit. Schwitter was known for his use of collage, found art, montages, and assemblages and 'Merzbau' was a collaboration of them all. The work began on the walls of his studio before it enveloped eight rooms on multiple levels of his house. Merzbau stretched across spaces on both vertical and horizontal planes. It was assembled with found materials and objects to construct columns and sculptures which were all fixed to the architectural structure of the house. $\mathrm{He}$

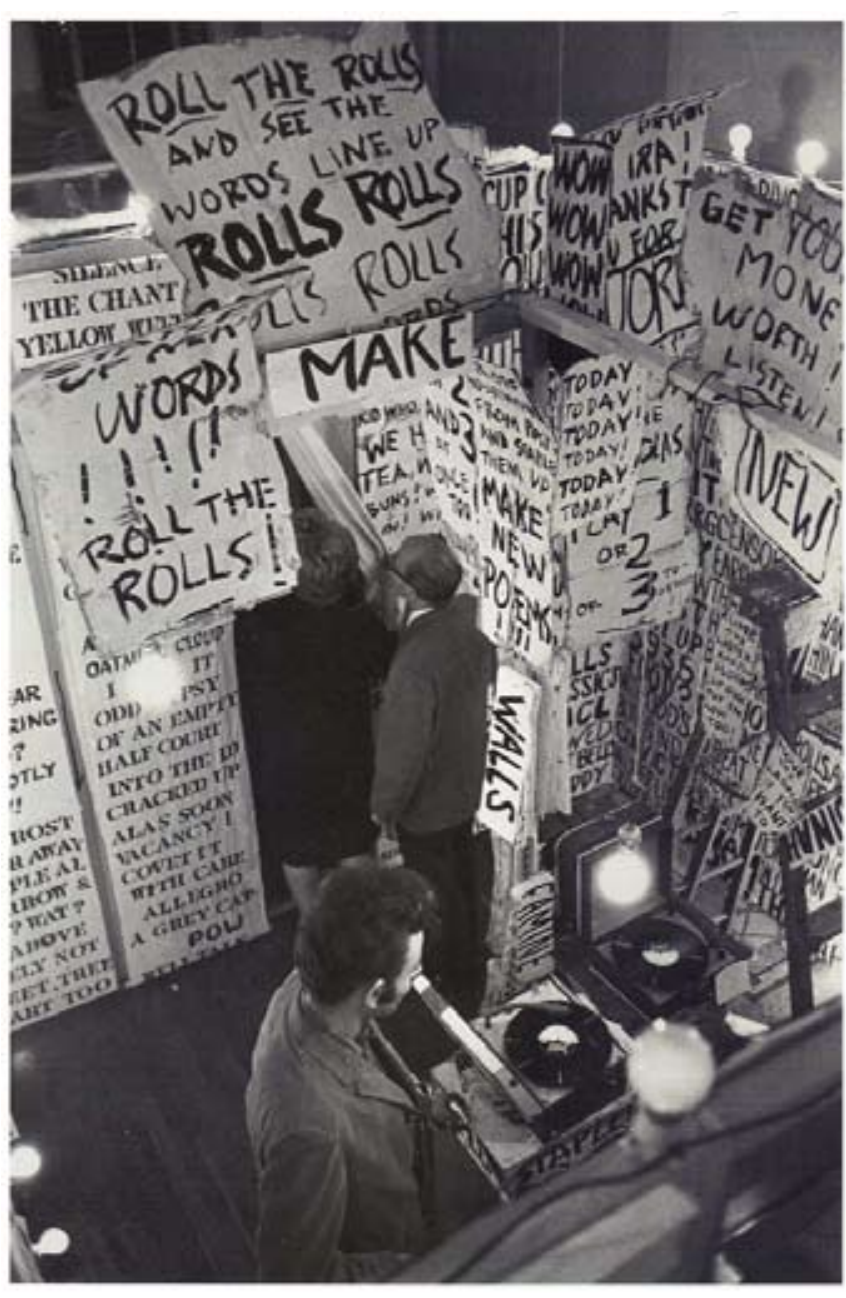

Figure 8: Allan Kaprow, 'Words', 1962 


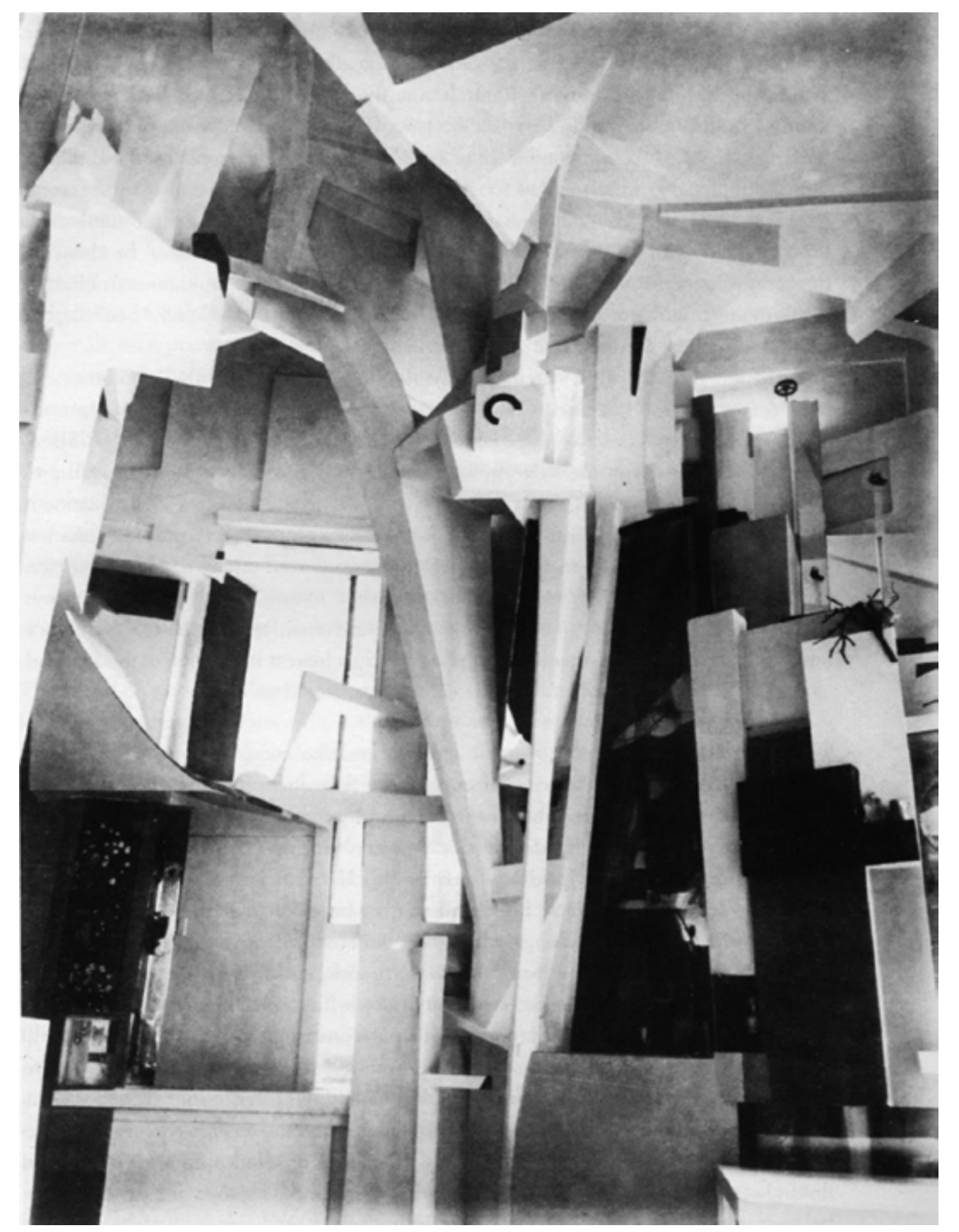


cut into the house creating apertures to continue extending the work within, creating new interior voids and tunnels in which he would often display other works of art. This work is the first example of architectural vocabulary used within an installation to create a spatial environment. It was an architectural construction that created relationships between object and object, space and space and construction and construction. Schwitter's aim of the work was to alter the interiors of his house and explore how these relationships could grow and express form through which he transformed the space into a sculptural environment.

Spatial installations have retained these fundamental ideas developed through its history, with a key principle now being the introduction of the viewer entering and occupying the artwork itself, as a spatial experience or 'environment'. The 'experience' is created by the encounter of the viewer into the artwork so that the meaning of the artwork is 'not contained entirely within its frame or form' but rather in the relationship created by entering space between the audience, the context, and the form. ${ }^{10} \mathrm{~A}$ Spatial installation is created by the process of viewing art where it no longer is about a 'fixed point of view'. 11 The audience now moves around and in the artwork, often involved within creating the social experience or narrative. In fine arts the gallery is a vessel in which to house an artwork; spatial installation art however incorporates this vessel into the work as the context that informs not only the art but the audience too. The context of a spatial installation becomes the canvas on which the work of art evolves and builds. Many artists, such as Mary Miss (e.g. 'Perimeter/Pavilions/Decoys') designed their own spatial container through the spatial installation itself; the context then became involved within the meaning and content of the work. Spatial Installation began to take into account the environment and the audience's journey and sensory experience. Artists believe that involving the

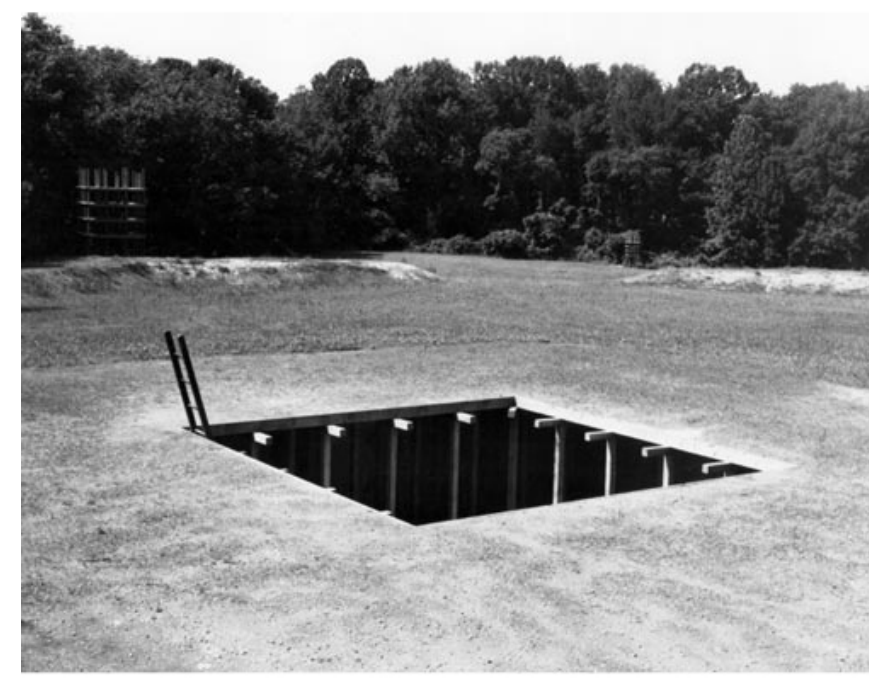

Figure 10: Mary Miss 'Perimeter/Pavilions/Decoys', 1977-1978

audience within the work is a huge part of understanding the work itself, which over history constantly progressed into involving cultural, social, and related topics of the time to express a meaning and connect the audience through a physical experience.

These different forms of manipulation of picture plane, object and architecture have continued to be developed by artists to create spatial installations that challenge the way space is perceived and objects and forms are occupied. Spatial Installation art has developed to hold a unique identity within the art world. Artists create works that have been designed not only with form and aesthetics in mind, but space, audience and site all holding equal importance in the experience and understanding of a work. The movement was derived by numerous avenues: the manipulation of picture plane and two-dimensional space, as well as 
the manipulation of object and sculpture, and thirdly the manipulation of architecture and interior spaces. It has

embraced the concept that the environment within which the artwork is embedded plays an integral part in constructing

spatial environments that are in an active dialogue with

the meaning, experience and narrative of the holistic

work. It merges the boundaries of many disciplines and art

movements through history in order to invite the audience to

enter, touch, occupy and be involved within an experience of a built environment. Spatial installations developed to involve

the interaction between built form, architectural vocabulary,

environmental site, and the extensive use of common objects often in unexpected contexts.

This summary of the history of spatial installation art critically analyses how it has developed through the manipulation of different dimensions to construct space within art. Also its development into art which the audience can enter and occupy spatial experiences that provoke new understanding of the built environment. This understanding of the history of spatial installation creates a foundation for this thesis allowing it to develop further these principles of installation art with the collaboration of interior architecture. The thesis will now look at specific examples of installation artists who use architectural vocabulary to construct spatial environments. 



\section{REVIEW OF PRACTICE}

A. Spatial Installation Artists

"The boundary between self and other is fluid rather than fixed: the other is included within the boundary of selfhood. We are talking about a more intersubjective version of the self that is attuned to the interrelational, ecological and interactive character of reality." 12

ii. This section analyzes contemporary installation artists who clearly engage architectural vocabulary to explore spatial environments that can be occupied by the audience. These spatial installations deal with both conceptual and physical space with a focus on altering the space in which it sits and is created. It considers the characteristics each artist has developed to construct their own sense of space and how the works have evolved to invite artists and architects to challenge presumptive thresholds separating installation art and interior architecture.

Spatial installation art has mainly grown from the manipulation of numerous disciplines including architecture arts, landscape architecture and interior architecture. As such it draws principles from each discipline establishing the works as part physical experiment, part personal and artistic expression and part designed space. This chapter explores various artists whose spatial installations use architectural vocabulary in order to create spatial experiences that the audience are able to enter and occupy. The chosen artists establish their own sense of space through the selection of medium, narrative, spatial formulation and ordering systems that evolve the works into challenging the viewers' experiences and perceptions of the space and environment. These experiences allow visitors to perceive a very different sense of entering a work rather than viewing a work. Each artist deals with their own sense of space as form, allowing the audience to perceive their own sense of the work through physically entering the experience. Although these artists are creating space they have not engaged the space with habitation or programme. This is the fundamental difference between Interior Architecture and Spatial Installation Art. The ultimate objective of this analysis is to further understand differences between the two disciplines of Spatial Installation and Interior Architecture in such a way as to inform the aim of the thesis. It is to challenge the collaboration of these two disciplines through the use of spatial installation art as a design medium that will be informed by the application of habitation and programmatic nature of interior architecture. 


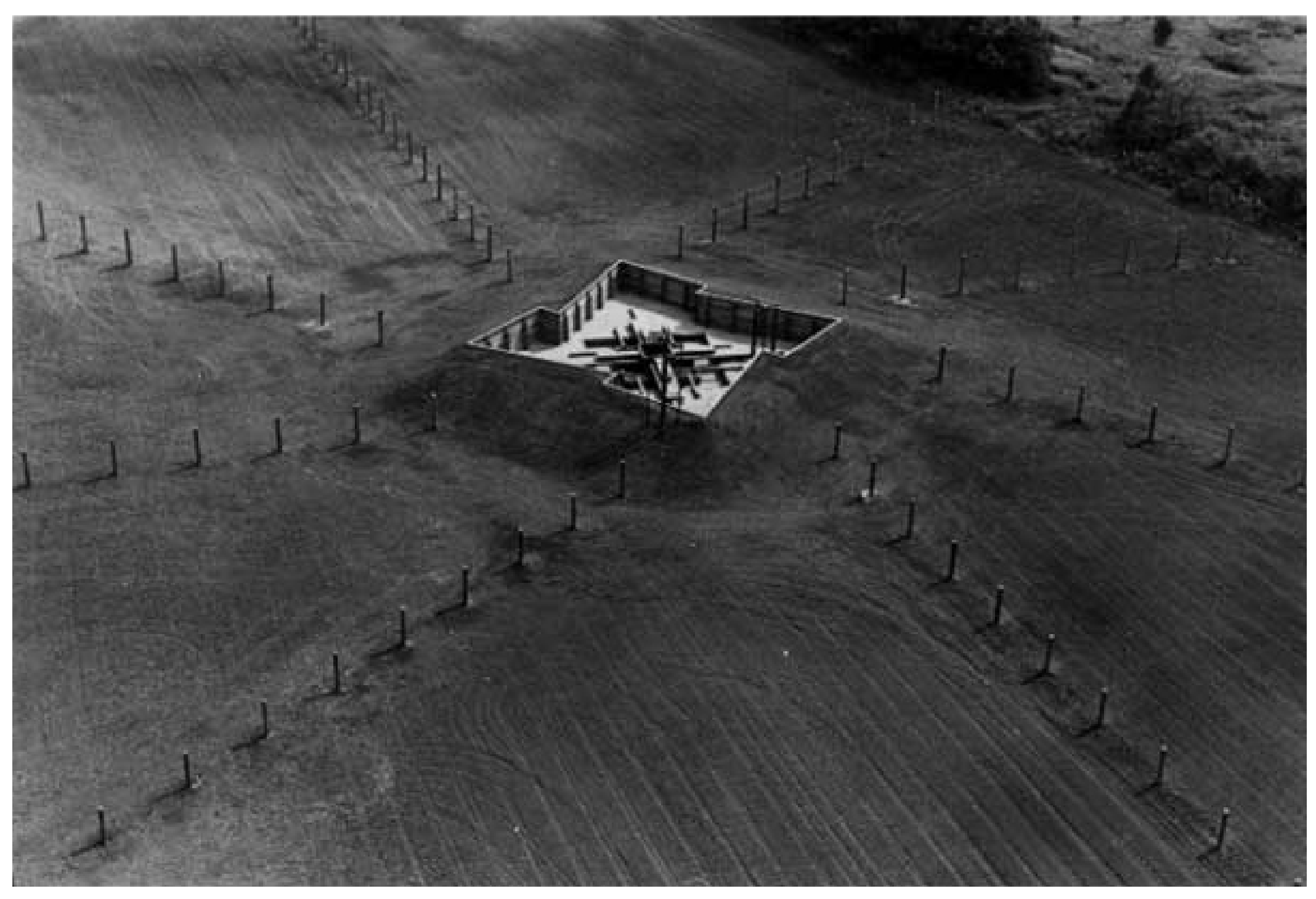




\section{Mary Miss (USA 1944 -}

"We began thinking about the deconstruction of defined territories and disciplines and trying to put things back together in a different way." ${ }^{13}$

From the 1970s Mary Miss is an artist who through her spatial installations has reshaped the boundaries between sculpture, architecture, landscape architecture and installation art. Miss is interested in questioning physical, spatial and emotional boundaries; her projects can be seen as in-between spaces. Many of her works are constructed in exterior environments opening the works to the public and exposing the work beyond the confinement of the architectural vessel of a gallery space. Miss's works explore a transition in space and scale from the human scale to the urban scale. Miss uses the contexts (interior or exterior) in her works as a tool for making 'space'; rather than a 'canvas' in which a work sits, she creates the notion of being 'within' the outside.

"Miss's works moved past the viewer occupying the same space as an object to involve the viewer, to enter the object and its materiality." 14

The artwork 'Field Rotation' uses the landscape to create its own architectural container allowing the audience to enter the work and context as one space. It is situated in the middle of an expansive field; as one approaches, the earth rises to a mound at eye level with the horizon. Miss uses the land as a malleable material, moulding it to a form that creates encompassing space. The work then drops down, excavating the earth to form the architectural container. Once occupying the space, the audience is eye level with the landscape and can look beyond using the architectural structures within of platforms and walkways to gain different vantage points. These architectural structures are timber constructions within the container that Miss has designed to frame the landscape; as one moves about the project the audience can move to different levels being exposed to views beyond the project.

The space of the artwork which the audience enters extends beyond the architectural container, the 'posts' that spiral out from the centre introduce the work to the audience before even being held within the created container. These 'posts' give the container a sense of centrality to the work and a destination to the audience. Through entering the artwork itself the audience has negotiated with space and form, making the 'object a transitional space'. ${ }^{15}$

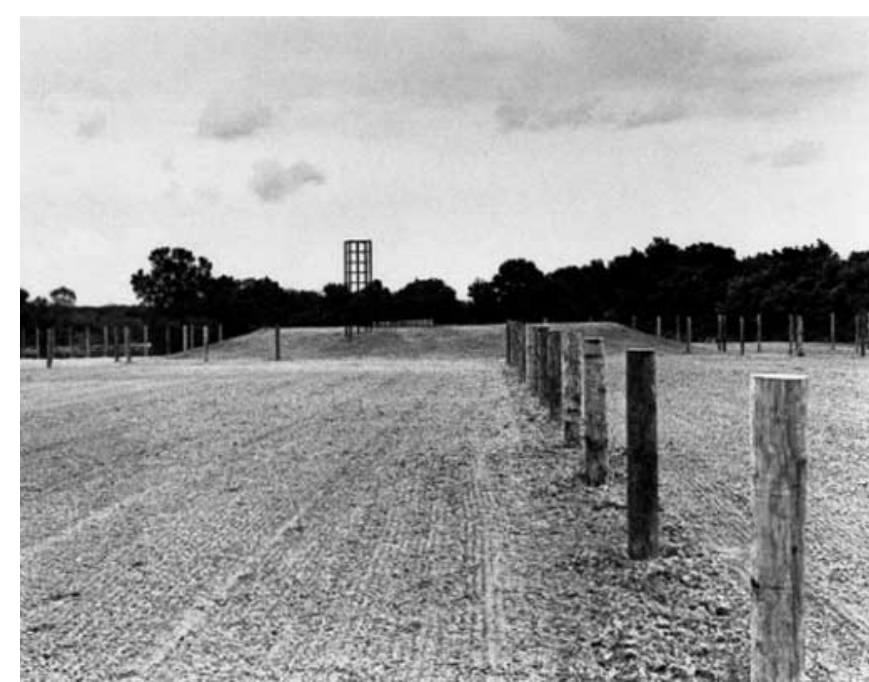

Figure 12: Mary Miss Field Rotation', 1980-1981

Figure 11: Mary Miss Field Rotation', 1980-1981

13 Bonnemaison, Installations by Architects pg19

14 Miss, Mary Miss, pg10

15 Ibid, pg22 
Miss created works that dealt with designing space for one to physically enter often to enhance the surrounding environment. Frequently her works would create their architectural container through the use of architectural

vocabulary and the context of the work, such as 'Perimeters / Pavilions / Decoys' and 'Greenwood Pond'. The works are no longer seen from a fixed view point like that of traditiona art but instead are seen as they are entered and discovered. This introduction of the audience evolved the work to becom one of continuous transformation, made by the movements of the audience, exposing the work as a process made by the audience. The forms of the work are designed as voids to enter. These works involved architectural vocabulary of a tactile quality to create walkways and platforms. These elements are not only part of the project, but become a way of viewing the project and accentuating the surrounding

landscape. Miss designed through relationships or the object, the viewer and the environment.

"The object is but one of the terms in the newer aesthetic. Another is the viewer, who is now bound into a more 'reflexive' exchange with the object, which, by virtue of its surrender of internal relationships (the complex play of size, surface, volume, material, colour, and space - the traditional province of all sculpture, but particularly of its abstract forms) has determined the look." 16

The difference between Miss's installations and Interio Architecture lies in the use of space and architectural vocabulary. As Miss's works often lie in-between the boundaries of these disciplines, she challenges the threshold of 'sculpture/object and architecture/place,' creating a place of reflection at the boundaries of each. ${ }^{17}$ She moves her works beyond only form and object to the construction of space. The work employs architectural vocabulary through form, often engaging it in repetition and order to create spatial structure. This space is a space of transition both physically and mentally through the connection of the known (architectural vocabulary) with the unknown (one's imagination) to embody and emphasise the environment. The known elements (the architectural timber structures) often have no set function; she allows the audience to consider and observe the form, surrounding context and work. She is interested in expanding the meaning of form into space rather than having form focus on function. Miss uses architecture as a structuring device as well as an exploration of her discipline. However architecture's use of structural systems in building space is to construct a defined space which is inhabited according to the set programmatic unction. Unlike Interior Architecture Miss's work is defined

by art as a process. The built environment constructed has no built-in functional programme of space, leaving the space open for interpretation. The focus is not on the space per say but on the way it is used to emphasise an aspect of the environment that has gone unnoticed. 


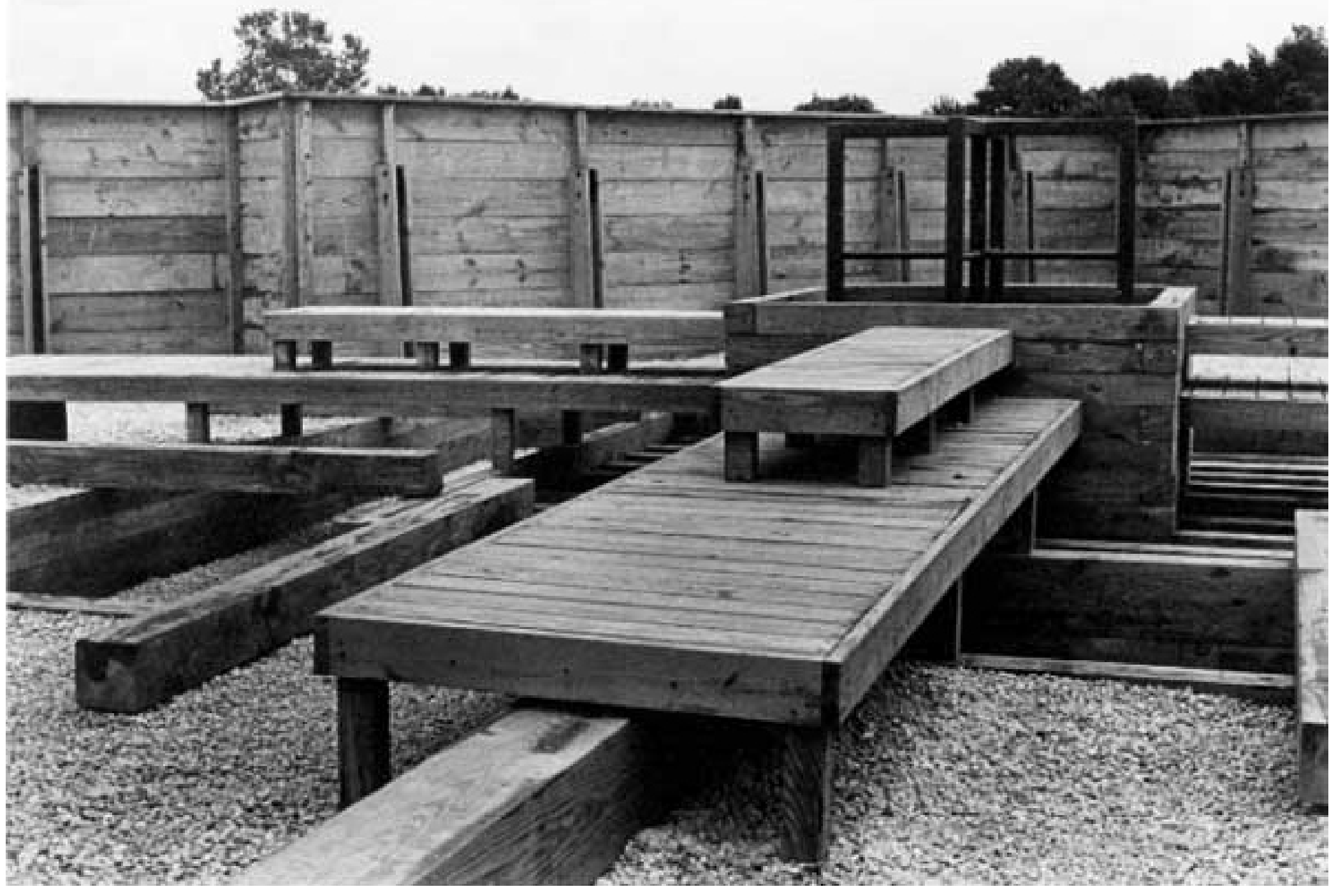




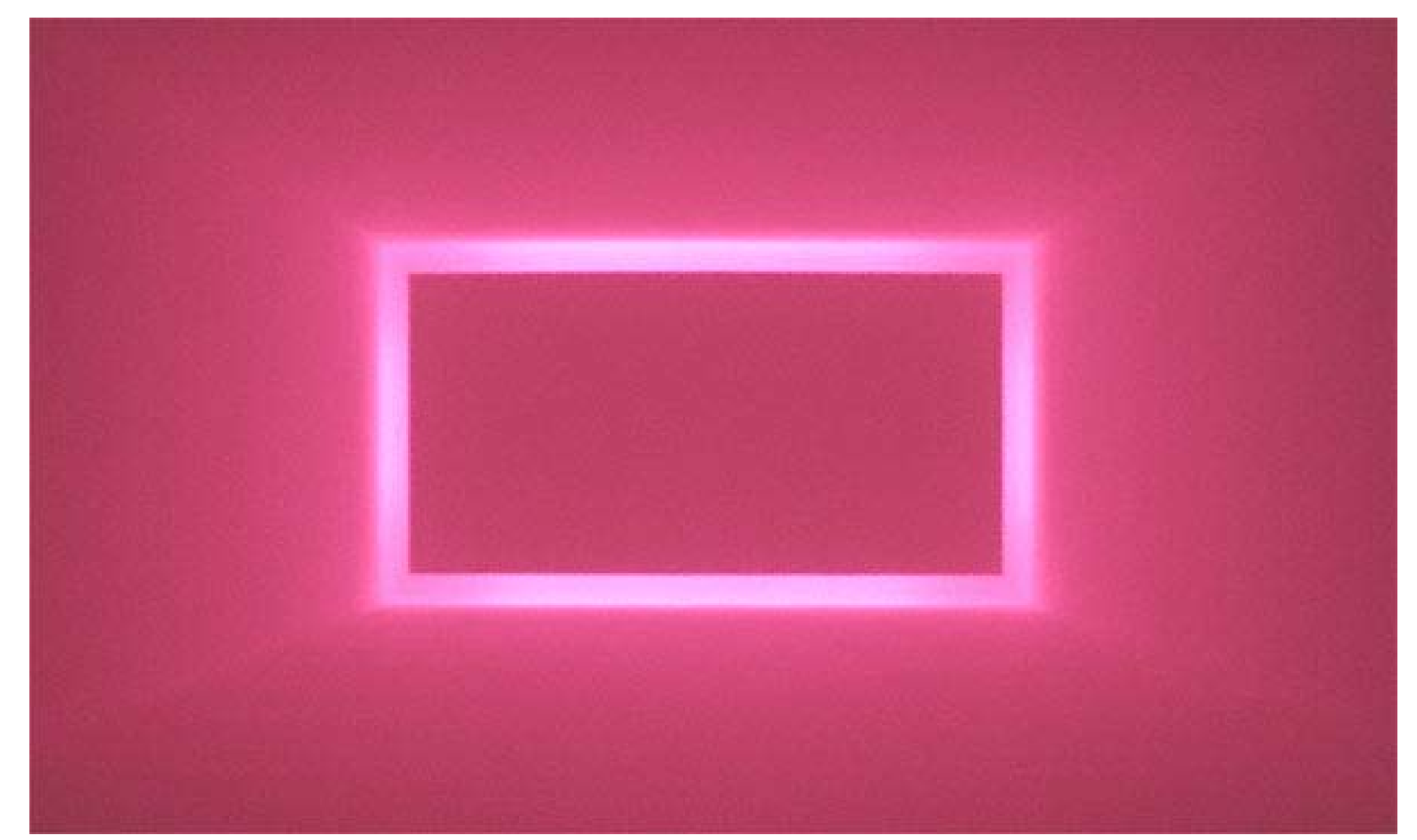


James Turrell's light projections provide an insight into an approach to space created through non-physical materials. The spatial qualities of his installations are unlike the other artists discussed here. His focus is not on how form can produce space but rather how light can inform space to alter its visual perception. Turrell's works express potential for interior space to be developed beyond the physical built environment, and how it can be extended and flattened with the medium of light. They invite the audience to experience a different type of built environment and spatial qualities through exploring the structural properties of light. As a

medium, light allowed Turrell to expand the artistic boundary of space where the illusion of the architectural boundaries of space slowly is absorbed by light.

"From a distance, this shape had a solidity literally composed of light. And, at a distance but moving to the side, this impression grew stronger because the cube seemed to reveal itself in perspective. Advancing toward the image, it would eventually dissolve to the point where you saw not the object in space but the actual light on the wall." 18

James Turrell began his light projection works in 1966, in which he uses light (a non-physical material) to construct and challenge the illusion of physical space through the use of different media. Turrell gained an interest in light in his spatial installations as light is a primal experience in life. Light is a central source in our lives, symbolic in religion, our well being, a source of understanding of senses; it was these elements of light that drove his experiments on how it could be perceived within space. Turrell explored light as a tangible material creating it into a substance. The light projection works such as 'Alta (white)' construct light into form that

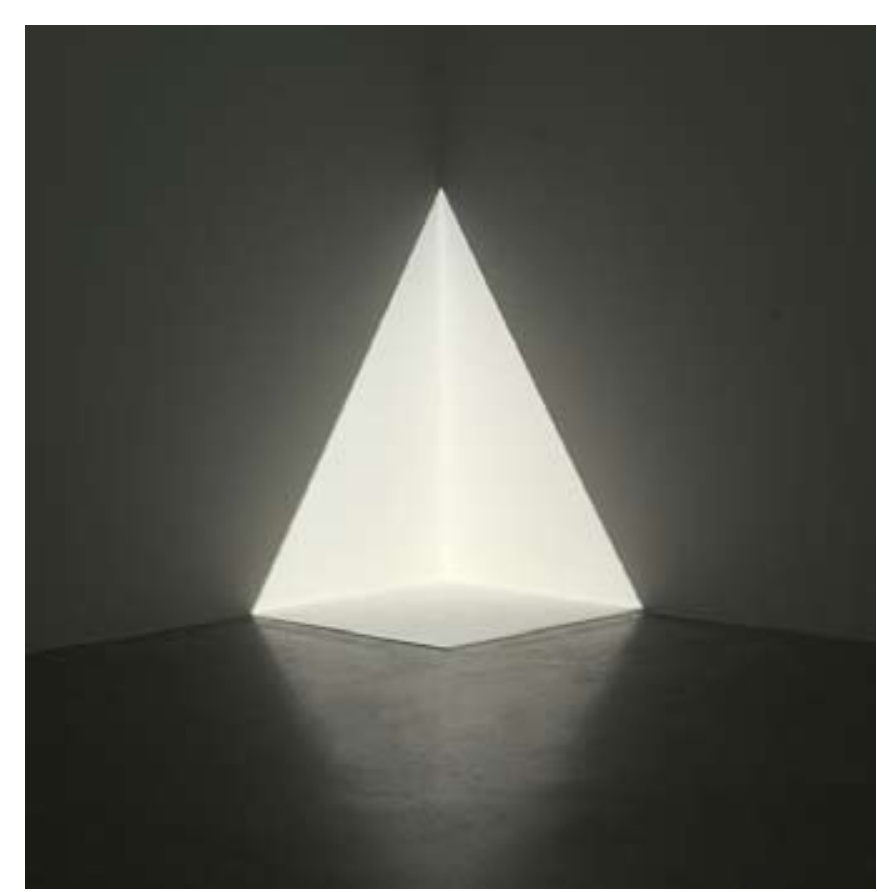

Figure 15: James Turrell, 'Alta (white)' , 1967

seems to have mass and weight, using it as a spatial tool. As the audience moves around it the light form seems to rotate. Turrell was interested in the real and invented qualities of space placing emphasis on perceptual qualities of space. He produced works that considered how different colour, quality and the angle of light could be fundamental to how it alters the perception of both light and space created. He tested where the form of light positioned in the room can change the space, and how a room could be perceived to extend beyond its four walls through projection. The light 'forms' create conceptual solidity and voids within a space. His works 
push the boundaries of spatial qualities through the creation of space by using primarily light, an untouchable material, and making it appear to take the qualities of physical form substance and space, "a three-dimensional space that in itself contains something not quite three-dimensional." 19 Light becomes a malleable material in the construction of space and causes the perception of the space to alter.

"My works are not looking at, but looking into; not the displacement of space with mass, but the working of space; not objects in a room, but the room. The format is not things within space, but space itself." ${ }^{\text {"20 }}$

Turrell works in two different ways where the light constructs an illusion in the spatial installations. The first are called 'Projection pieces' an example being 'Phantom (White)'

1967, where light is projected as an image in the space;

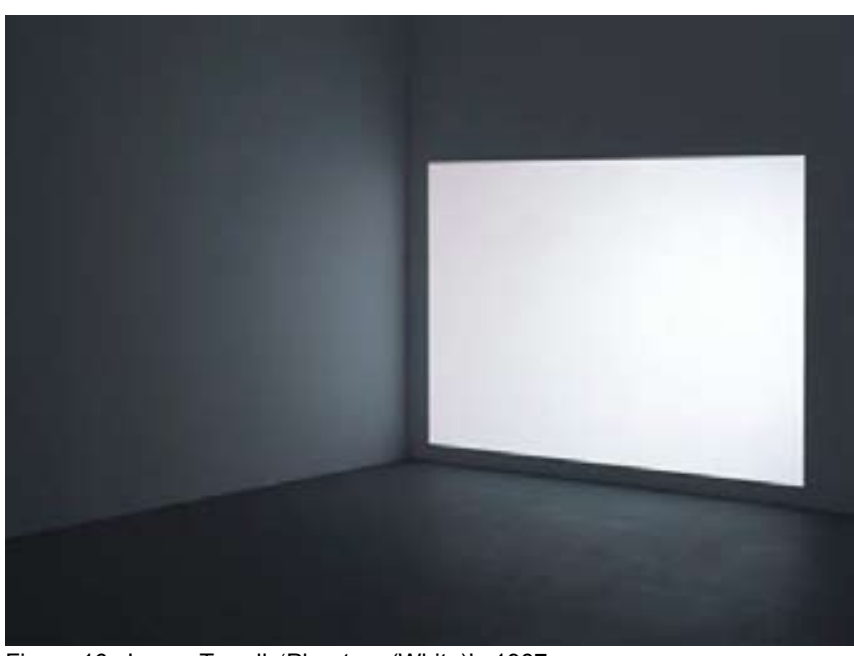

these works the light generates a sense of three-

dimensionality out of only light projected into an empty space. These lend a visual freedom for viewers to be convinced of the form and able to break it down as they move through the space. Turrell designed these to alter as the viewer moved into the light: "All of these pieces existed at the limits or very slightly inside the limits of the physical space. They affected the viewer's awareness of the space and tended to create a hypothetical or imaginary space within the gallery that could be dissolved on approaching the image." ${ }^{21}$ The second kind of installation is 'Shallow Space Constructions'; light is used to light a shallow three-dimensional space in a room and transform a three-dimensional space into a two-dimensiona one. The work titled 'Raemar' has a secondary wall constructed in front of the gallery wall, which is illuminated so that the space is filled by light and the wall appears to be floating. The light begins to blur the boundaries of space as it occupies a space between "solidity and emptiness". This space appears flat and appears like a painting on a wall in a museum. These shallow spaces are not entered or occupied by the audience - only by the light altering its perception. "The object becomes the light; the light becomes the object."22 Both types of spatial installations were ones in which the audience can move around freely, not restrained by physical objects in space. As the audience experiences the projections and progresses through the space, the space is revealed to be conceptual, created purely through light, light that challenges the audience's perception. The light becomes physical space which envelops the audience in the experience of visual space. Within the work it is not only the audience that occupies the space produced by light, but just as much the light that occupies the space, so that light is physically present in the space.

Turrell, James Turrell: The art of light and space pg14

Ibid pg36

Turrell, Light and Space, pg17

22 Turrell, The art of light and space pg19 
Donald Judd (USA 1928 - 1994)

Donald Judd explored both architecture and installations in his time. He did not consider his installation works to sit within the discipline of sculpture as he had not sculpted the works; instead he created forms that considered the fabrication of space. He called his works "specific objects". ${ }^{23}$ He believed his works to be structures rather than sculptures and considered them closer in thought processes to that of Bauhaus Architecture. His spatial installations often consisted of geometric shapes particularly cubic, circular and rectilinear volumes. He allowed this use of simple geometric forms to create architectural vocabulary that created an interplay of complex and thought-provoking compositions, which dismissed traditional compositions including the notion of the need of hierarchy. This complexity offers a new consideration on the ordering of space, on how the ordering systems created by forms create space both inside and around the forms. The space surrounding the installations is considered in the creation of the work just as much as the objects, making space between the objects. Judd often used the play of positive and negative space as a driving force for a project. He believed the audience provided an active role in establishing a work through the involvement of viewing, making the viewer aware of the physical space created through the experience with form, through the movement through positive and negative space. The works were an exploration of space, scale and materials in order to create open volumes that created these spatial formulations. Judd's work drew particular attention to the relationship between the object, the viewer, and its environment. Interior Architecture today can use these relationships to concentrate on how each of these elements can inform and drive the progression of volume, presence, program and habitability of the structure and the space.

Judd sought to deny the boundaries of what art could be and express. Judd considered how the object and the architecture were relating and creating space together, first through that of reflective materials, where the surrounding space was captured in the material and then progressing further to the compositions of the objects within a space. This can be seen in his 100 'untitled' works in mill aluminium, 1982-86 these are permanent installations in Marfa, Texas. These installations housed within an interior space use the constraints of the walls, windows and doors as an informant to the spatial formulations of the objects, movement and views of the audience and the overall experience making the installation. His works establish a physical connection with the floor and sometimes the wall, which in turn create a visual connection with the ceiling. His spatial installations

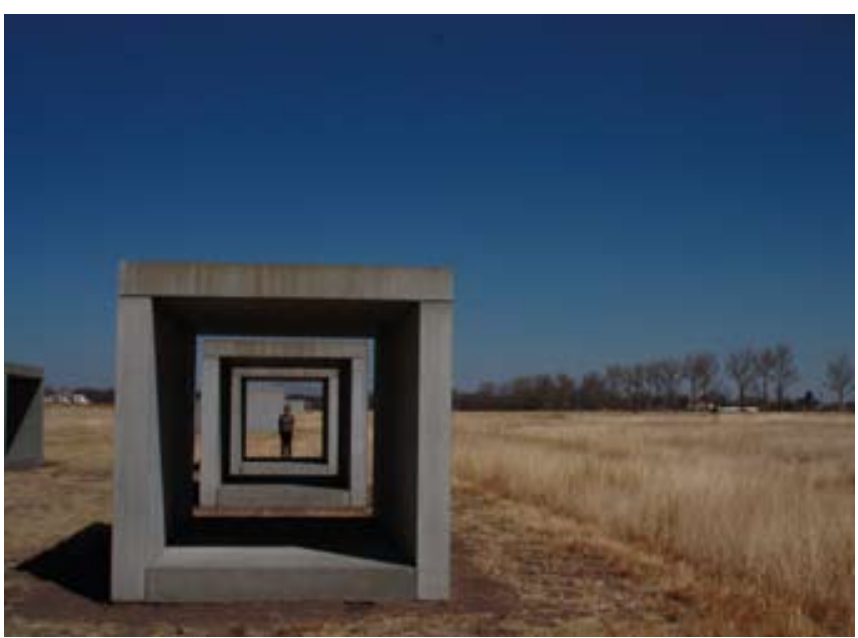

Figure 17: Donald Judd, “Untitled" 1980-1984 


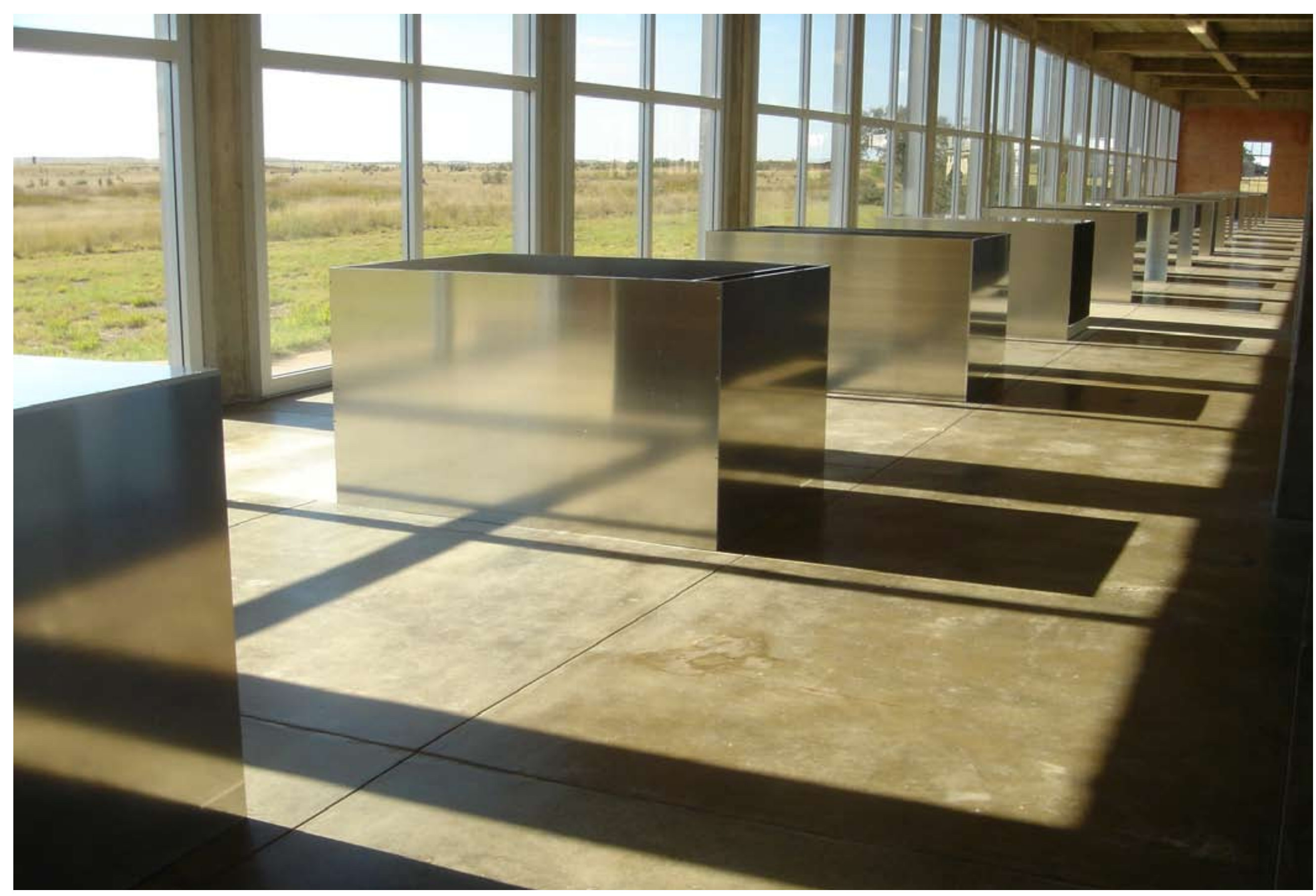


consisting of 15 'untitled' repeated concrete forms were exhibited within an exterior compound in Marfa, Texas. These explore changing scale as a tool to explore space the audience continually moves through shallow interior spaces into exposed vast exterior conditions. One would experience the containment of the built environment versus the openness of the urban context, yet still occupy the space constructed by the project.

Judd's continued exploration of the connection of space, object and site moved towards more architectural

formulations of space. Judd created these formulations through the interplay of relationships of positive and negative spaces in actual objects, the use of simple form which was often repeated to establish space both inside the form, but also the voids created by the space in-between the forms. This so called 'empty' space between each form becomes a vital part of the installation itself, establishing cohesion of internal, in-between and empty space connecting into one space.

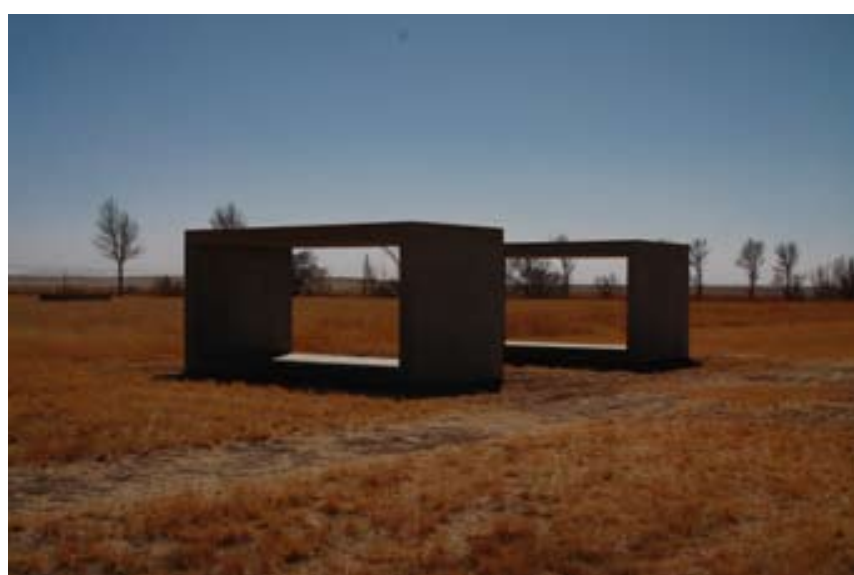

Figure 19: Donald Judd, "Untitled" 1980-1984
Gordon Matta-Clark (USA 1943 - 1978)

During the 1970's Gordon Matta-Clark took a different approach to spatial installations than the other artists discussed in this chapter. The installations were explored through the physical engagement with architecture. In a series of works called "building cuts" Matta-Clark used architecture as his medium to create space, objects and experience that dealt with opening the mind to perception, exposure and light. He was concerned with how one

experiences the spaces created through his installations and the messages they express. Through this series of works

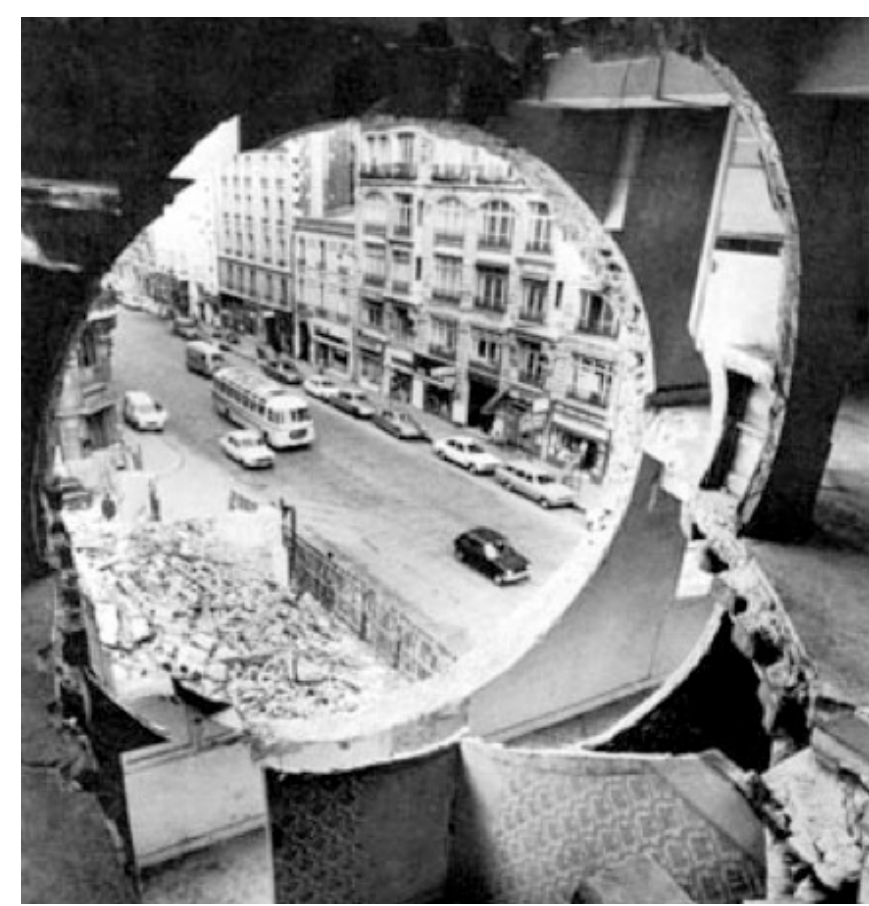

Figure 20: Gordon Matta-Clark, 'Conical Intersect', 1975 
Matta-Clark sculpturally transformed the architecture into spatial installations by cutting and carving geometric shaped sections directly out of the physical fabric of buildings, its floors, walls, ceilings and sometimes the entire building. These cuts created unexpected apertures and incisions which opened and redefined the spaces. These cuts redefined the circulation of the building and how one could then move about the space to experience these cuts. His installations were moving space beyond the traditional to gain a further dimension. He explored how a simple gesture such as a 'cut' can complicate the visual area of a space making multi-perceptual experiences. The cut made in the architecture produced a new sense of space beyond that of the physical boundaries of the building. ${ }^{24}$ The cut was the means to explore the notion of complexity both in the creatio of perception and viewpoint, as each cut would extend the view through and beyond what had previously existed. MattaClark's works explored through this physical act of cutting the deconstruction of the 'box' (the architecture); he exposed issues about community and urban experience through the engagement with and transformation of architecture. The cuts constructed voids that became objects in the space; these made the audience aware of elements of absence, mass and elimination.

"Now on the face of it nothing seems more ridiculous than undoing a building. Quite the contrary. Undoing is a terribly significant approach for advancing architectural thought in this point in time. Everybody, to some extent, accepts architecture as something to look at, to experience as a static object. Few individuals think about or bother visualising how to work away from it, to make architecture into something other than that a static object." 25

One of his well-known works from this series was "Splitting" in 1974 and involved the house being cut in half vertically to allow light from the new incision to spill into the interio and unite spaces in an unexpected manner. Matta-Clark was interested in how light was introduced into the building through these cuts and how the light could also alter the audience's perception. The cut was the controller of light; it created new pathways and access for the light to pass through the building, emitting new light into a space. The cut physically expands the visual space of the audience's experience through and beyond a room, the building, into the urban context of the community. He created spatial and visual complexity through this use of cutting, developing the idea of perception of space as the cuts are able to extend and in turn restrict the view and movement through the building. The vertical cut imposed a new position and reaction to the interior spaces of the house, exploring the notion of the familiar within the house being replaced by the new experiences, views and spaces created by the cut. The aim was to also expose 'process,' the physical act of constructing architecture. Each cut through physical material would reveal the hidden layers of the house - those beyond the walls, floor, and ceilings adding to the audience's awareness of a built environment.

Matta-Clark's goals were in counterpoint to the aims of this thesis, the creation of spatial installation through the medium of architecture. This section investigates how he has embraced and translated the combination of the two disciplines. It considers how Matta-Clark has represented culture, perception of space, and process through the use of architecture. Although he has altered space and created new spaces through 'cuts,' the spaces (like the other artists discussed) do not explore program and habitation as a defining method for the creation of the work, like that of Interior Architecture. 


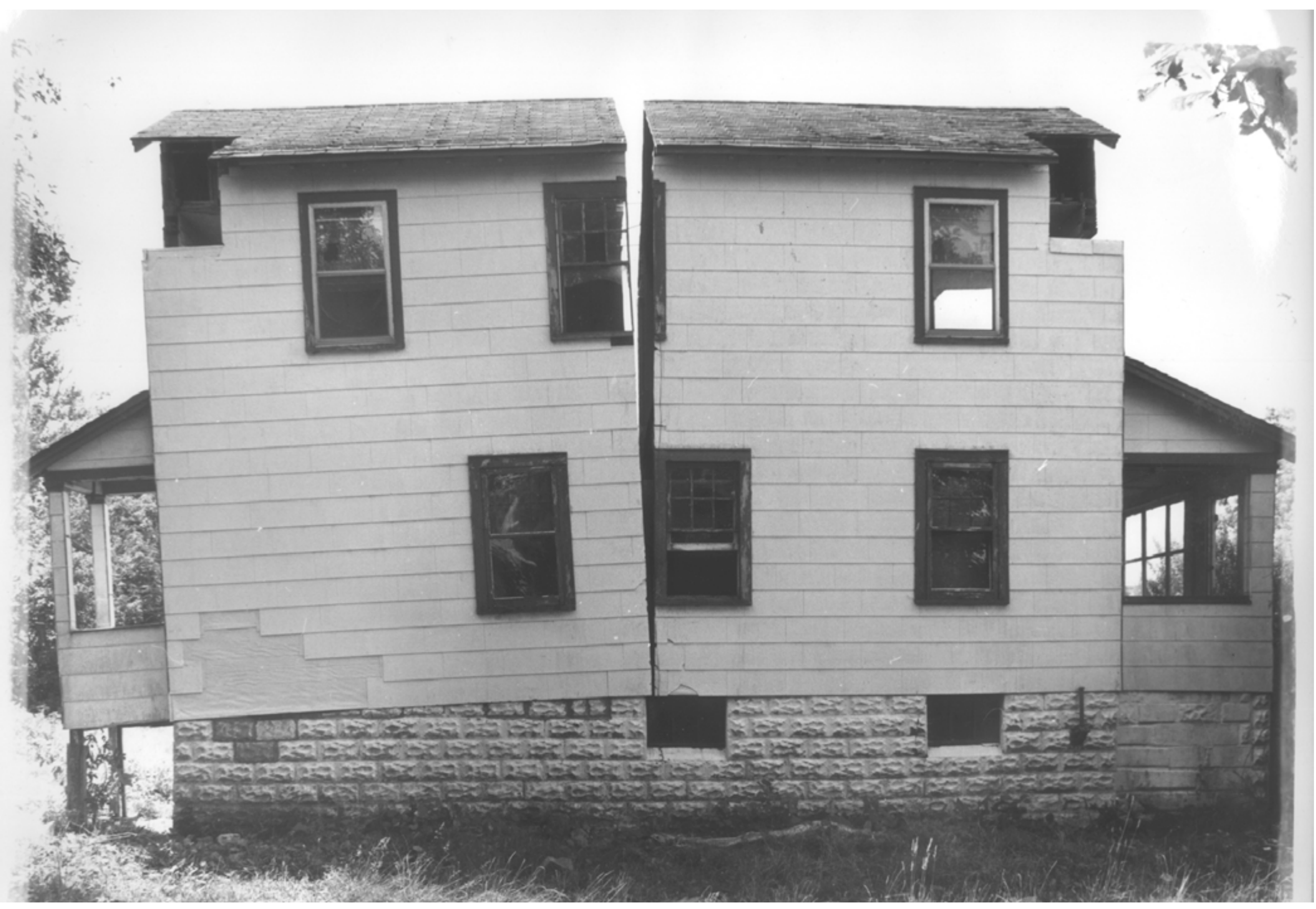


These artists and their spatial installations enable further understanding of the differences between Spatial Installations and Interior Architecture, and how they might be combined to challenge the space of Interior architecture with that of

Spatial installation. These artists have each explored space in their own right; each has successfully established space that the audience is able to enter and occupy whether conceptually or physically, and each has questioned the boundaries of spatial installation and interior architecture. All critically use architectural vocabulary to engage the audience within a spatial environment. However opportunities for this thesis arise through investigating how each artist has created space with the combination of programmatic and functionality defining the use of that space. The aim of the thesis is to consider spatial installation and use it as a medium for the creation of space in interior architecture and develop them together as a new visual and spatial language for architecture. Each artist places importance on developing works through the elements of the audience, the object, the context and the process. Often it is the audience that causes an amalgamation of these elements, or it is the audience that once engaged in the work gives the work substance. The

installations invite exposure to the process of art; to integrate this with Interior Architecture invites greater understanding of the built environment. Visitors or occupants can then inhabit

rather than occupy, through the applied programming of spaces.

This relates specifically to the objectives of the thesis in chronicling the examples of recent spatial installation artists who use architectural vocabulary but these examples have not yet invited habitable program to also enter. The next section will examine architects that challenge the traditional conditions of architecture. Chapter three will be a series of experiments within the alleyway which provoke habitable

program to enter into the realm of installation art to cross the boundary into interior architecture. 


\section{B. Architects}

"The painter starts with the real world and works toward abstraction. The architect starts with the abstract world and, due to the nature of his work, works toward the real world. The significant architect is one who, when finished with a work, is as close to that original abstraction as he could possibly be..." 2

iii. This section analyzes architects who clearly engage their architecture to challenge the conditions of traditional architecture through form and space. Each architect examined has approached the creation of space through experimental variations of form. The thesis will consider how this has impacted function of space. It considers the characteristics of form and function each architect has developed to construct their architecture and how to challenge presumptive thresholds separating installation art and interior architecture.

Traditional architecture responds to the consideration of function with regards to social needs; the need for shelter, warmth, and protection provided by the idea of containment by walls. As argued by Daniel Libeskind we applaud the 'well mannered box' that traditional architecture has been contained in. This chapter explores various architects whose architecture breaks free from the constraints of the four walls to create architecture that explores the freedom of form to define habitable space. The thesis will consider how the presumptive environments created by architectural structures can be challenged within the discipline of interior architecture. Investigating how each architect has used a method of spatial installation language as a tool to transform the perception of interior space. 
Bernard Tschumi (1944-)

"...there is no architecture without events, without actions or activity. His early work recognized that buildings respond to and intensify the activities that occur within them, and that events alter and creatively extend the structures that contain them. In other words, architecture is not defined by its

"formal" container, but rather by its combinations of spaces, movements, and events." 27

Park de la Villette, 1982-1998, is a architectural park by Bernard Tschumi that embraces the design of architecture through non-conventional conditions. The project is

constructed of 25 architectural spatial structures (follies)

that combine to assemble what Tschumi described as 'a discontinuous building' but a single structure nevertheless. ${ }^{28}$

The idea of a discontinuous building consisting of a series

of architectural structures can be related to that of spatial

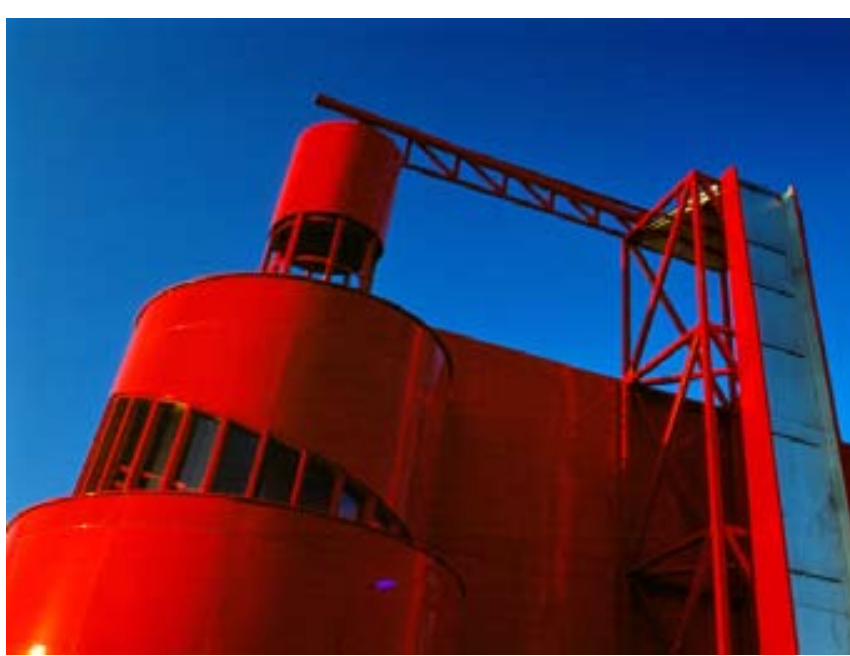

Figure 22: Bernard Tschumi, ‘Park de la Villette', 1982-1998 installations in which many disconnected elements are considered and experienced as a single entity. Instead of designing another mass (a traditional architectural container) into the site, Tschumi constructed a series of structures that deconstructed the needs of the program and then dispersed these programs throughout the site in relation to the system of the grid. This allows the occupant to experience the whole site and discover the new activities and programs created by the architecture. These architectural structures overlap with the site's existing features including two existing buildings, covered walkways, bridges, and landscaped gardens to articulate new activities. ${ }^{29}$ The project's objective was to develop a complex program of both cultural and entertainment facilities. The architectural structures give presence and establish new activities within the existing site. The urban architectural park was designed through three ordering systems: the points of the follies, the lines of the paths, and the planes of the sport areas. Firstly, the points become the follies placed in relation to the grid, these points provide the park with reoccurring landmarks. These follies then offer the park with a system of navigation as the inhabitant orientates from one to another. Secondly, the lines become the connecting pathways of circulation through the site, connecting each folly, programs and structures, creating one continuous architectural building. Thirdly, the surfaces are the horizontal planes for the activities of the park.

"Park de la Villette project had a specific aim: to prove that it was possible to construct a complex architectura organization without resorting to traditional rules of composition, hierarchy, and order."

Tschumi designs with an unconventional use of form to create architecture that has the freedom of form as a 'spatial installation'. This is not to say that it is created through 


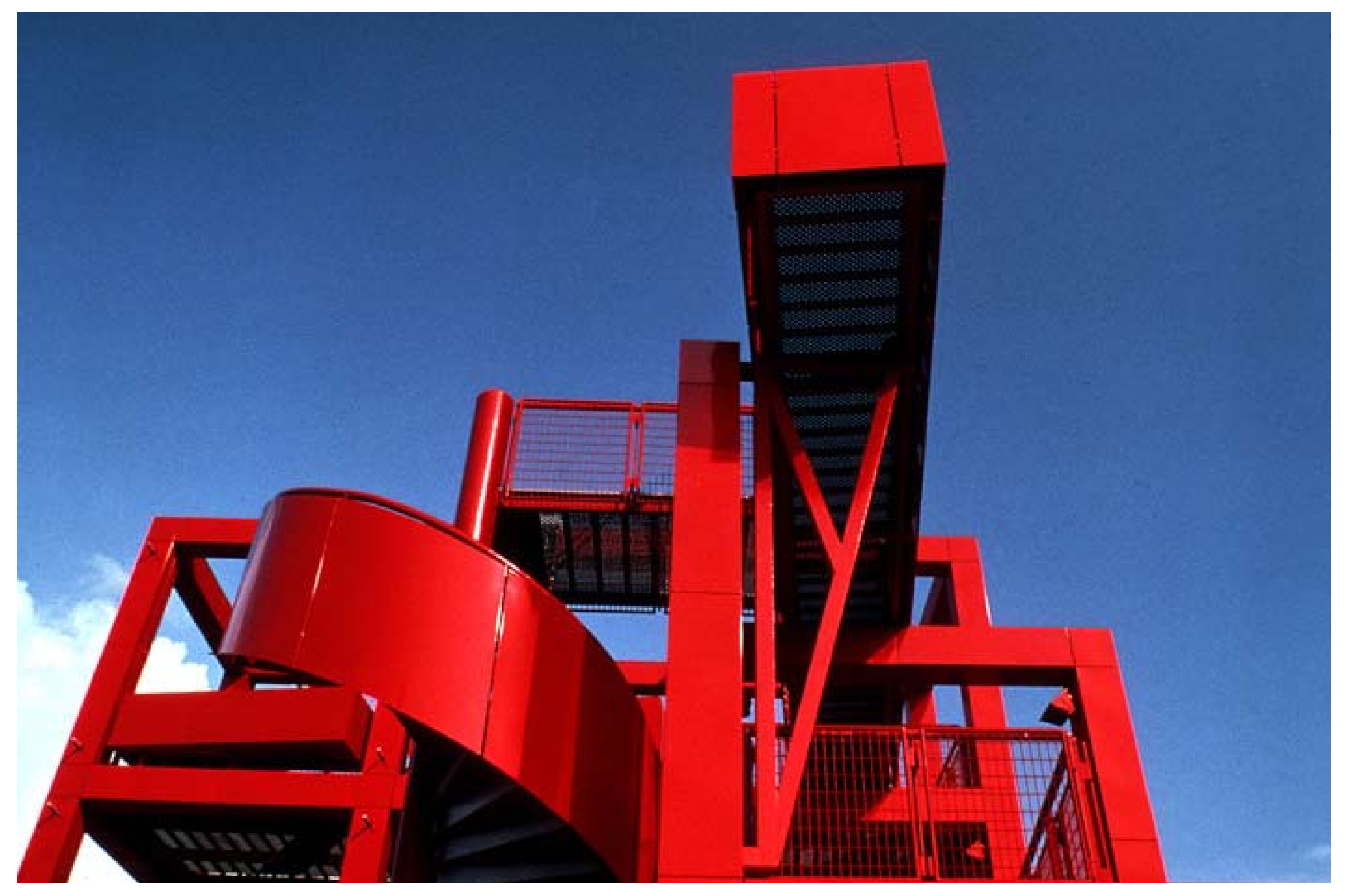


the processes of spatial installation art. Each folly begins with the same allocated space $(36 \times 36 \times 36$ foot cube) then the cube is divided by three in each direction. The primary structure is a cage, which is deconstructed into fragments and connected with other simple geometric forms. This generation of form acts as architectural representations of deconstruction, this deconstruction is according to rules of transformation (repetition, distortion, superimposition, interruption and fragmentation). ${ }^{31}$ Each is the deconstructed and reconstructed exploration of the cube..$^{32}$ Each folly consists of inhabitable space that holds one distinct function for each folly. The neutral forms constructed through each folly are qualified by the function that inhabits them. ${ }^{33}$ The programmatic function of the space defines the form of the follies providing meaning and substance to the architectura space. Each folly has independent programmatic concerns. These functions then collaborate to holistically become a social and cultural park. The park allowed for the occupant to establish his or her own interpretation of the architecture.

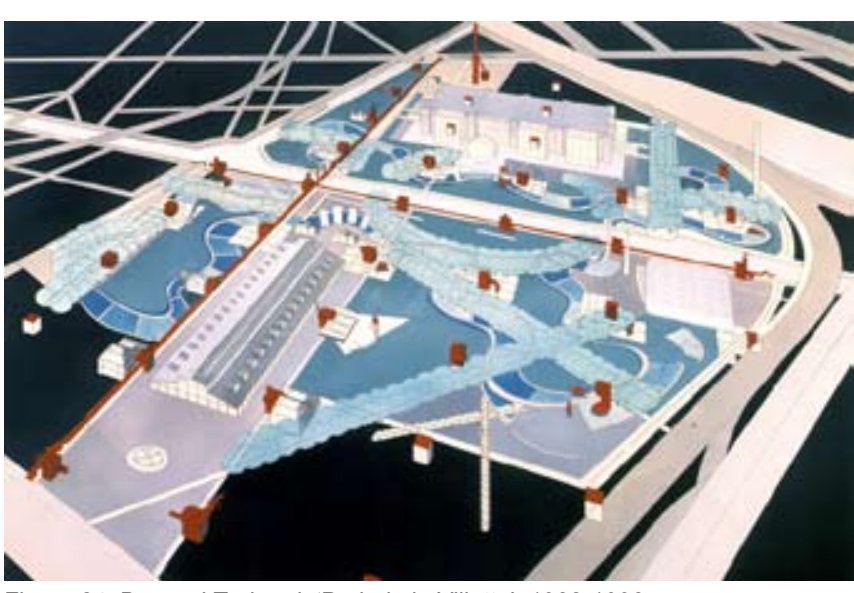
Houses' is a different approach to interior architecture. It is a change in work from built architecture to architectural poetry through an artistic expression in order to explore the constraints of form, function and habitation. This is

Figure 24: Bernard Tschumi, ‘Park de la Villette', 1982-1998
Tschumi's use of a conventional method of architecture
using the 'determinate' grid to define the entire park to have structure, order and connection between each folly (the programs) coupled with the non-conventional invention of form and the deconstruction of a 'mass' (a traditional architectural container) shifts his architecture away from the traditional conditions.

Raimund Abraham (AUT 1933-2010)

Raimund Abraham's theoretical project 'Metaphorical

's umis use of the grid gives structural formulations and rganization both spatial and programmatic. It offers order between the program and architecture. The follies are unified by the system of the grid which becomes the core of the

"The grid, then, presented the project team with a series was anti-nature. We had to fulfil a number of functions: the grid was anti-functional. We had to be realists: the grid was (he grid was . We had to be sensitive to site boundaries:

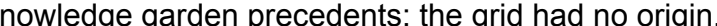
it opened onto an endless recession into prior images and 


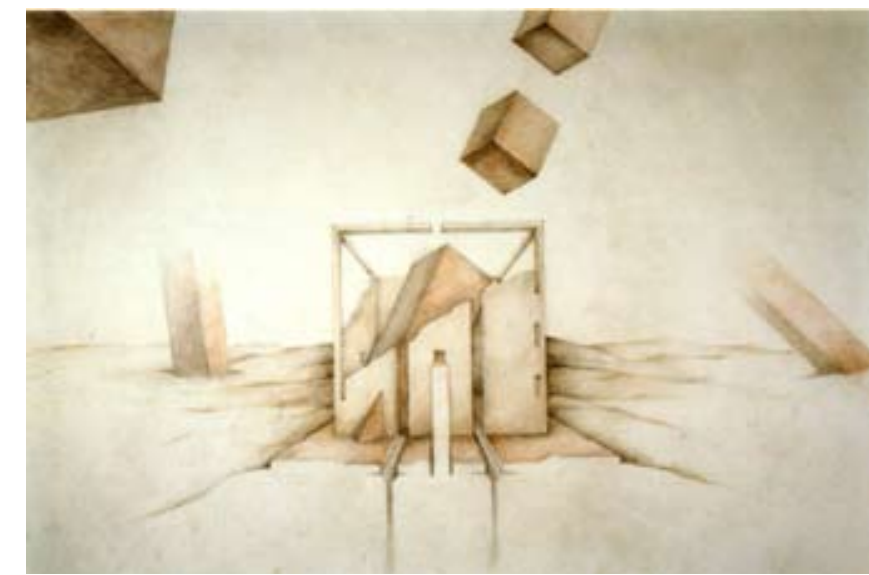

Figure 25: Raimund Abraham, ‘The Last House’, 1984

explored through the project on 'Houses' consisting of a series of conceptual works and drawings sometimes with poetic text. These are Abraham's artistic expressions of habitable spaces. Although the habitable spaces designed by Abraham are purely conceptual and were never executed so therefore did not exist in the physical world, any less of an architectural exploration than those that have been built. This is because each was drawn as if it could be built and inhabited. The fact that they do not exist in the physical world however plays a large factor in the expression of space each 'House' undertakes. The exploration of habitable space through drawing allows each 'House' to be designed around the ideals of function and habitation without the conditions of traditional architecture. The constraints of social needs of sleeping, eating and shelter space do not need to exist in Abrahams work, the works have the freedom of his imagination to place a emphasis on 'thought' and habitation rather than convention. Abraham designed through the freedom of memory, fantasy and imagination to create spatial formulations to define the function embraced in each design. Throughout this series of architectural experiments Abraham considers the program of each house as a driver for that design. Each drawing of a 'House' challenges the language in which we perceive interior architecture through this unconventional artistic expression of habitable space such as 'the house with curtains'. Abraham considers habitation as a ritual, that each must determine their own meaning to inhabit a space. ${ }^{35}$

"you can say circle is a circle is a circle, square is a square is a square-until a material challenges it. A square in concrete a square in steel, a square in stone, is a different square "36

These explorations of 'houses' are the architectural expressions that create clear relationships between abstraction, materials, tectonic space, form and human experiences through the conditions of function of a habitable space. Each exploration of a 'house' uses these relationships as a focus to accentuate one condition such as the horizon, or the wall, or curtain. He explores how each can exist solely to discover that one function. The drawings use geometric

forms to express the program such as the "square, cube, circle, sphere, point, line, and plane as an interplay between these which creates an inner tension, an existential,

dialectical, ultimately tectonic, that is, a constructed idea of place, time, the world." ${ }^{37}$ The houses use complex thought in order to create simple spatial reflection on the formulations of space.

This series of architectural drawings establishes the shift from traditional conditions of interior architecture through the relationships he creates through artistic abstraction of space. As spatial installations focus largely on perception of space and in the creating of space that involves every 
element of the site and the audience's sensory experience, Abraham's architecture creates a new conception of program and habitation through his generation of architectural space. As his architecture is drawn rather than built it is not defined

by the constraints of traditional architecture allowing it to

focus on the experience created in each house by the

programmatic response each house is undertaking. Raimund

Abraham expands the boundaries of the discipline of interior architecture through the introduction of constructing space with the emphasis on thought, imagination and dreams and

the abstraction of form, program and habitation.

The artists and architects discussed in these two last sections have investigated either installations that have not approached habitable space or architecture that denies its traditional conditions but both approaches have yet to challenge the presumptive boundaries through the combination of the two disciplines together. The following chapter will summarise the distinctions currently between

installation artists who do use architectural vocabulary verses

the traditional definitions of interior architecture, in order

to understand the certain elements that can be applied to

spatial installation art, to integrate or enhance the narrative

nature of interior architecture. 
DEFINITION

"Art and Architecture are frequently differentiated in terms of their relationship to 'function'. Unlike architecture, art may not be functional in traditional terms, for example responding to social needs, giving shelter when it rains or providing a room in which to perform open-heart surgery, but we could say that art is functional in providing certain kinds of tools for self reflection, critical thinking and social change. Art offers a place and occasion for new kinds of relationship 'to function' between people. If we consider this expanded version of the term function in relation to architecture, we realize that architecture is seldom given the opportunity to have no function or to consider the construction of critical concepts as its most important purpose." 38

This section analyzes the relationships between spatial installation art and interior architecture. It identifies the defining conditions that define the boundaries of each discipline as it currently sits. This section will enable the understanding of when a discipline has crossed the threshold into the other through the combination of these conditions. 
As examined in the section on the background of installation art, this discipline can be largely diverse; this thesis examines specifically spatial installation art. The typica meaning of this art form is site specific installations that create space that challenge the perception of space. The characterising difference between spatial installation art and interior architecture comes by defining programmatic function which identifies whether a space when entered is occupied as spatial installation or inhabited as interior architecture. To 'occupy' is defined as 'to place oneself in' whereas to inhabit is defined as 'to reside in a place', this defining difference between the two disciplines is determined by the response to programmatic function of a space.

Spatial installation art, as with most art, is considered to have no programmatic function and no predefined involvement with the space that is created. The audience is offered with opportunities to enter the space which often offers a place for reflection and contemplation either of space, the process of art, or the meaning behind which the art piece is created.

Interior Architecture on the other hand is a functional space; it involves habitation as a key principle for its existence. Interior Architecture engages with the social, spatial, and physical needs of the built environment and its inhabitant through the requirements of habitation, programmatic order, and problem-solving. One must be able to move through a space with functionality. The program that defines interior architecture defines the discipline's traditional conditions, the containment by an architectural shell (walls, ceiling, floors) to provide the shelter and defined space for separate functional needs (such as eating, sleeping, shelter).

"Artists value architecture for it's social function, whereas architects value art as an unfettered form of creativity." 39
The way to apply program that allows the thresholds of spatial installation art and interior architecture to cross is not to define the design intervention with a set program such as a gallery or park etc but rather to enable program to exist and enable habitation to exist without predetermining what that will be. 


\begin{tabular}{|c|c|c|c|}
\hline Elements of Disciplines & Interior Architecture & Spatial Installation Art & Landscape Architecture \\
\hline Presence in Space & Inhabit Space & Occupy Space & Inhabit Space \\
\hline Dimension & $\begin{array}{l}\text { Inhabiting three } \\
\text { dimensional space }\end{array}$ & $\begin{array}{l}\text { Occupy three dimensional, } \\
\text { two dimensional and } \\
\text { conceptual space }\end{array}$ & $\begin{array}{c}\text { Inhabiting two } \\
\text { dimensional space }\end{array}$ \\
\hline Built Containment & $\begin{array}{l}\text { Contained within an } \\
\text { Architectural Building }\end{array}$ & $\begin{array}{l}\text { Contained by its } \\
\text { chosen site, interior and } \\
\text { exterior environments }\end{array}$ & $\begin{array}{l}\text { Contained within } \\
\text { exterior environments }\end{array}$ \\
\hline Physical constraints & $\begin{array}{l}\text { Contained by walls, } \\
\text { floors, ceilings to respond } \\
\text { to social needs of shelter, } \\
\text { eating, sleeping }\end{array}$ & $\begin{array}{l}\text { Contained by the conditions } \\
\text { set by that of the artist }\end{array}$ & \\
\hline $\begin{array}{l}\text { Programmatic } \\
\text { constraints }\end{array}$ & $\begin{array}{l}\text { Inhabit space through } \\
\text { programmatic functions }\end{array}$ & $\begin{array}{l}\text { Experience space with no } \\
\text { programmatic functions }\end{array}$ & $\begin{array}{l}\text { Inhabit space through } \\
\text { programmatic functions }\end{array}$ \\
\hline Elements & $\begin{array}{l}\text { Concealed from } \\
\text { the weather }\end{array}$ & $\begin{array}{l}\text { No concerns for } \\
\text { the weather }\end{array}$ & Exposed to the weather \\
\hline Material Qualities & $\begin{array}{l}\text { Constructs space through } \\
\text { physical materials }\end{array}$ & $\begin{array}{c}\text { Constructs space through } \\
\text { both physical and } \\
\text { non-physical materials }\end{array}$ & $\begin{array}{l}\text { Constructs space through } \\
\text { physical materials }\end{array}$ \\
\hline
\end{tabular}





\section{CONCLUSION}

The analysis in this section of the relationships and defining differences between the disciplines of spatial installation art and interior architecture is used to underpin the design intervention experiments explored in chapter three. The challenge of disciplinary boundaries occurs first through the coupling of spatial installation art with habitable program. Secondly, the experiments challenge interior architecture to exist outside of Libeskind's 'well mannered box' through inhabiting an outdoor urban site (Woodward St), where the exterior facades of the surrounding buildings become the interior walls of the design intervention. Thirdly, the experiments invite the social conditions and inhabitants of the site to define the programmatic function of the design intervention, enabling it to embody the social needs of a particular time. This move away from the conventional

conditions of traditional approaches to these two disciplines enables them to cross the threshold between spatial

installation art and interior architecture. 



\section{BIBLIOGRAPHY}

\section{BOOKS}

Adcock, Craig E. James Turrell: The art of light and space, (Berkeley : University of California Press, 1990)

Bishop, Claire. Installation art: a critical history, (London, Tate, 2005)

Bjone, Christian. Art and Architecture: strategies in collaboration,( Boston, Birkhauser, 2009)

Bonnemaison, Sarah. Installations by Architects: experiments in building and design, (New York : Princeton Architectural Press, 2009)

Brillembourg, Carlos. "Raimund Abraham" Bomb 77, Fall, 2001

Budney, Jen. Unboxed: engagements in Social Space.(Ottawa, Gallery101, 2005)

Cabanne, Pierre. Dialogues with Marcel Duchamp, (London, Thames and Hudson, 1971)

Darden Douglas. Condemned Building: an architect's pre-text, (New York, Princeton Architectural Press, 1993)

Fernie, Jes. Two minds: Artists and architects in Collaboration, (London, Black Dog, 2005)

Gamard, Elizabeth, Kurt Schwitters' Merzbau: the Cathedral of erotic misery, (New York, Princeton Architectural Press, 2000)

Haskell, Barbara. Donald Judd, (New York : Whitney Museum of American Art in association with Norton, 1988)

Hejduk, John, The education of an Architect (New York, Rizzoli,1988)

Hejduk, John, The Mask of Medusa: works, 1947-1983 (New York, Rizzoli, 1985)

Margolius, Ivan, Art + Architecture, (Chichester, Wiley Academy, 2003) 
Mink, Janis. Marcel Duchamp, 1887-1968 : art as anti-art, (Koln, Benedikt Taschen, 2000) Miss, Mary, Abramson, Daniel. Mary Miss, (New York, Princeton Architectural ; Abingdon : Marston, 2002)

Miss, Mary. Mary Miss: projects 1966-1987, (London : Architectural Association, 1987)

Noever, Peter. Donald Judd : architecture, (Portchester : Art Books International, 2003)

O'Doherty, Brian. Inside the white cube : the ideology of the gallery space, (Berkeley, University of California Press, 1999)

de Oliveira, Nicolas. Installation art, (London, Thames and Hudson, 1996)

de Oliveira, Nicolas. Installation art in the new millennium : the empire of the senses, (London, Thames \& Hudson, 2003)

Petry, Michael. Installation Art. Art and design profile ; 30 (London: Academy Editions, 1993)

Reiss, Julie H. From Margin to Center : the spaces of installation art, (Cambridge, MA : MIT Press, 1999)

Rendell, Jane. Art and Architecture: a place in between , (London: IB Tauris, 2006)

Rosenthal, Mark. Understanding Installation Art : from Duchamp to Holzer, (Munich ; New York :

Prestel, 2003)

Suderburg, Erika. Space, Site, Intervention : situating installation art, (Minneapolis : University of Minnesota Press, 2000)

Tschumi, Bernard. Cinegram folie: Le Parc de la Villette; (Princeton, Princeton Architectural Press, 1987)

Turrell, James. Light and Space, (New York, 1980)

Walker, Stephen. Gordon Matta-Clark : art, architecture and the attack on modernism, (London ; 
New York : I.B. Tauris, 2009)

Zapatka, Christian. Mary Miss : making place, New York, N.Y. : Whitney Library of Design, 1997.

WEBPAGES

Archidose. "Parc De La Villette" (December 2010) http://archidose.org

Held, John. "An interview with Allan Kaprow" (July 2010) http://www.mailartist.com

Libeskind, Daniel. "17 words of architectural inspiration”, (March 2010) http://www.ted.com/

Labedzki, Annette. "Western Painting - Spatialism - A non Digital Multimedia creative

Phenomenon"(May 2010) http://ezinearticles.com

Tschumi, Bernard, "Bernard Tschumi: History”, (November 2010) http://www.tschumi.com

Tschumi, Bernard, "Parc de la Villette", (November 2010) http://www.tschumi.com

Winkenweder, Brain, “Robert Morris”,(July 2010) http://robert-morris.ens-lyon.fr/spip. php?article81

Woods, Lebbeus "Raimund Abraham's Dream" (January 2011) http://lebbeuswoods.wordpress.

com 



\section{LIST OF ILLUSTRATIONS}

Figure 1: Georg Baselitz, 'Between Eagles and Pioneers' Exhibition, 2011 Source: http://www.whitecube.com/exhibitions/georg\%20baselitz/

Figure 2: Lucio Fontana, 'Spatial Concept: Expectations', 1960

Source: http://www.moma.org/collection/browse results.php?object id=79874

Figure 3: Marcel Duchamp, 'Bicycle Wheel' 1913

Source: http://marcelduchamp.net/Bicycle_wheel.php

Figure 4: Robert Morris, installation in the Green Gallery, 1964

Source: http://artintelligence.net/review/?p=529

Figure 5: Richard Serra, 'The Matter of Time', 2005

Source: http://www.nysun.com/arts/richard-serra-man-of-steel/84120/

Figure 6: Donald Judd, "Untitled" 1980-1984

Source: http://www.chinati.org/visit/specialevents09concrete.php

Figure 7: Allan Kaprow, 'Household', 1964

Source: http://pervasivegames.wordpress.com/2009/12/11/pervasivehappenings/

Figure 8: Allan Kaprow, 'Words', 1962

Source: http://www.bo-ring.net/?page_id=359

Figure 9: Kurt Schwitter, 'Merzbau' 1923-1935

Source: http://badarchitecturesucks.blogspot.com/2009_11_01_archive.html

Figure 10: Mary Miss 'Perimeter/Pavilions/Decoys', 1977-1978

Source: http://www.marymiss.com/index_.html

Figure 11: Mary Miss Field Rotation', 1980-1981

Source: http://www.marymiss.com/index_.html 
Figure 12: Mary Miss Field Rotation', 1980-1981

Source: http://www.marymiss.com/index_.html

Figure 13: Mary Miss Field Rotation', 1980-1981

Source: http://www.marymiss.com/index_.html

Figure 14: James Turrell, 'Raemar' , 1968-1969

Source: http://www.artscenecal.com/ArtistsFiles/TurrellJ/TurrellJFile/TurrellJPics/JTurrell3.

$\mathrm{htm}$

Figure 15: James Turrell, 'Alta (white)' , 1967

Source: http://c4gallery.com/artist/database/james-turrell/james-turrell.html

Figure 16: James Turrell, 'Phantom (White)' , 1967

Source: http://c4gallery.com/artist/database/james-turrell/james-turrell.html

Figure 17: Donald Judd, "Untitled" 1980-1984

Source: http://blogs.evergreen.edu/quaintancefieldjournal/

Figure 18: Donald Judd, “Untitled” 1982-86

Source;http://blogs.evergreen.edu/quaintancefieldjournal/

Figure 19: Donald Judd, "Untitled" 1980-1984

Source;http://blogs.evergreen.edu/quaintancefieldjournal/

Figure 20: Gordon Matta-Clark, 'Conical Intersect', 1975

Source; http://eroonkang.com/16x16/?tag=\%E2\%80\%98building

Figure 21: Gordon Matta-Clark, 'Splitting', 1974

Source: http://www.agmamagazine.com/on-line/2010/fall/gordon-matta-clark/

Figure 22: Bernard Tschumi, 'Park de la Villette', 1982-1998

Source: http://www.tschumi.com/projects/3/ 
Figure 23: Bernard Tschumi, 'Park de la Villette', 1982-1998

Source: http://www.tschumi.com/projects/3/

Figure 24: Bernard Tschumi, 'Park de la Villette', 1982-1998

Source: http://www.tschumi.com/projects/3/

Figure 25: Raimund Abraham, 'The Last House', 1984

Source: http://lebbeuswoods.wordpress.com/2010/02/14/raimund-abrahams-dream/ 

$\int_{\text {SITE ASSESSMENT }}$ 



\section{SITE CONDITIONS}

i. This section introduces Woodward Street, a pedestrian alleyway, as the chosen vehicle for the design intervention It introduces the urban context of the site and then further investigates the micro conditions. It establishes the alleyway as spatially contained by the surrounding urban buildings defining the site on either side. The site has distinct separate zones at each end of the street, highlighting its ability to have both intimate and public conditions. It demonstrates the opportunity for engaging the traditional presumptive boundaries between interior architecture, architecture, landscape architecture and urban planning.

Woodward Street is a pedestrian alleyway that connects The Terrace to Lambton Quay. The alleyway is located between the governmental, corporate businesses of Lambton Quay and the young professionals and residential properties of The Terrace. The site is heavily populated throughout the day providing a thoroughfare for each population from either end of the site. These connecting streets create two distinct zones at either end, Lambton Quay being of grand scale and open public movement, while The Terrace is at a much more intimate scale.

The site has two courtyards that project off to either side of the main alleyway. At present, the alleyway on the left opens out to be a car park, while the one on the right has been built over with a one story building. This courtyard on the right still holds a clear imprint to the site as its surrounding environment is of multiple story buildings, leaving its recessed footprint easy to see.
The exterior condition of this site provides significant opportunities to the development of the design intervention in the following chapter and to immediately challenge the traditional presumptive boundaries between interio architecture, architecture, landscape architecture and urban planning. It enables the interior condition of the design to be spatially contained by the urban buildings on either side of the alleyway. This leads the design intervention to investigate the nature of habitability and program within a constructed installation space that crosses the boundaries into architecture. 


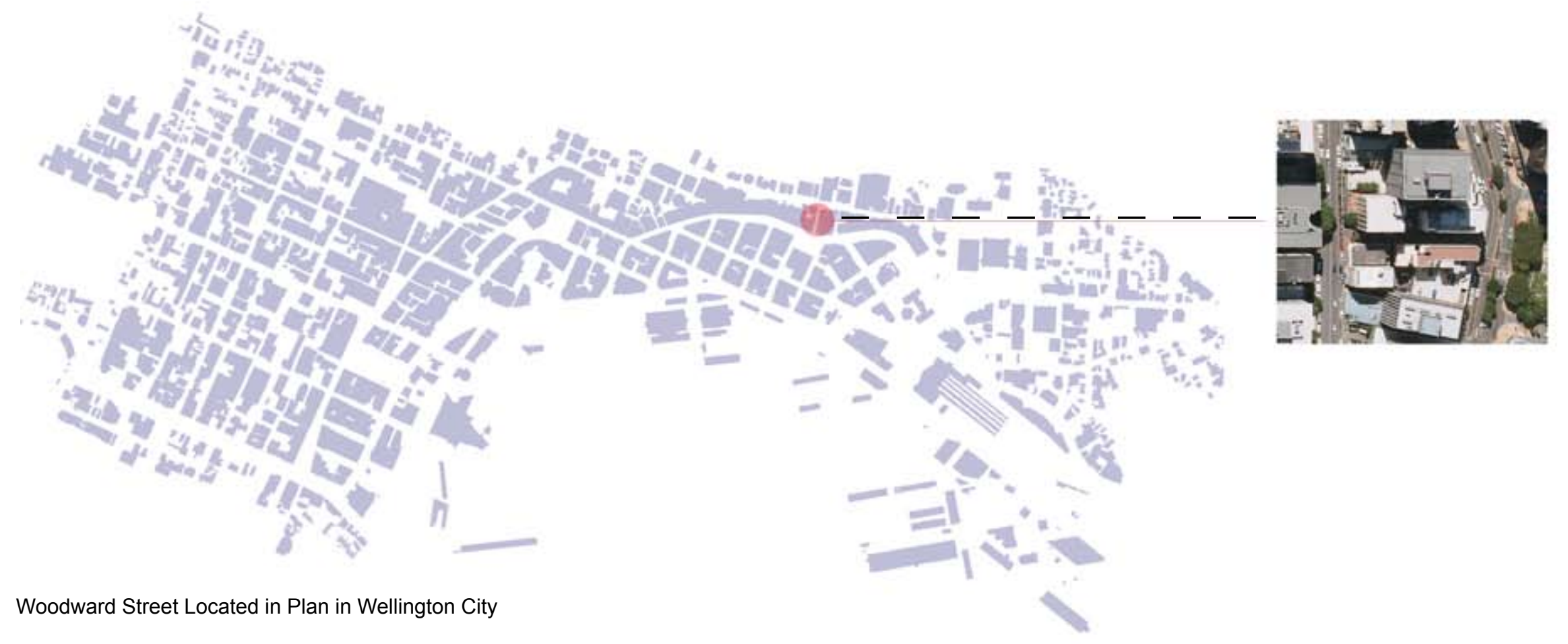



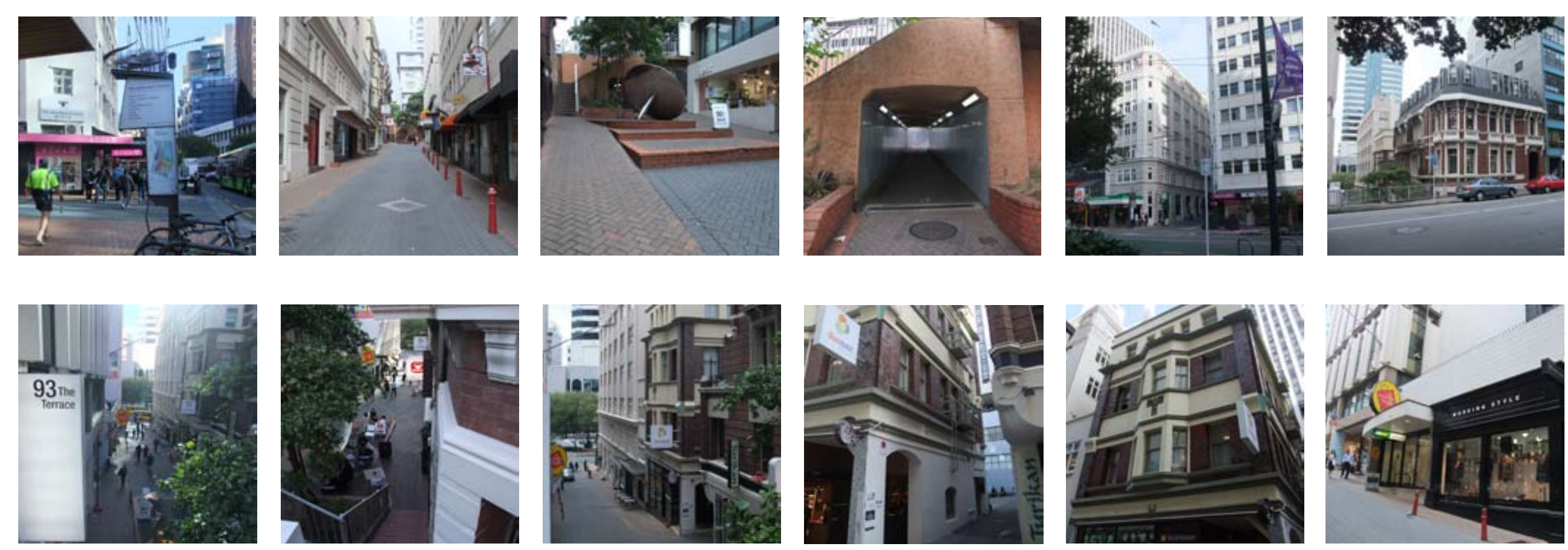

Photos investigating the existing site. 


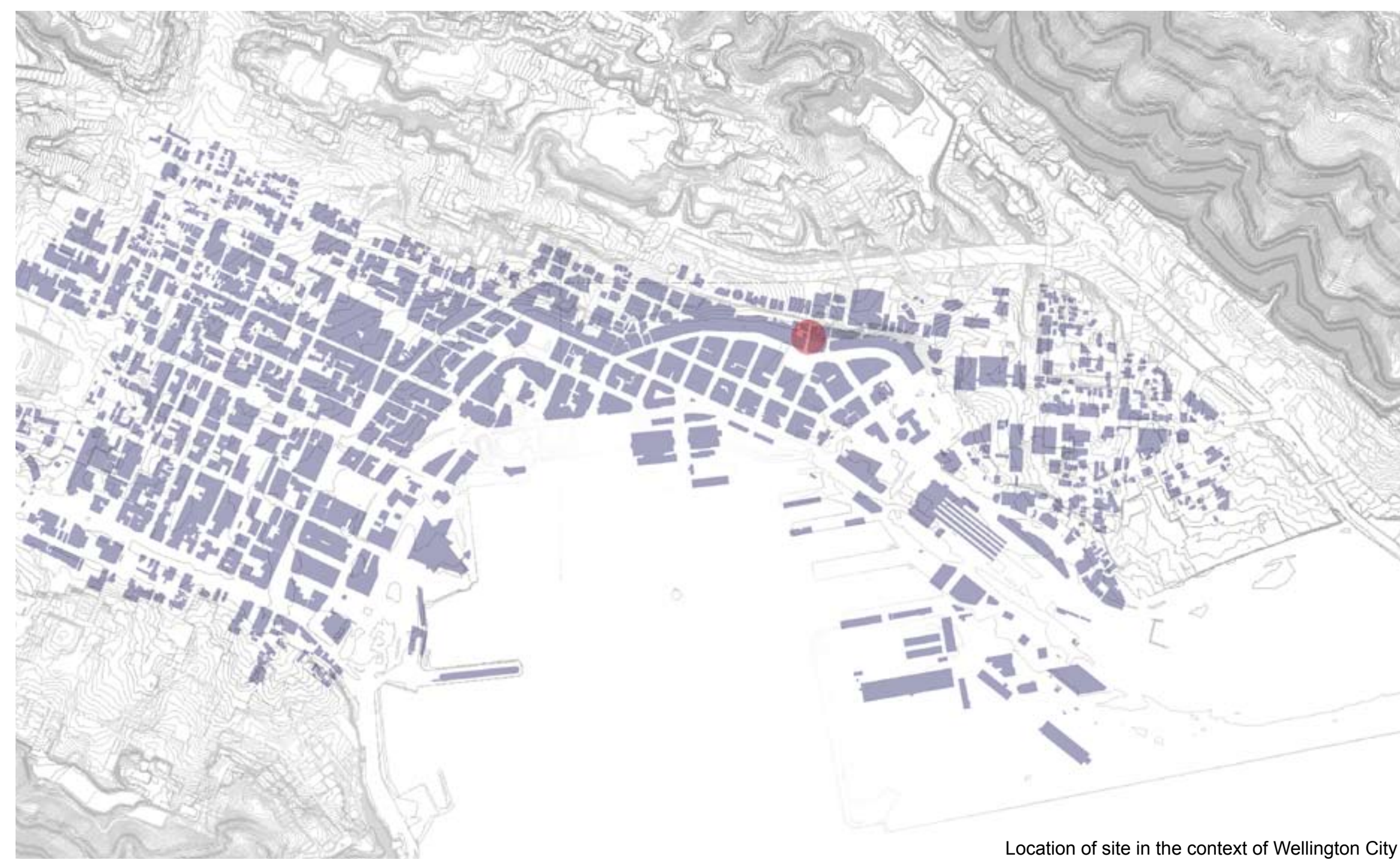




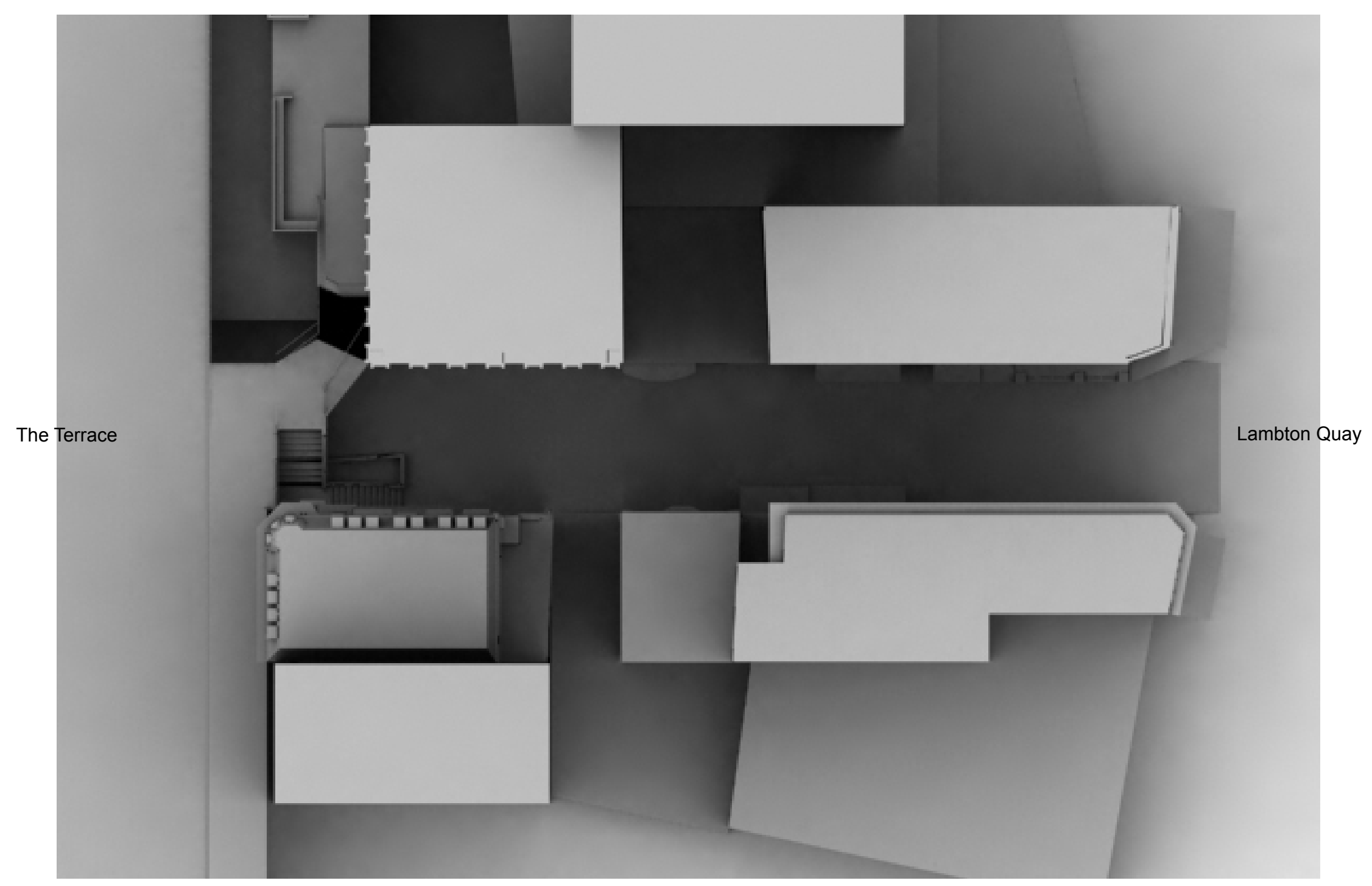




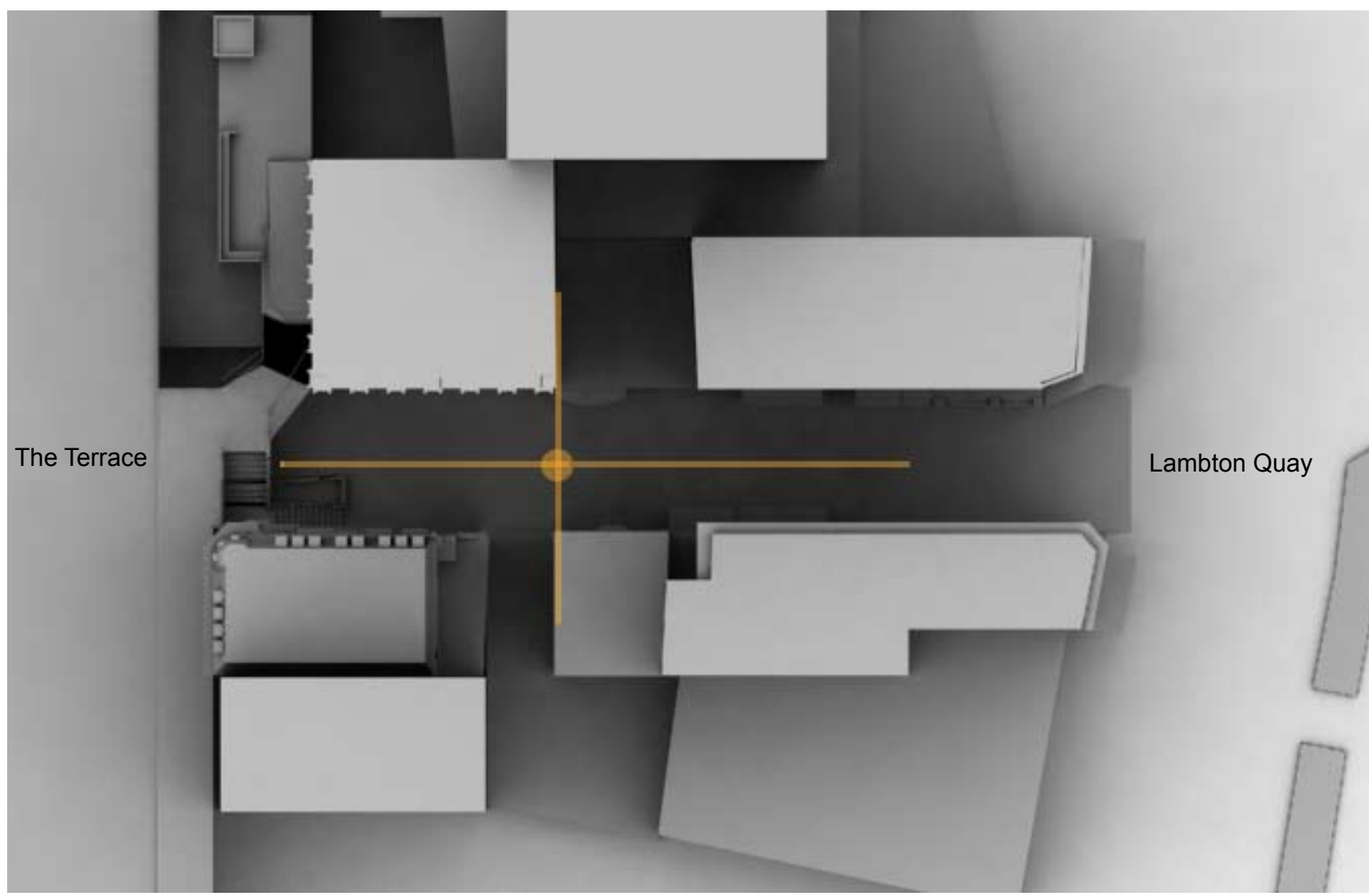

This diagram shows the location of the axis in the site. This axis shifts and projects the two courtyards. At

this axis point is a clear shift in scale of the site, from Lambton Quay which is public to The Terrace end which is intimate and personable. 

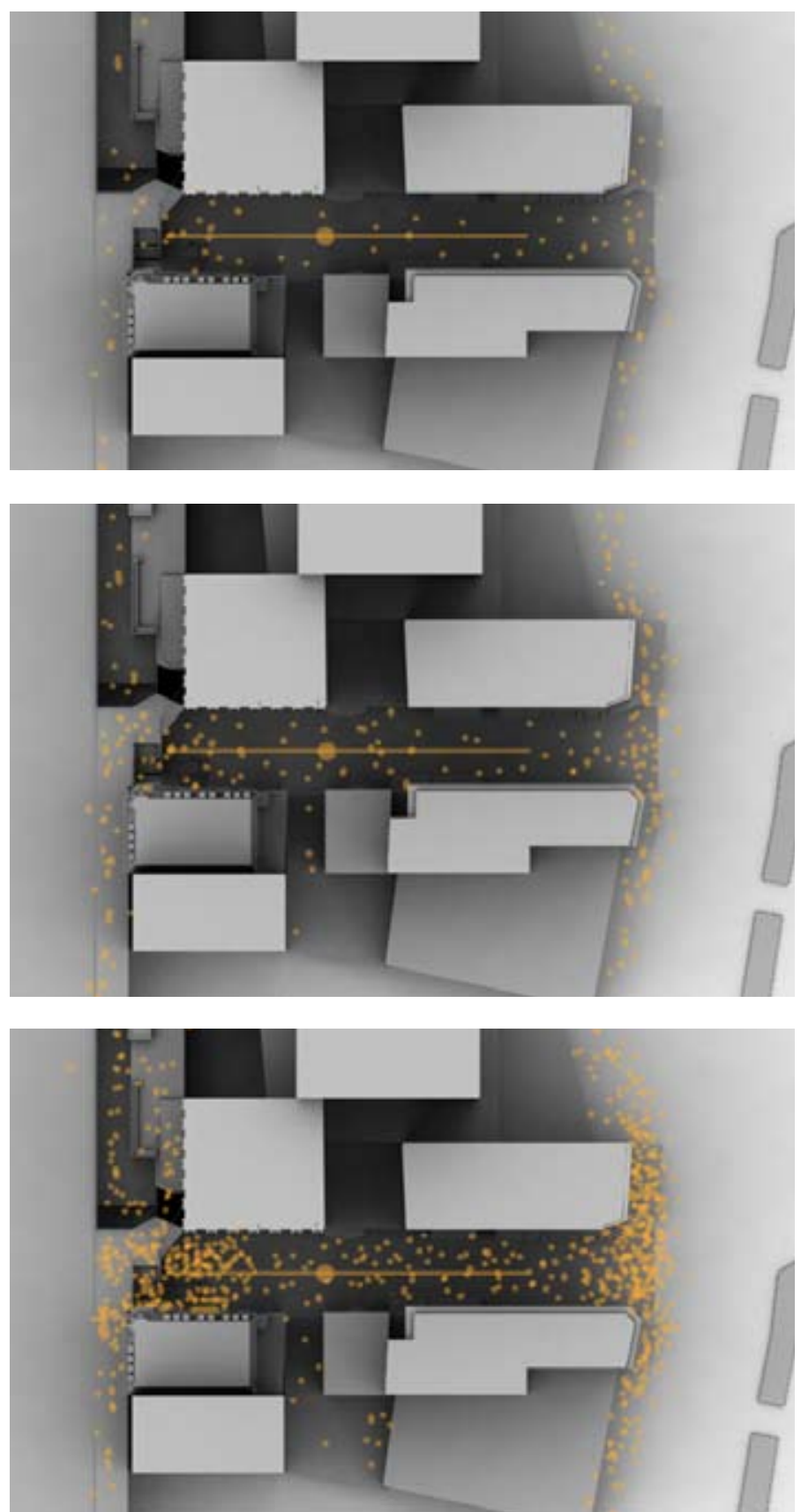

These diagrams show the change in site use at three times of the day. At the connecting streets of Lambton Quay and The Terrace the flow of traffic is the most heavist. During the research the times of $8.00 \mathrm{am} 12.00$ till $1.00 \mathrm{pm}$ and again at 5.00 to $6.00 \mathrm{pm}$ were the heaviest in foot traffic through the site, this being due to its nature as a connection point from the two streets. 


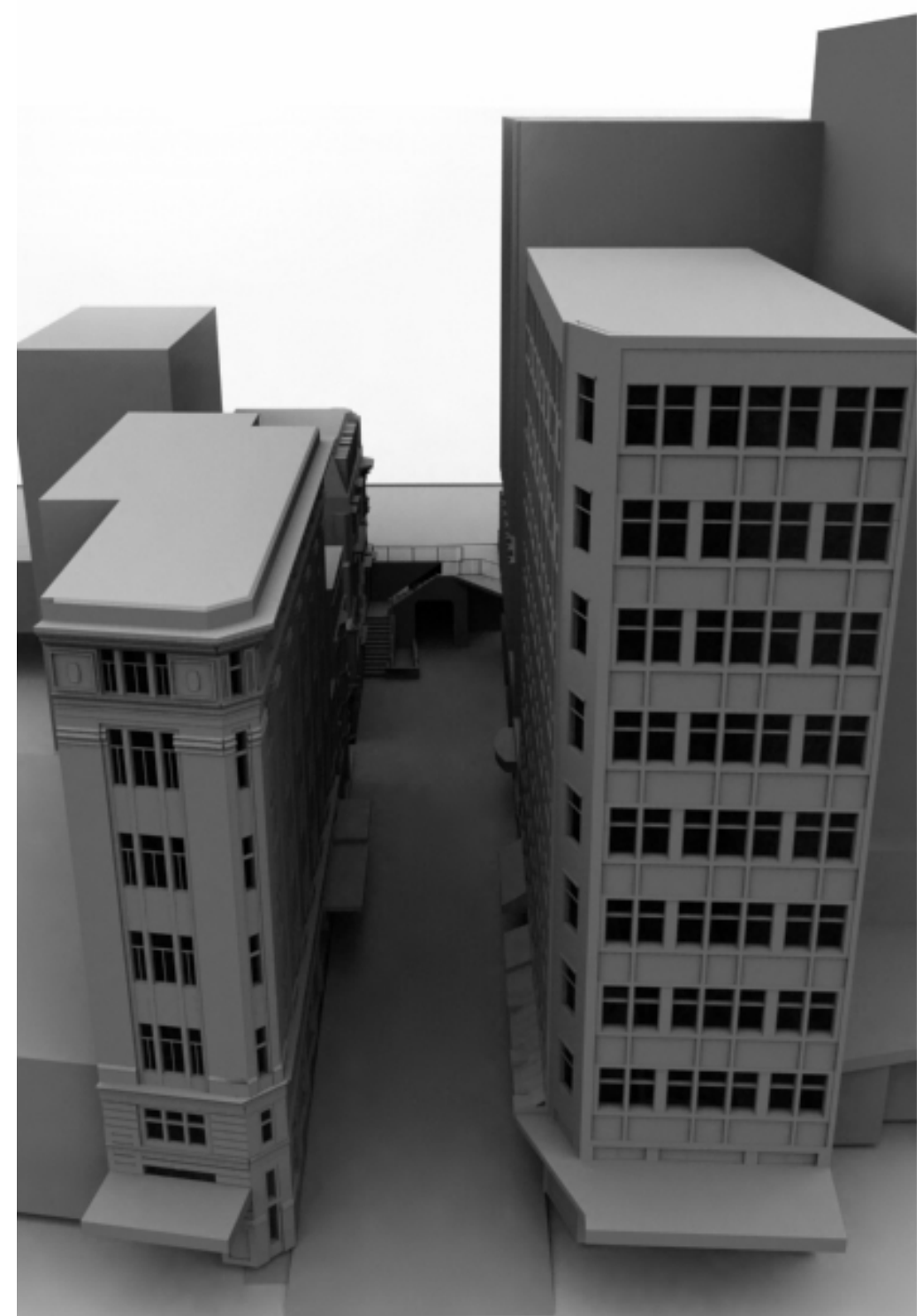


Render of site at The Terrace End. This shows how the buildings met the footpath. The Buildings at this end of the site are at a more intimate scale.

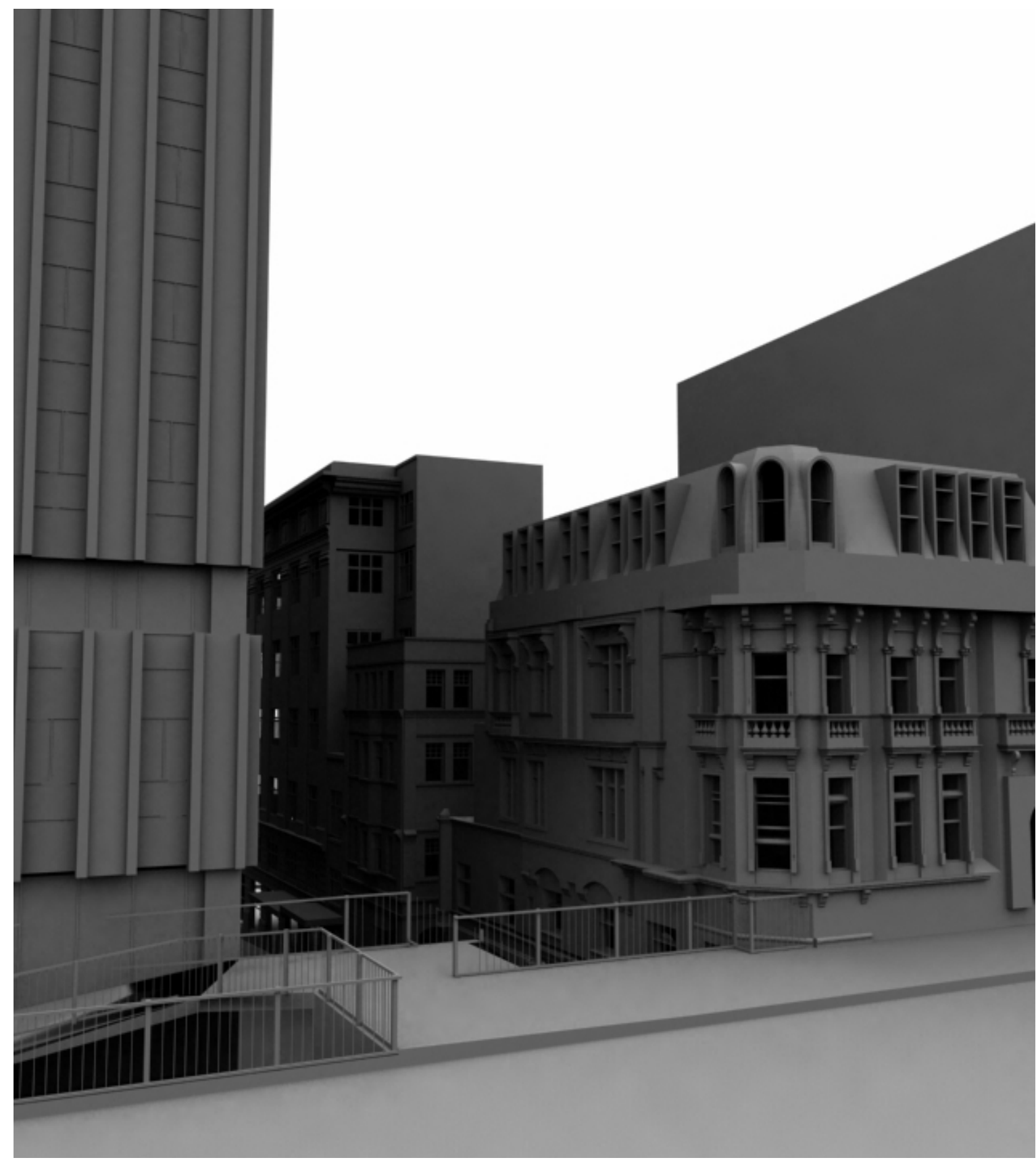



1_ DESIGN INTERVENTION 



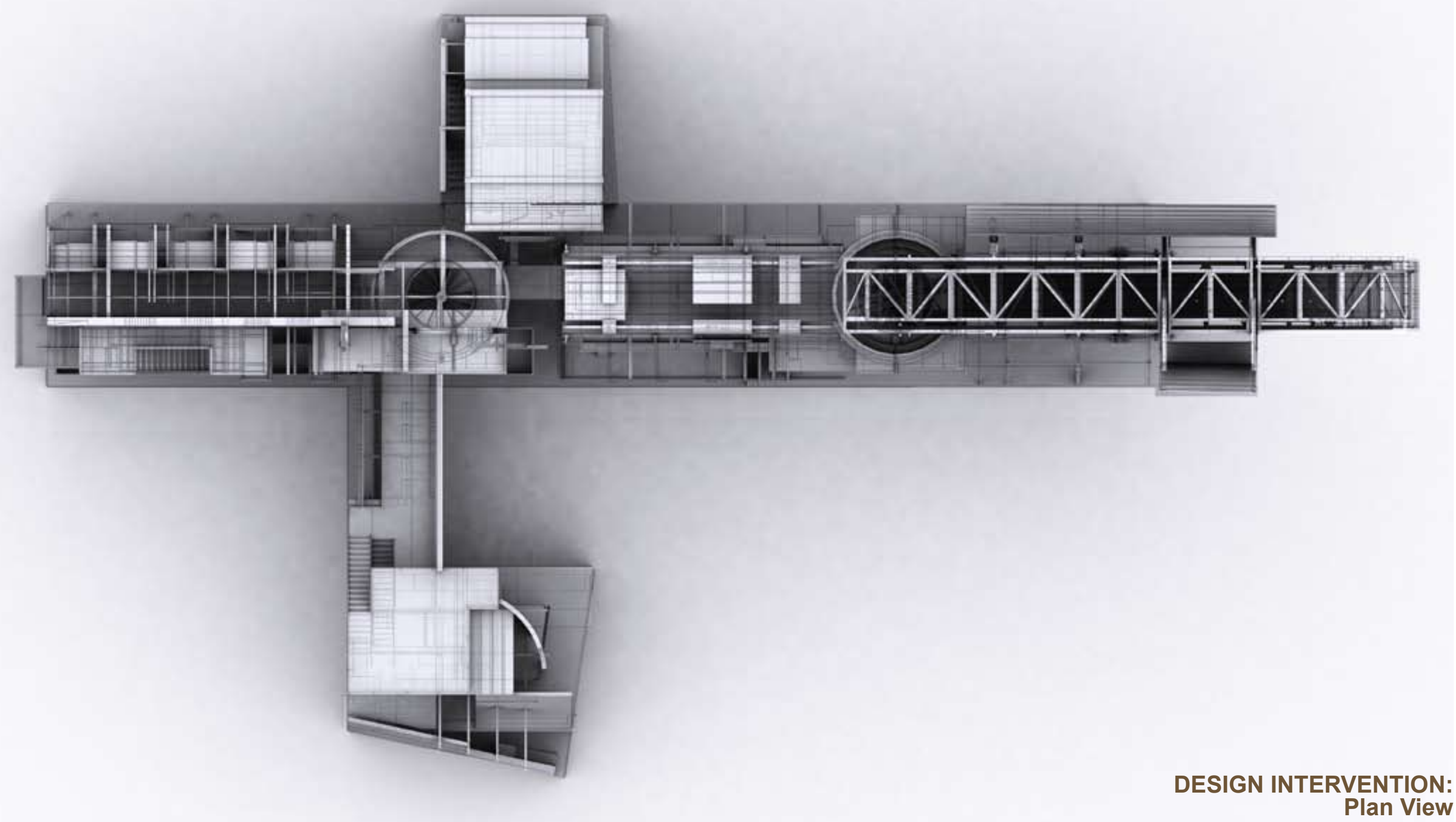





\section{INTRODUCTION}

"Artist and architects speak different languages and think in different ways but there are many parallels to be drawn between their practices. This makes it interesting to see what happens when they come together." ${ }^{40}$

This chapter explores the design intervention which is not to create a relationship between the discipline of spatial installation and interior architecture but rather to investigate how the processes of each discipline can be applied to the other; it embraces spatial installation art within the discipline of interior architecture. The intervention is designed to define function of space which changes throughout the design according to different times of day and to those inhabiting it. The chosen site used as the vehicle to drive the design has two different populations at each end, one at Lambton Quay and the other The Terrace, both of whom enter at either end and met in the middle. Lambton Quay is used by the corporate businessmen and government officials while the Terrace is entered by the young professional and the young mother and child, these groups meet and cross over and use the space together. This intervention embraces these existing qualities and explores how the space is used by each user. At each moment in time each space can be used very differently. 

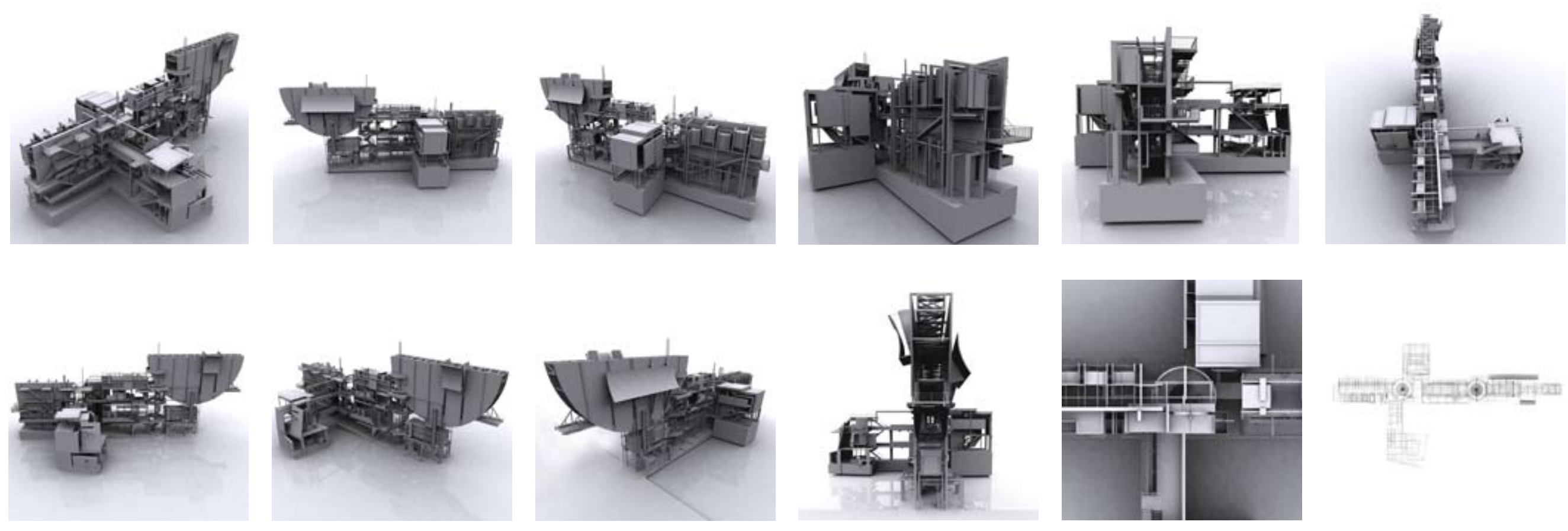


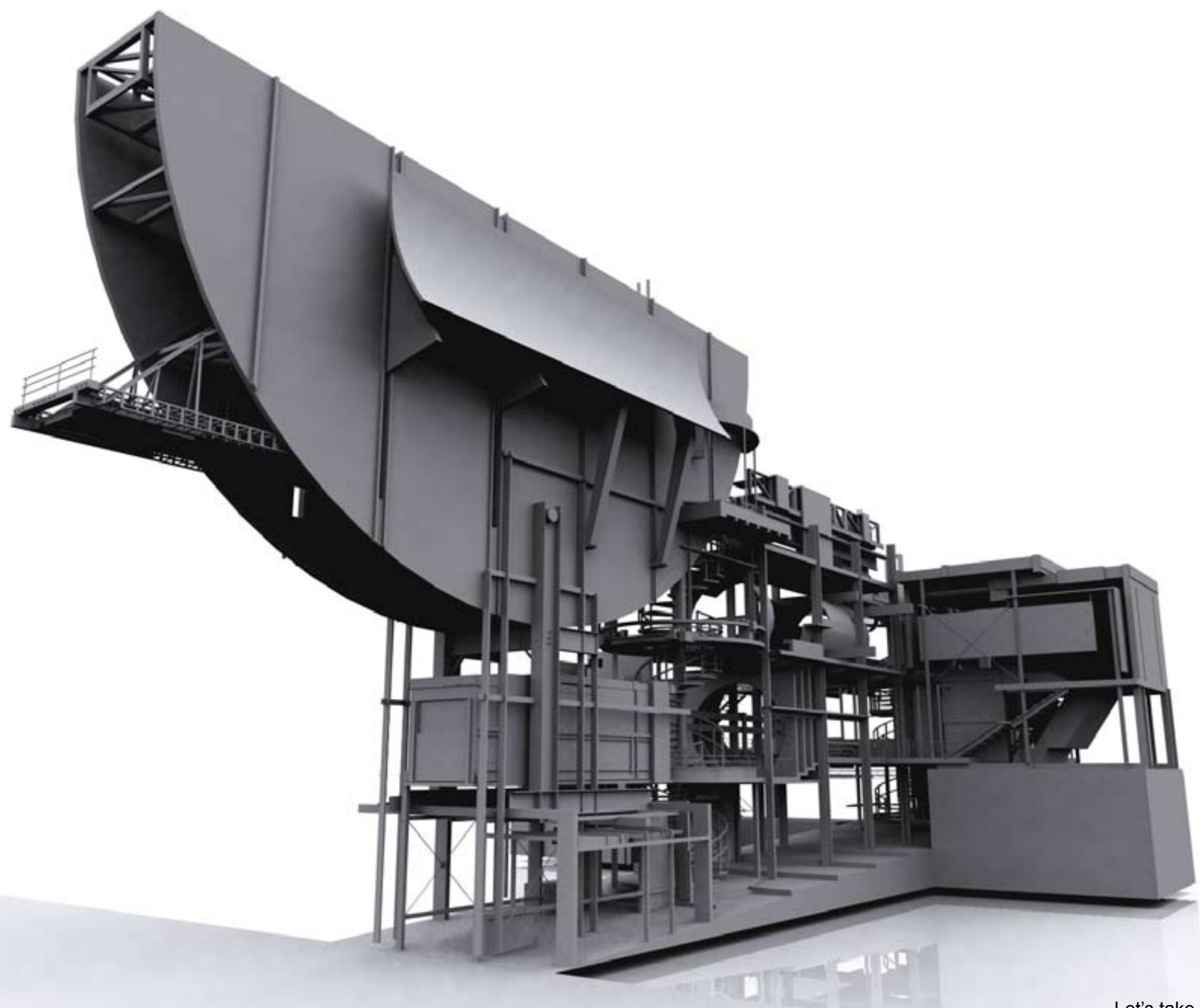




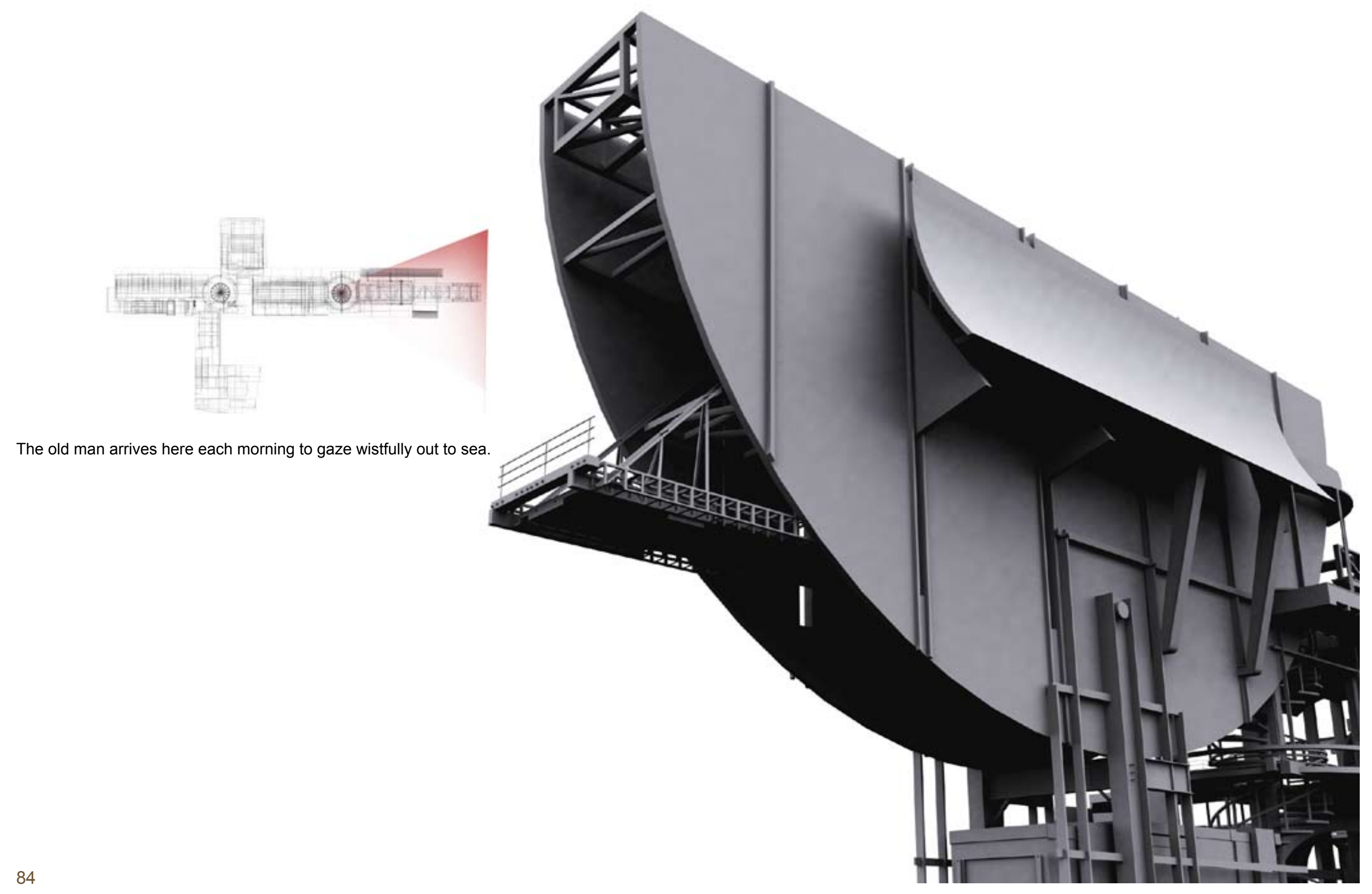




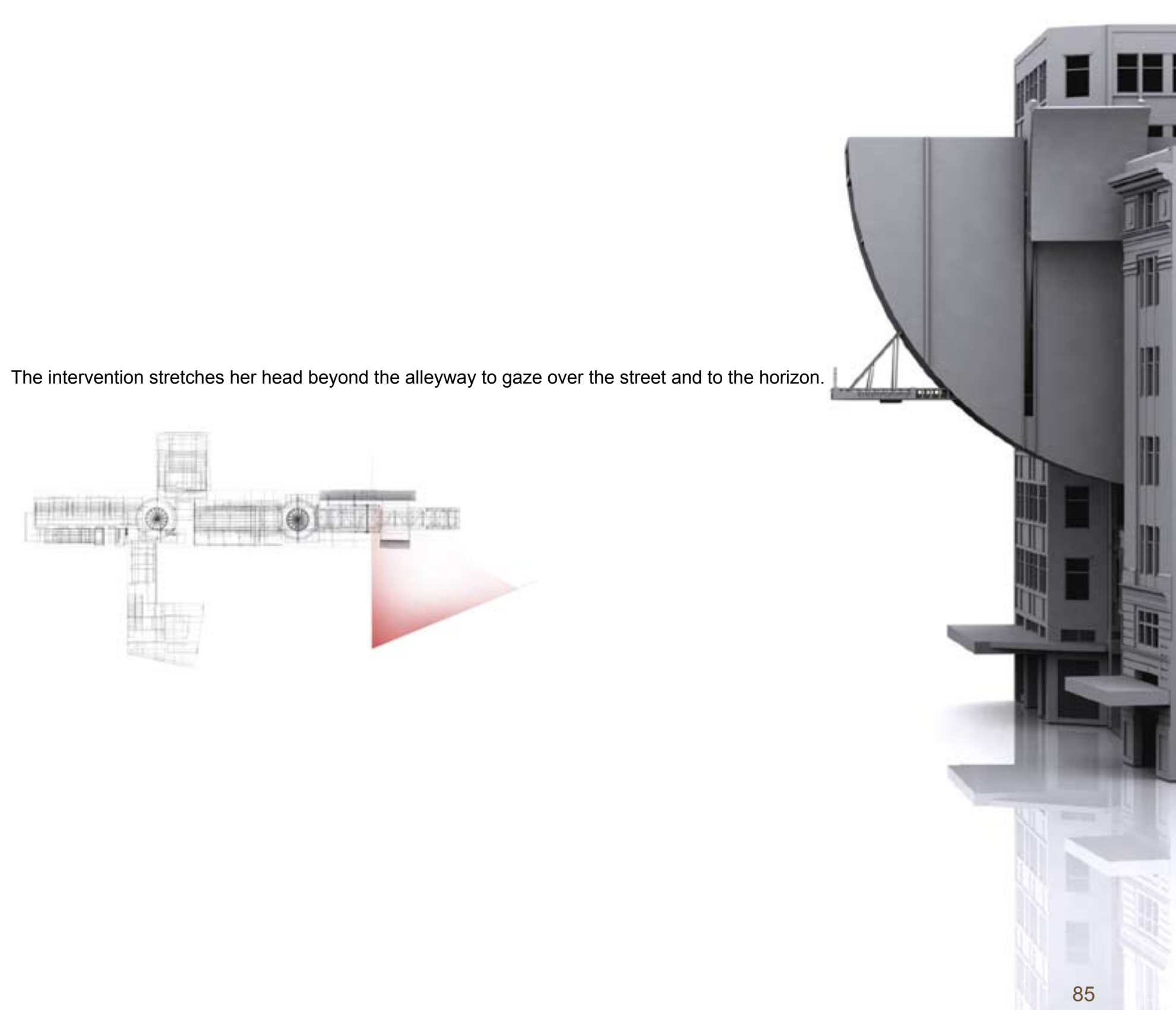




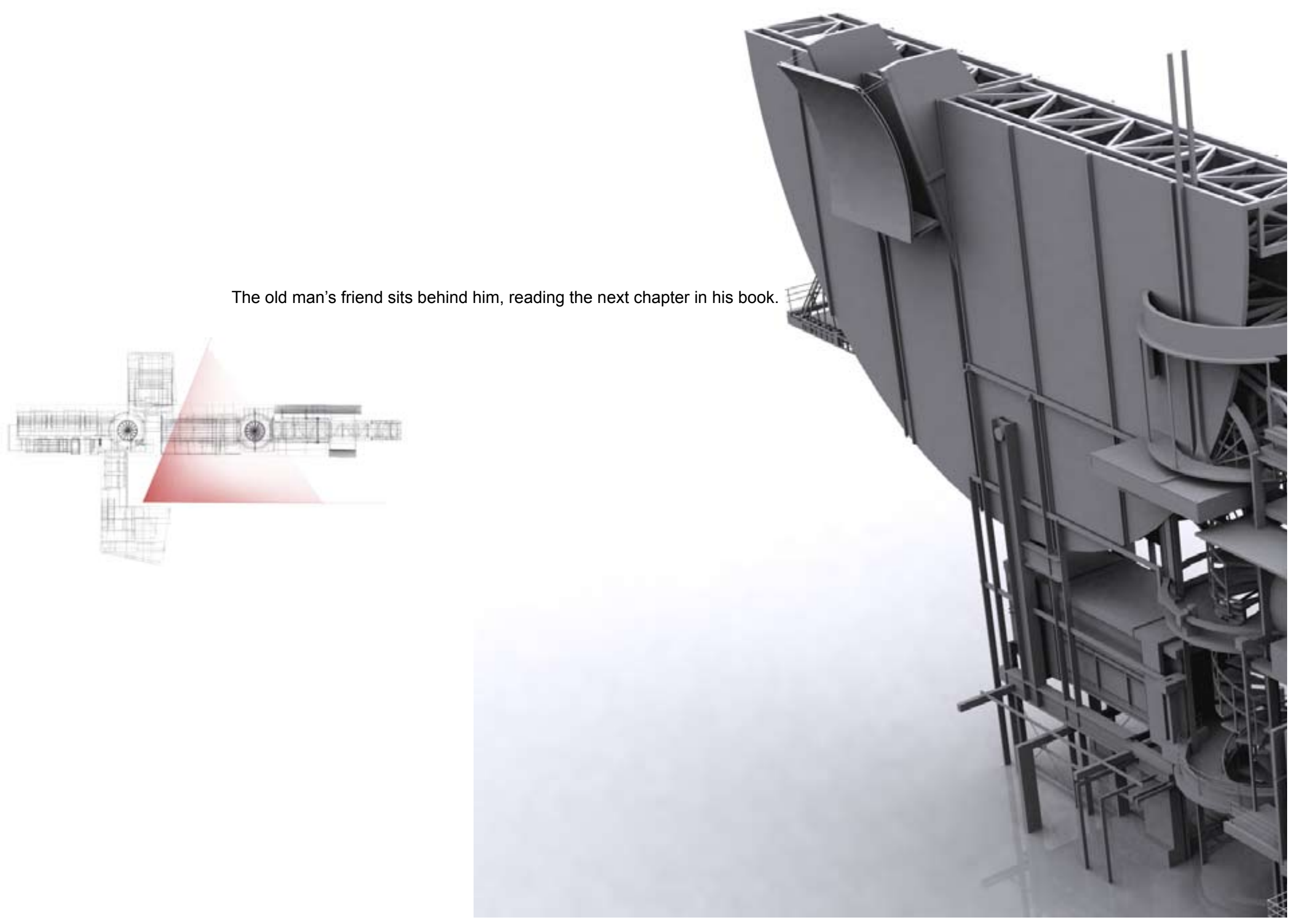




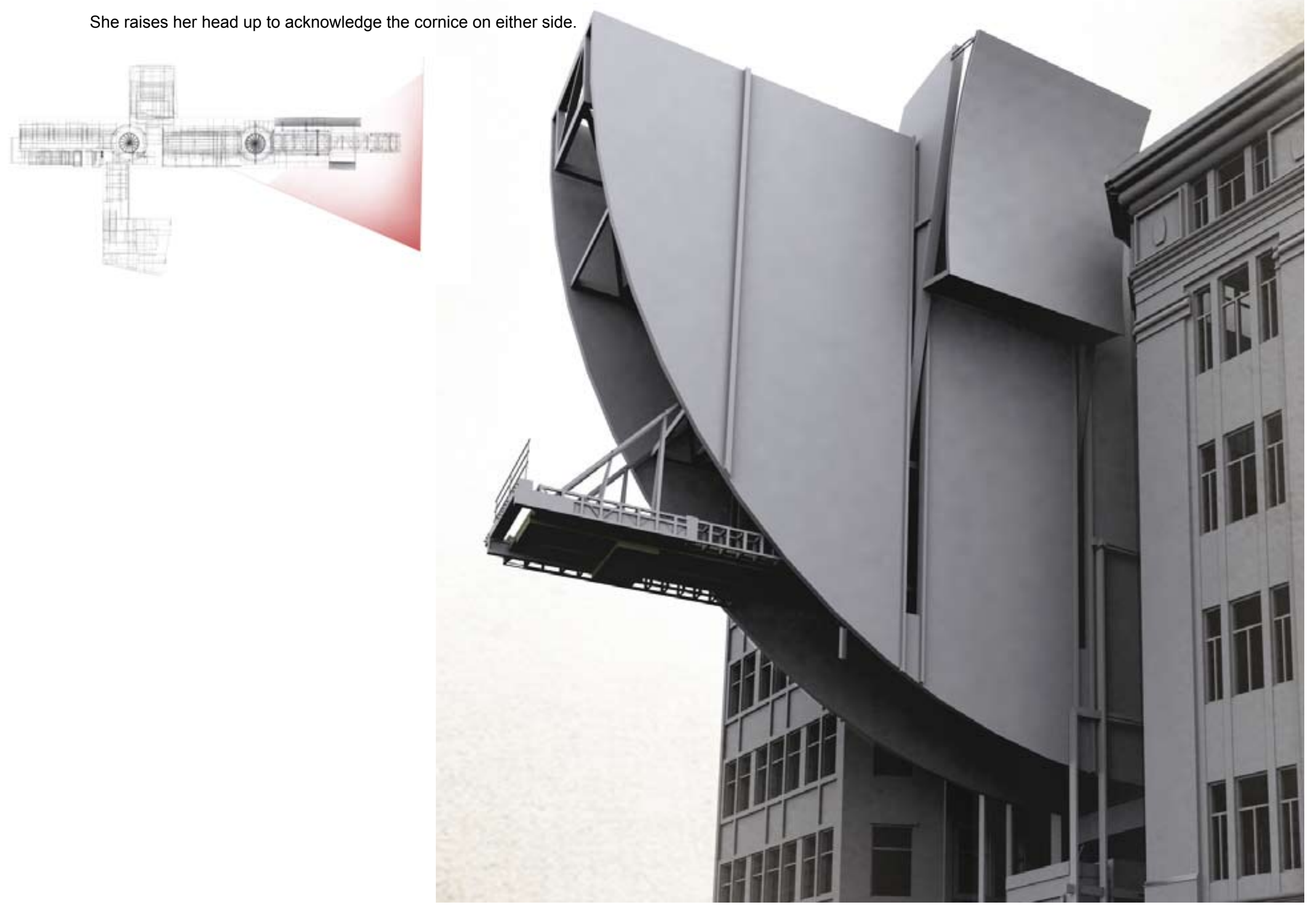




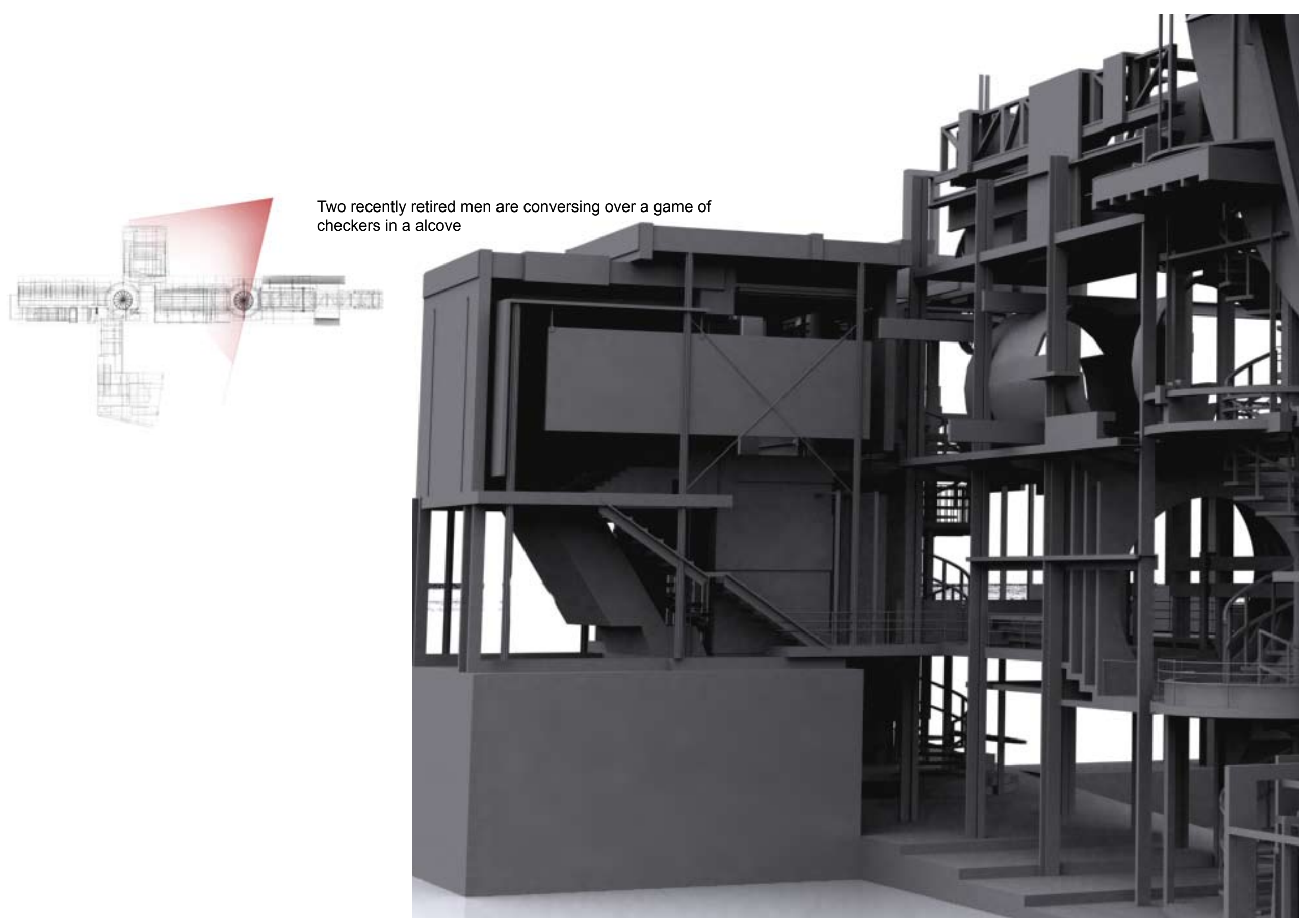




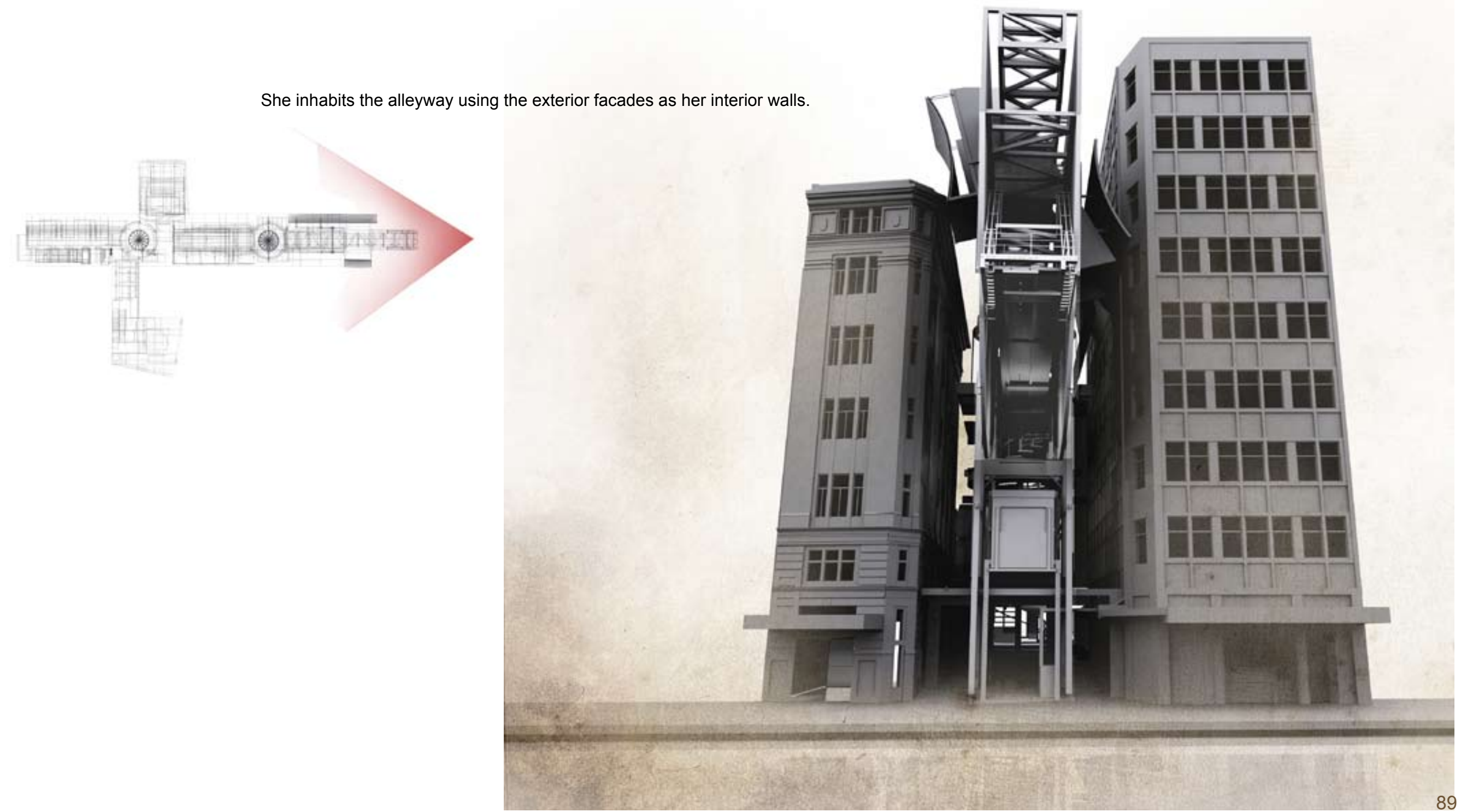




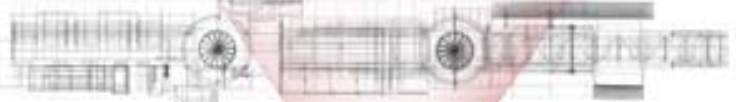

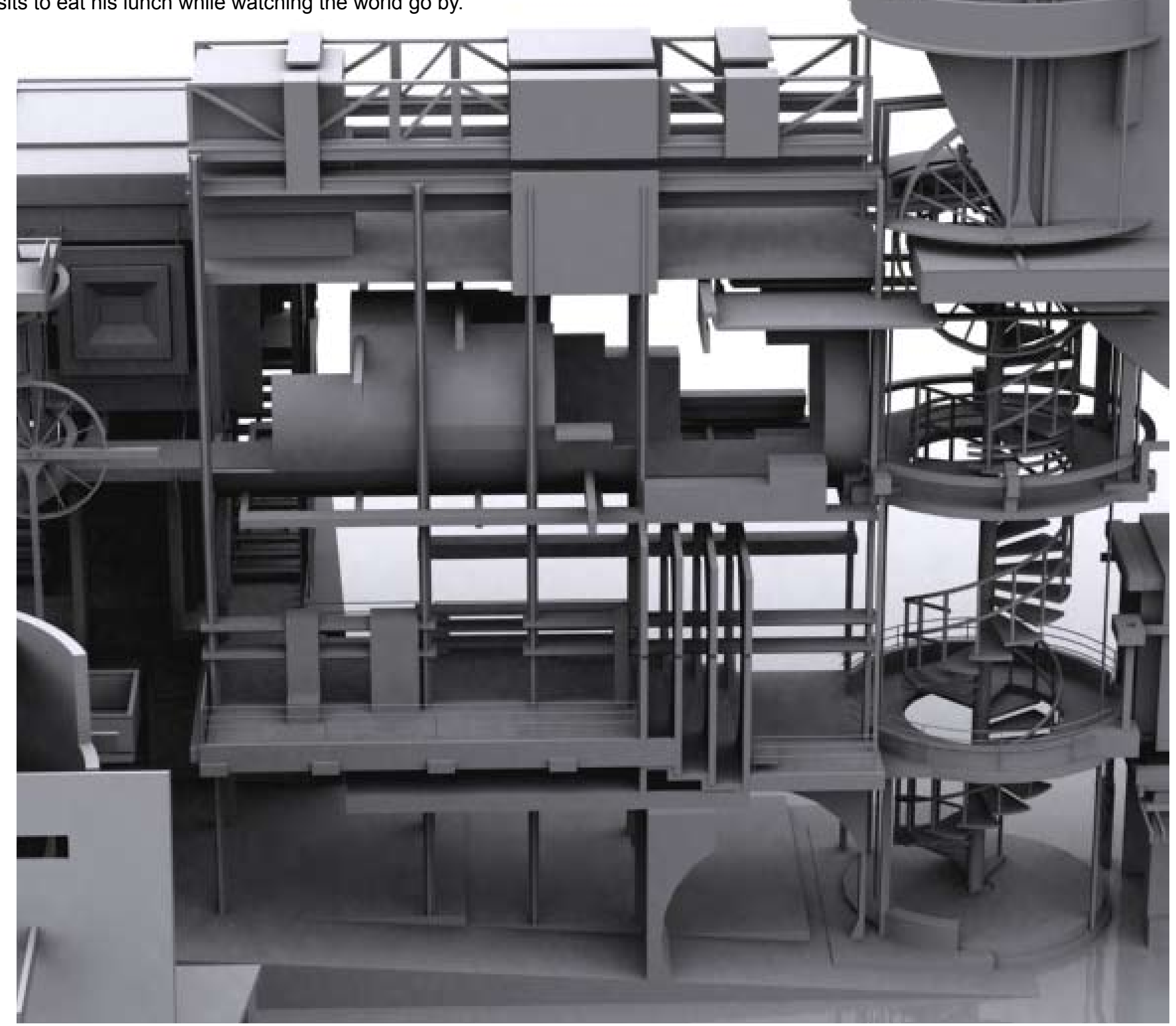




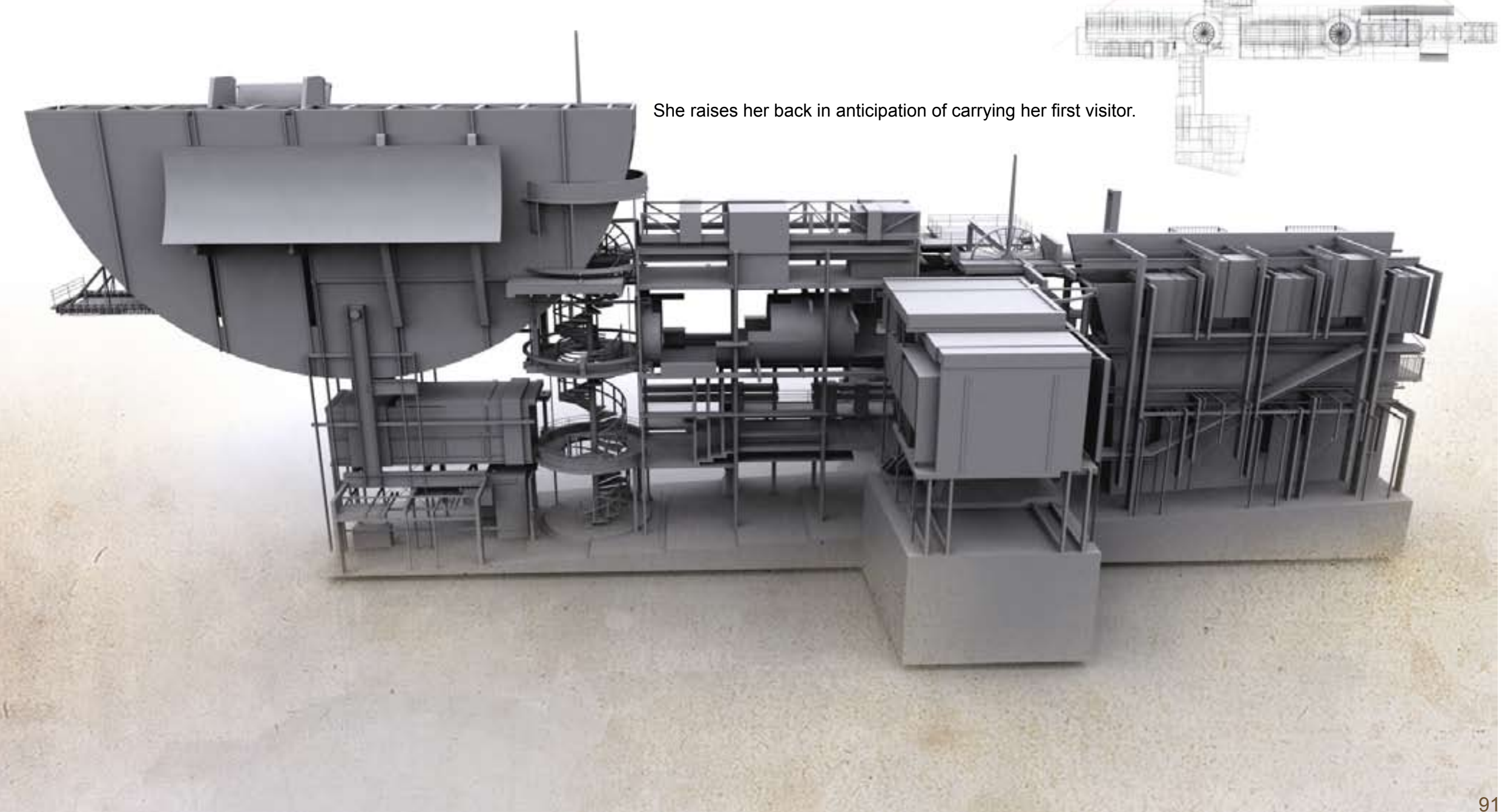



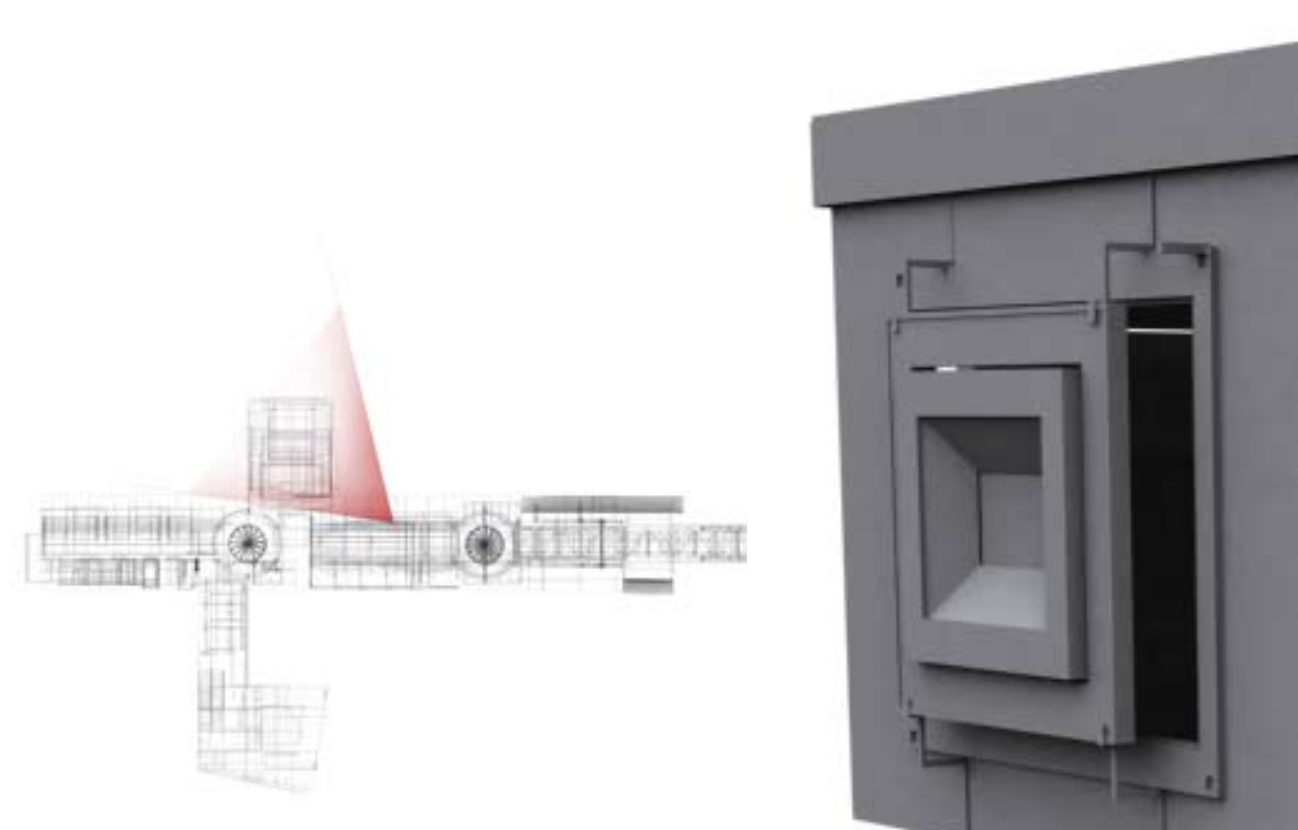

The art gallery's curator is arranging a set of films for exhibition on two different scales.
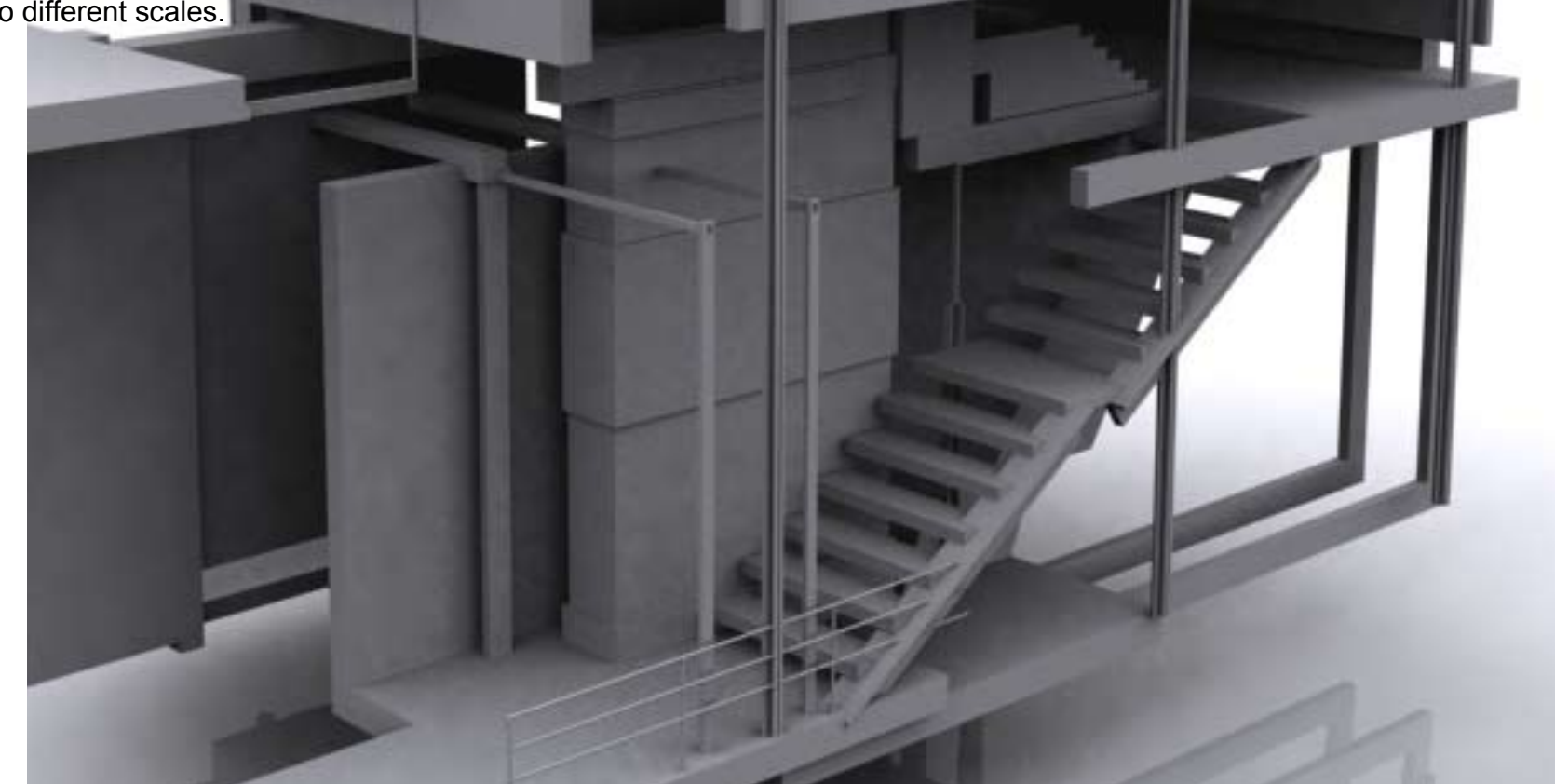


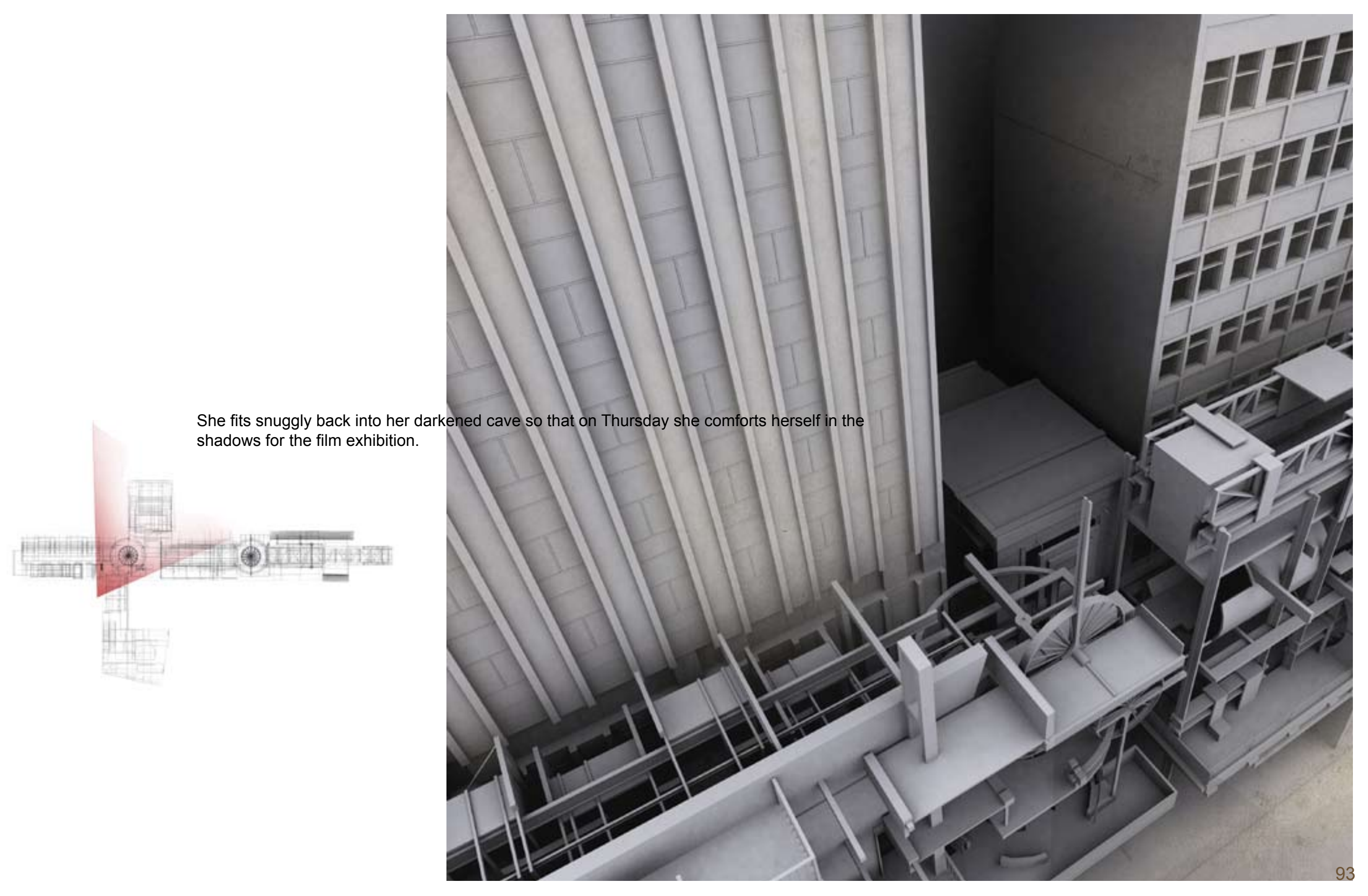




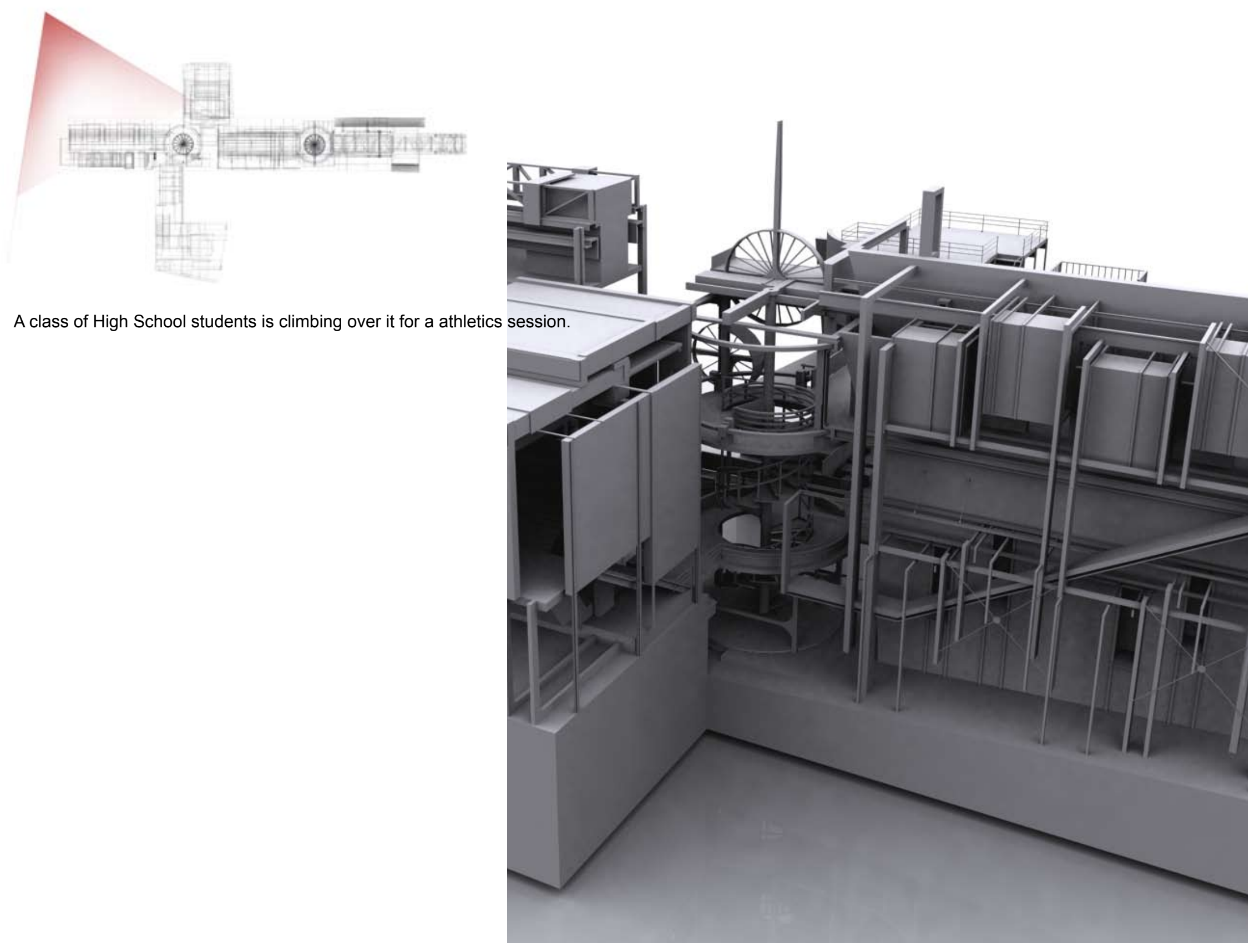




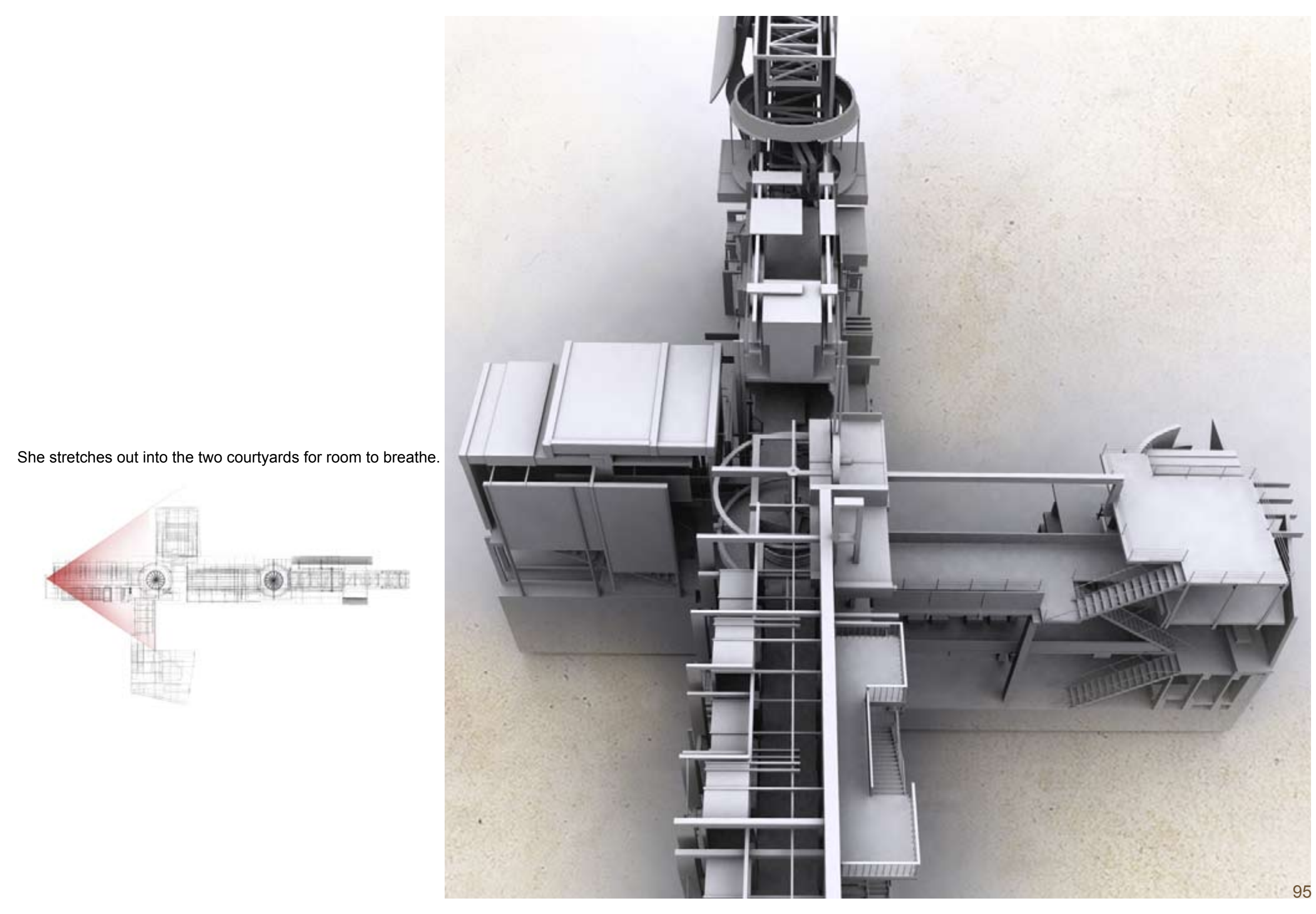


Three University students have taken over the open gallery for a pop up exhibition of their work.
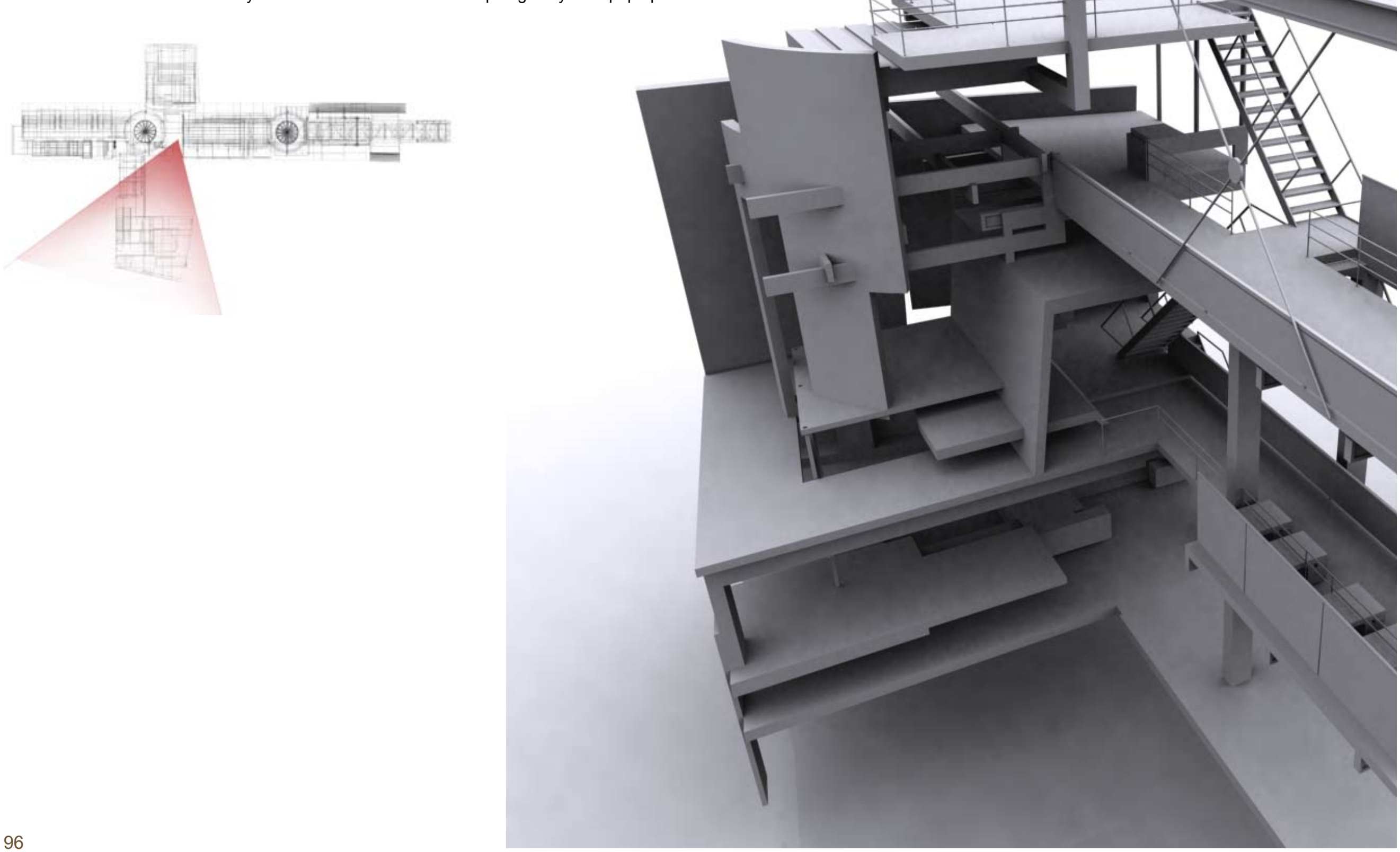
As she stretches out she shifts to either side of center to the central axis of her site.
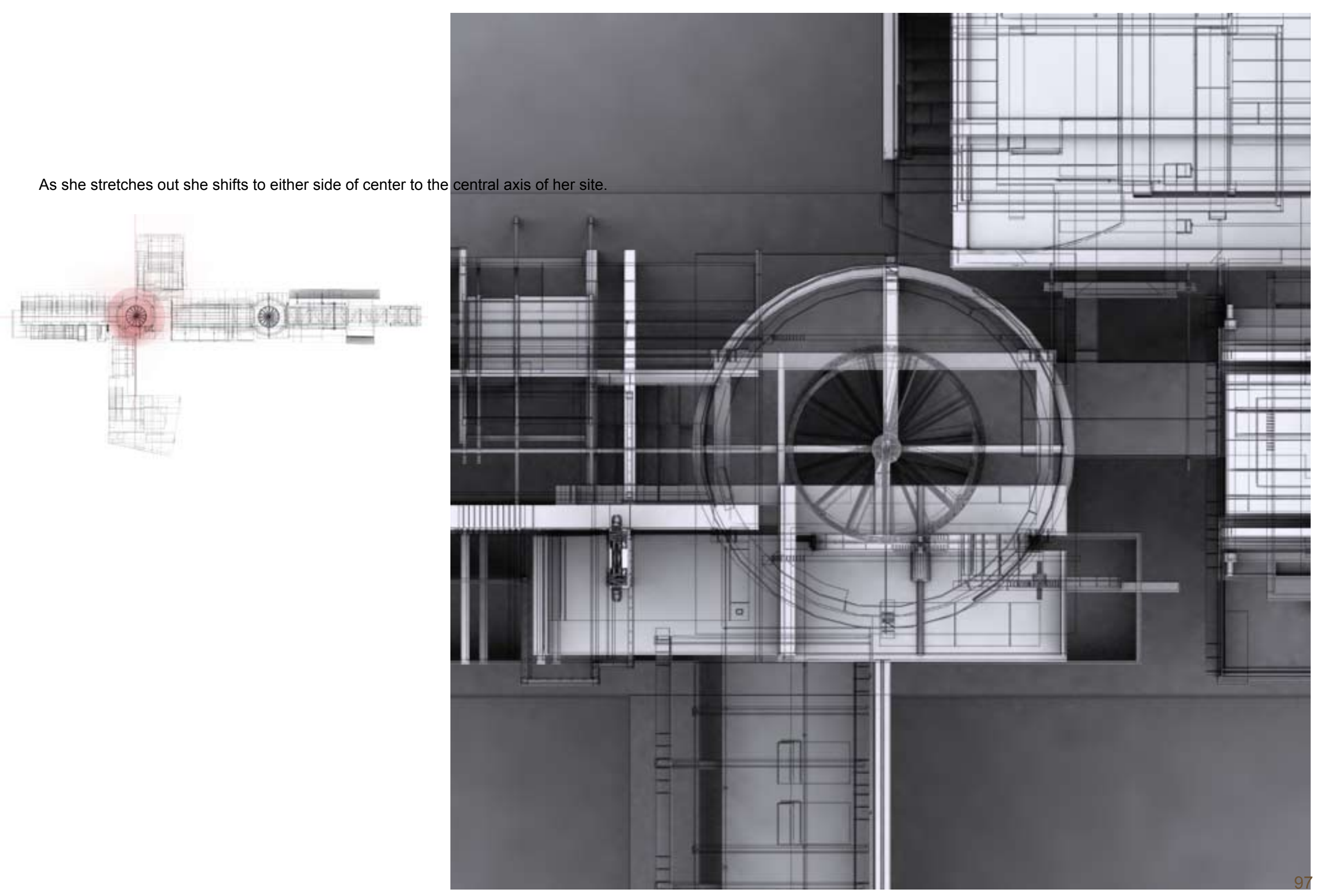


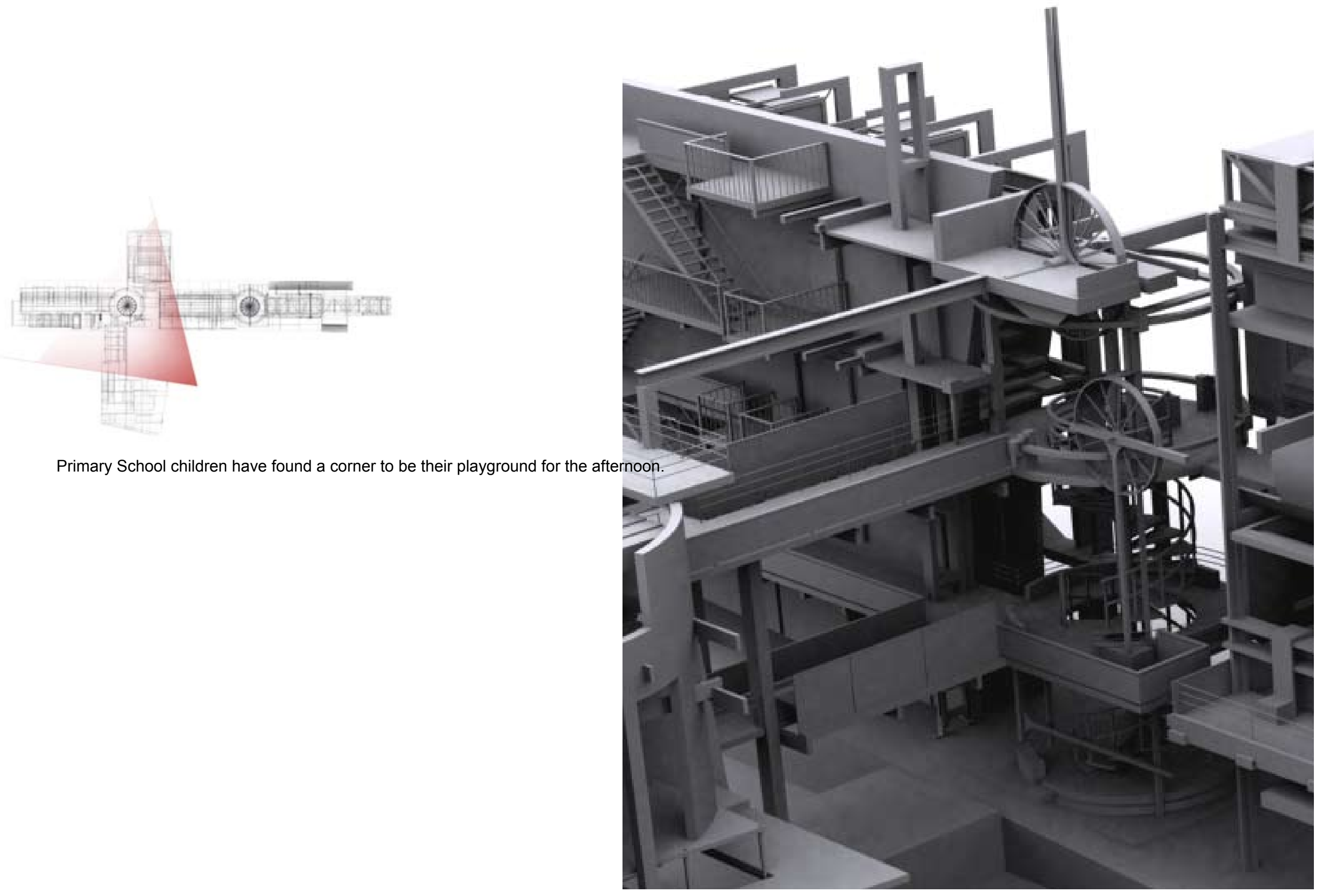


On Saturday she is illuminated in bright red as the art gallery curator changes the art projects.

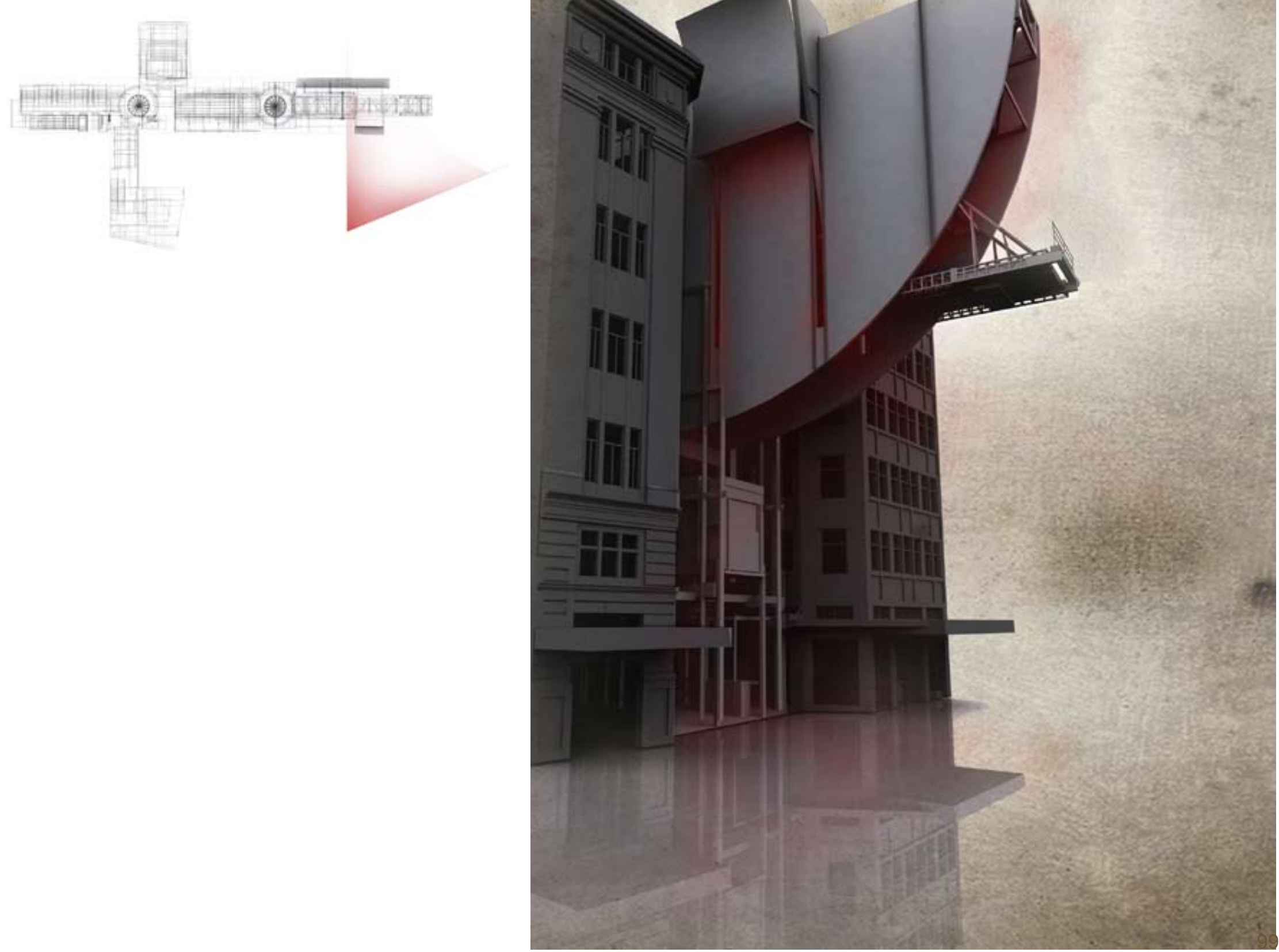




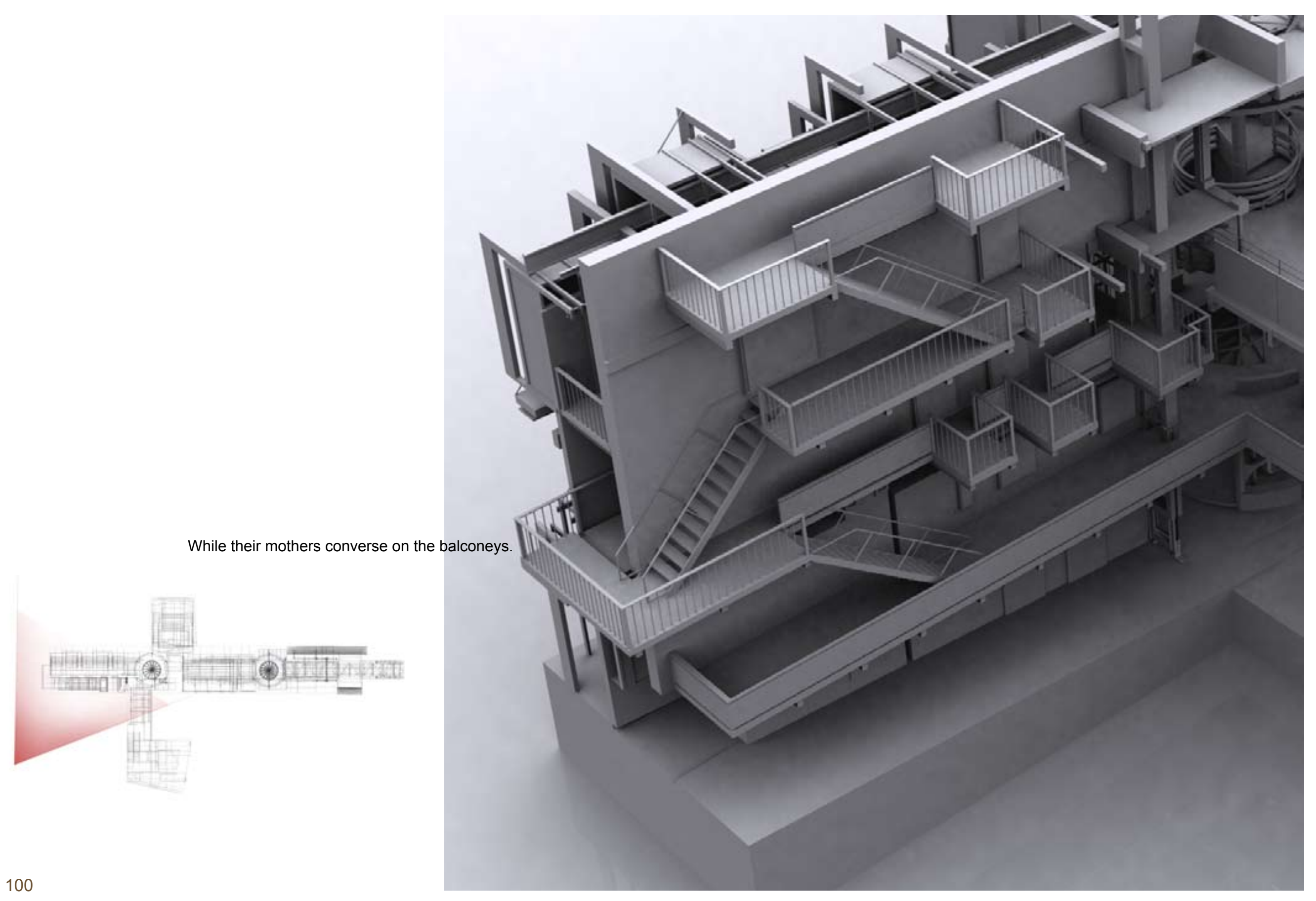




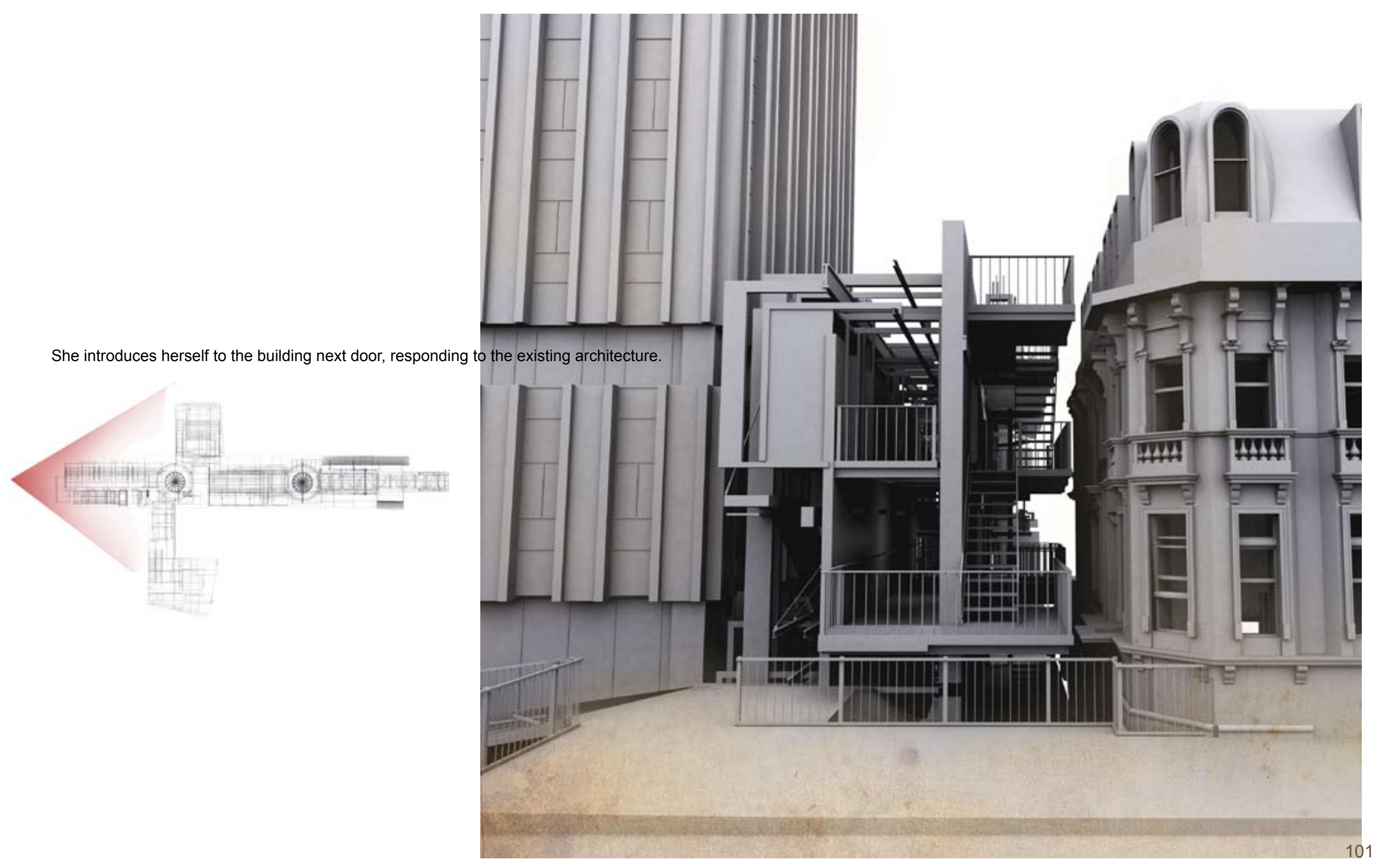




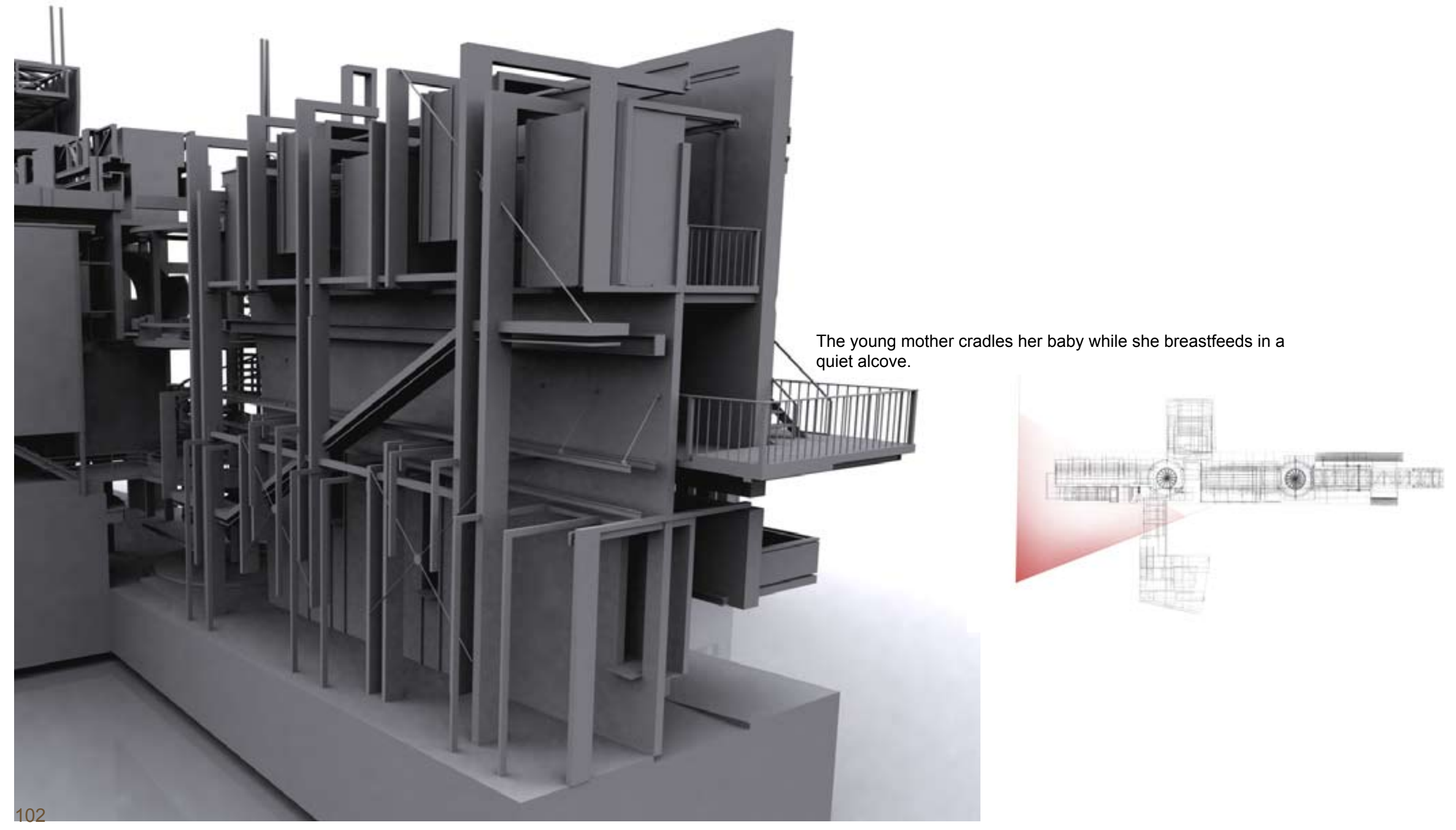



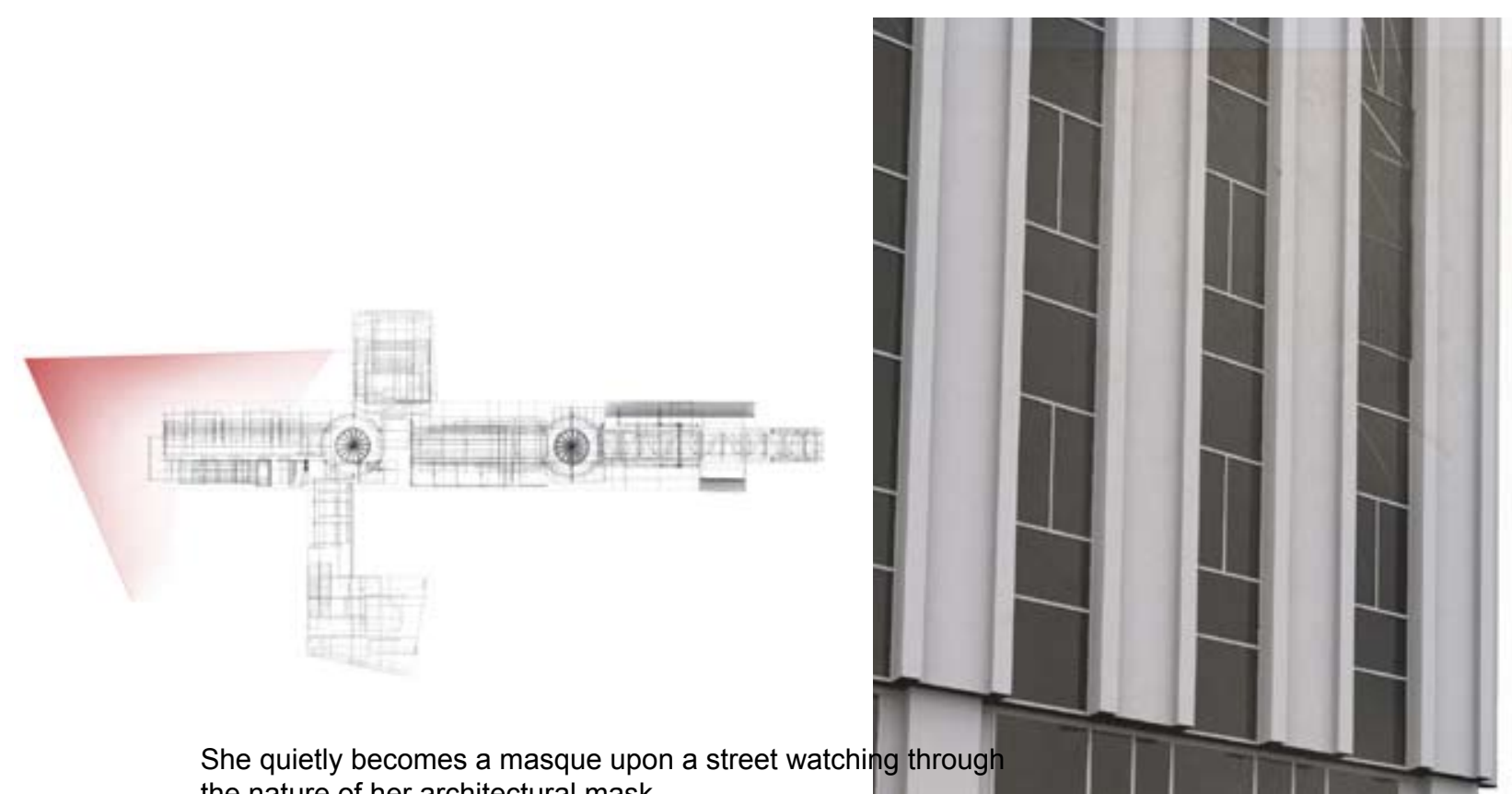

She quietly becomes a masque upo
the nature of her architectural mask

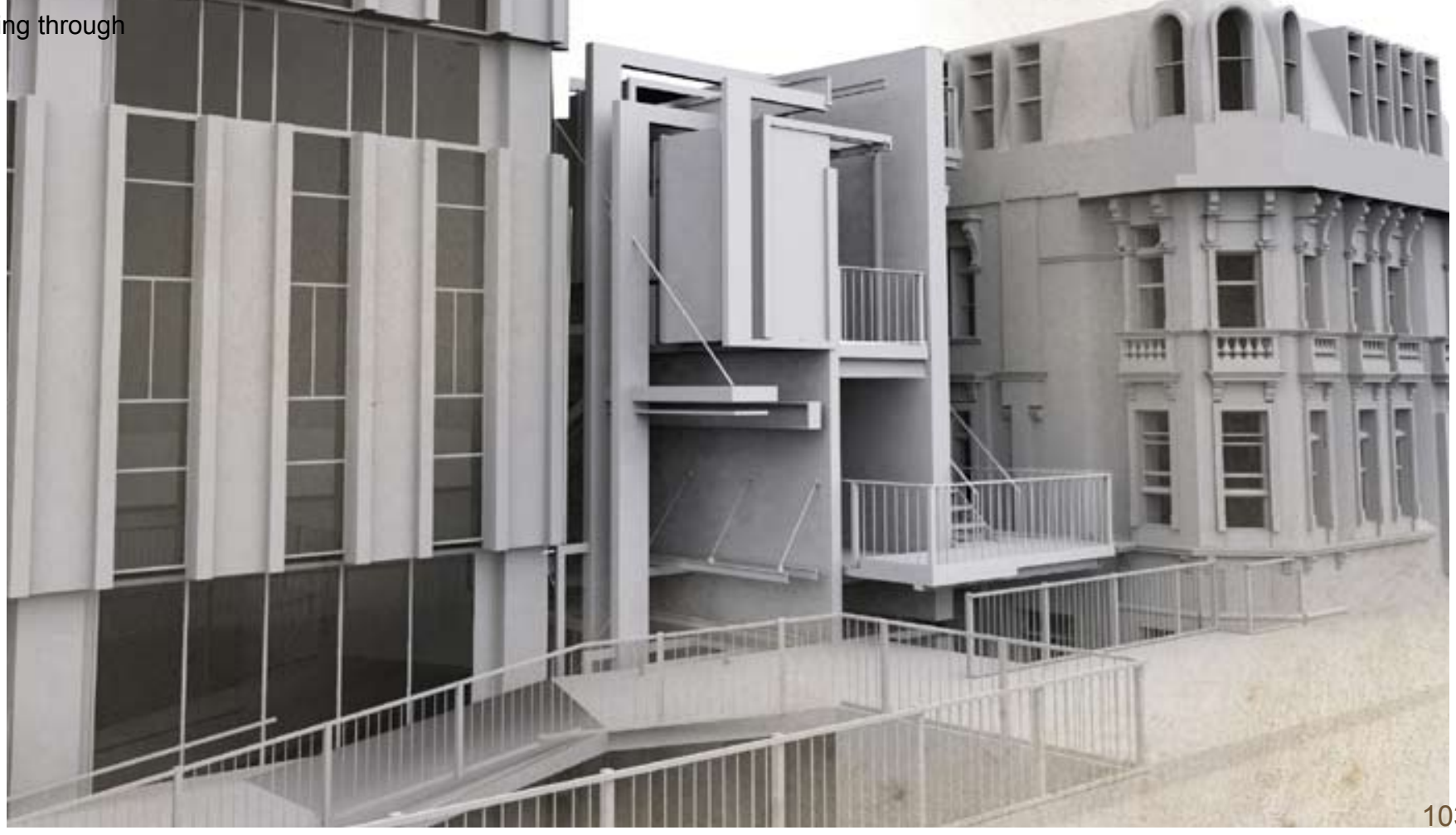




\section{DESIGN ANALYSIS}

The design intervention began with design explorations of aspects from precedents such as the work of Douglas Darden and John Hedjuk. Neither architect was explicitly constructing spatial installation space. This thesis's aim to combine architecture with spatial installation art, so it began by integrating the vocabulary of these architects as explorations of form. These explorations of form are used in very different ways to that of the original architects; the intervention is being concealed instead of exposed. The form became interior architecture to be inhabited rather than Darden's work which is about the exterior. The design process explores the transfer of habitable program into the realm of spatial installation art to cross the boundary into interior architecture.

Spatial Installation Art is typically unconstrained by habitational or programmatic functions. It is able to develop three-dimensional space in order to create spatial environments the audience can enter and occupy, unbound by any programmatic or functional restrictions.

Traditional interior architecture, however, is the opposite; its contextual containment and habitational restrictions are its defining principles. Interior Architecture is typically constrained by the physical conditions of space, defined by the built containment of walls and ceilings defining three dimensional vertical space. Inhabiting interior architecture is defined by the constraints placed upon it by the

programmatic functions that typically respond to social needs ( i.e. the need for sleeping and eating); these functions can define the architectural constraints, circulation and interaction with the built environment.

This design experiment challenges Spatial Installation Art as a vehicle to encourage Interior Architecture to extend beyond its traditional constraints. It integrates three diverse design disciplines: interior architecture, spatial installation art and landscape architecture. This design experiment demonstrates a transformation in the boundaries of interior space, establishing a revised adaptive use of containment by an architectural shell. The design integrates spatial art and architecture with the processes and functional systems through which interior architecture is typically defined

(programmatic functions, habitation and human aspects).

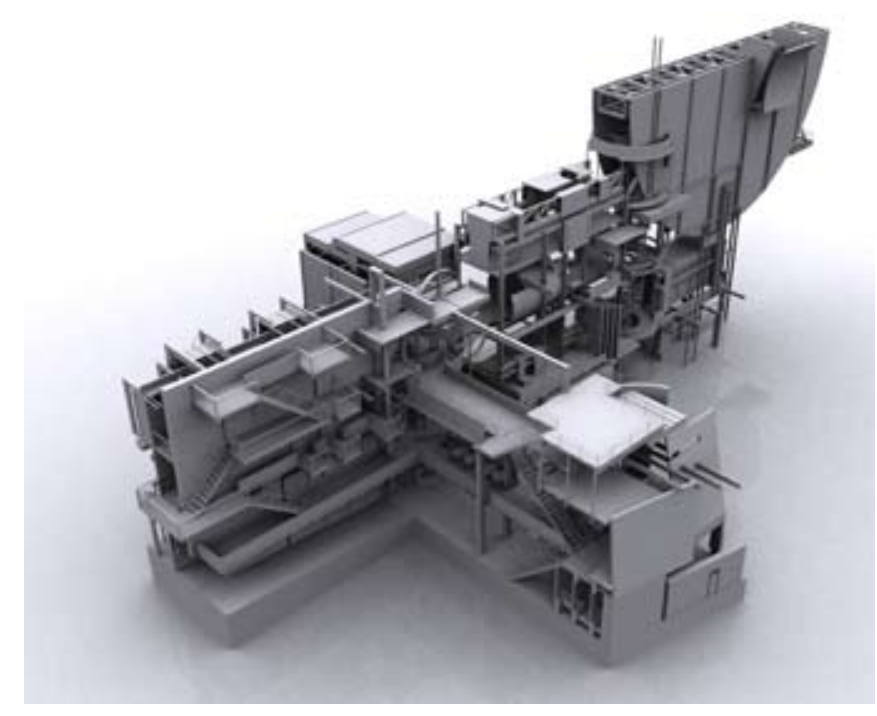




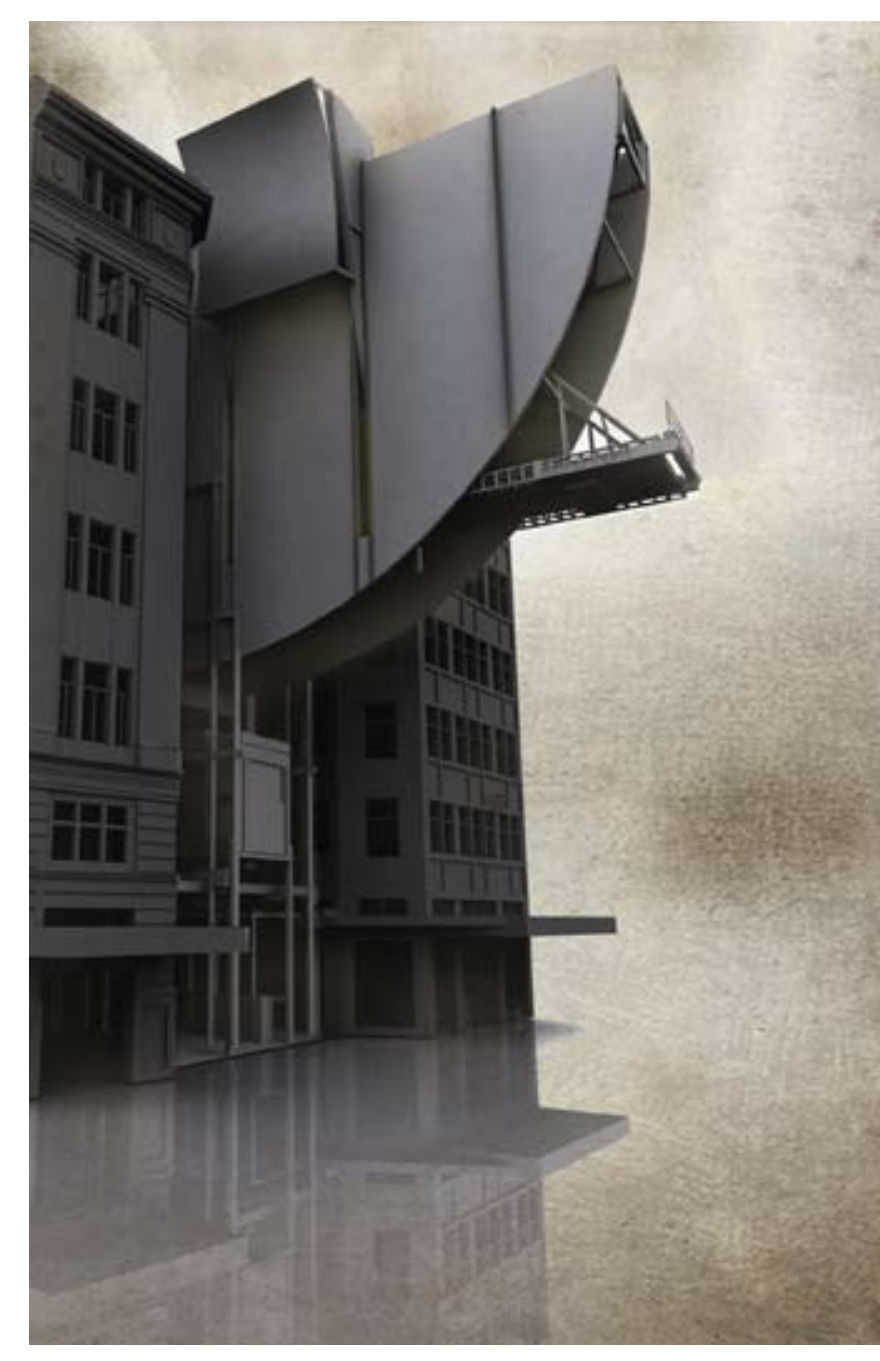

The outer architectural facade of the urban site provides the equivalent of inner architectural boundaries typical of traditional interior architecture. The design therefore challenges interior architecture to not be restricted to the interior constraints of a building but rather by buildings surrounding it. The exterior condition of the urban site becomes the interior condition of the design intervention.

This design intervention treats the surrounding urban context as the architectural shell in which it exists. The site of the outdoor pedestrian alleyway interacting with the design intervention inhabiting it, immediately challenges, through its exterior conditions, traditional presumptive boundaries of Interior Architecture. Secondly, approaching interior architecture as spatial installation in this design intervention integrates greater freedom from traditional constraints to drive the creation of interior architecture. Thirdly, the critical vehicle for the investigation is the nature of outdoor urban program and habitability set within a constructed installation space that crosses the boundaries into interior architecture.

The alleyway is the connective juncture of Lambton Quay through to The Terrace, two main streets of Wellington central city, and at present, it acts as a thoroughfare for pedestrians with two access points between the two streets. The Terrace end of the site is the highest point in the site, where the alleyway rises up to meet the footpath above. The Lambton Quay end of the site is opposite in scale. It has grand heights as the pathway drops down to meet the footpath at the end. The entry at the Lambton Quay end to the design intervention conveys and retains openness to continue the natural flow of pedestrians through the site. The design intervention mirrors the height and creates spaces for public interaction to happen. The design intervention creates 
circulation paths which are comprised of pathways mirroring the existing pedestrian thoroughfare. These walkways connect to the core of the design intervention through the centre of the site where the spiral staircase punctures

through the site. This stair acts as a marker for the central axis which shifts and projects left and right leading visitors into separate spaces opposing each other.

The design intervention is redefining what a program is, as there is no set program held by the intervention. It is a piece of architecture that is encouraging multiple programmatic uses by multiple inhabitants. The intervention changes in program due to the social needs of its inhabitants. The

programs can range from a place of reflection or relaxation to read a book to a gallery space for different types of art to be exhibited for public interaction. It can be sequestered for short periods by groups who want to take over the whole piece as an art installation or video installation for a week or a day, or it can be left empty to be filled with the social pedestrians moving through who wish to engage the architecture on their chosen level. When the space is left empty the design intervention becomes a piece of art itself and when inhabited and defined by the programs determined by the occupants it becomes a piece of interior architecture.

The linear site is divided by a shifted central axis which occurs at the one-third point of the alleyway. This point is where the site shifts off centre by the projection of latera alleyways on either side of the site. This shift is marked in the design intervention by the spiral staircase; this becomes the 'core' of the design. This core is where the scale of spaces changes from the public nature of Lambton Quay, to the private nature of The Terrace. The shift that occurs in the site through the core indicates where the scale of the spaces turn from public to private and where the side courtyards are projected out from a pivot point these shift off to either side of centre. These side courtyards enable the intervention to stretch out and breathe into open programmatic space on the left, while on the other side it fits neatly into the shadows of the surrounding buildings to enable the programmatic functions here to involve projections or film exhibitions through the natural dark space.

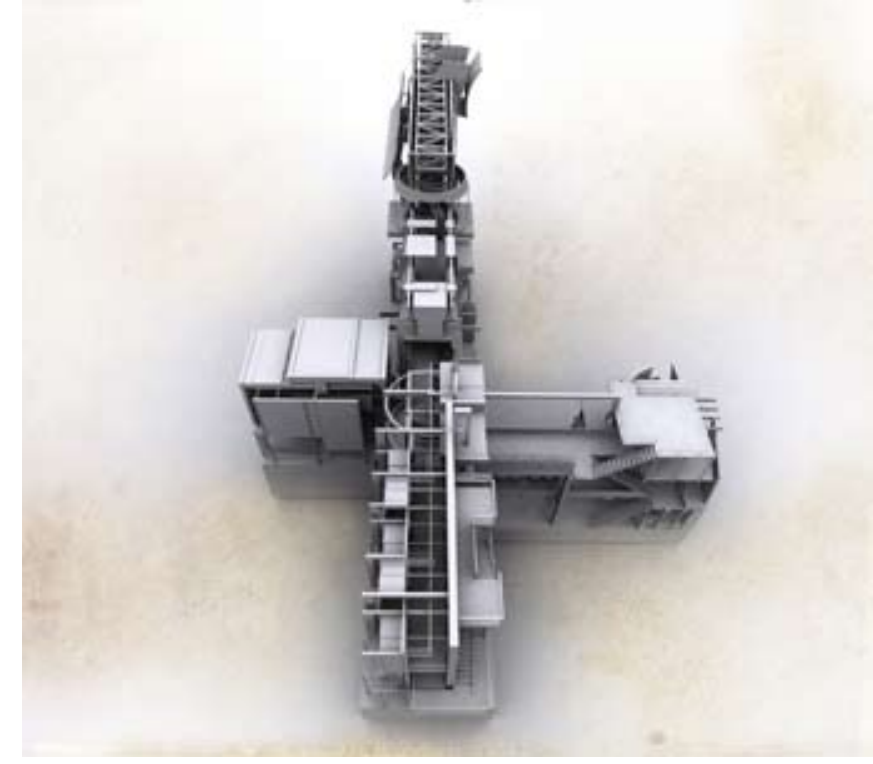

The core is where the vertical circulation occurs; through the middle, a vertical spiral stair punctuates the space while the horizontal paths become lateral projections through the design. These projections allow for more intimate 
functions, whereas the main core zones allow for more open public engagement. This stair punctuates through the axis of the site as a marker for the shift in the lateral projection spaces which has taken place. The perpendicular nature of the shift from the alleyways emphasises a continuous meeting point for the two different populations that enter the space from either end. The stair acts to imply and embrace the shifting of the site; it implies the different identities of the design, the back vs. the front, the public vs. the private. Not only does the stair act as marker for the physical shift in axis but as marker for the physical and emotional change in scale and space.

The stair is echoed again at the two-thirds point of the site. This stair enables the site to become a continuous pathway from the Quay to the Terrace or vice versa. This stair allows for the horizontal pathways to continue through the core of the design intervention in contrast to the other stair which interrupts the path and shifts it to either side down the

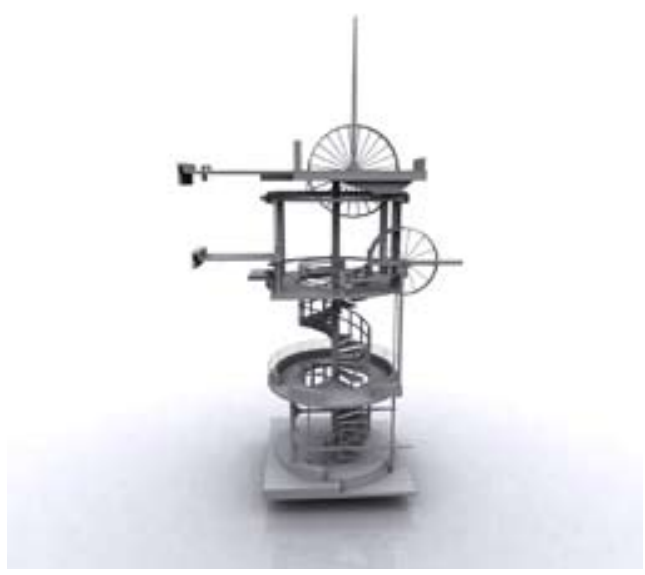

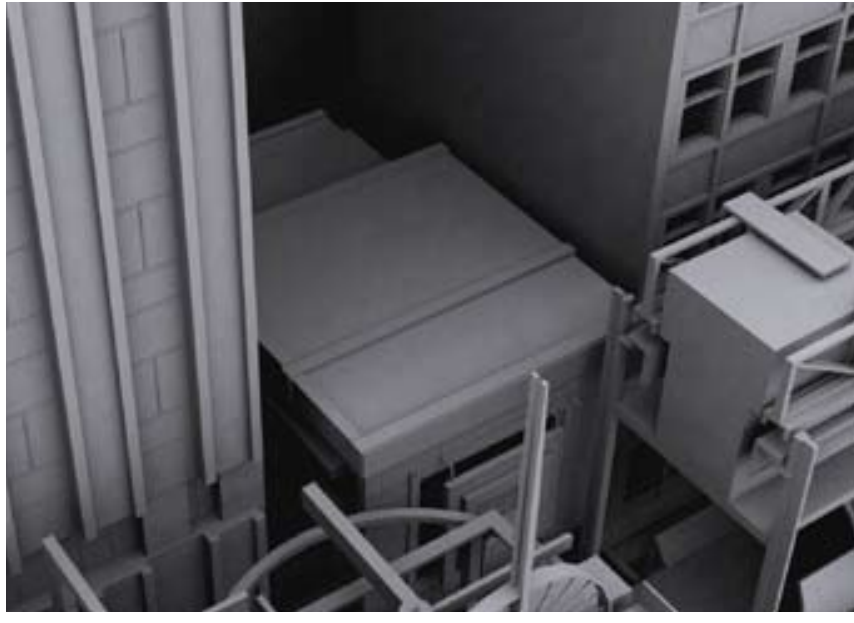

alleyways.

The courtyard, encased in natural darkness emphasises the natural characteristics of the space. This characteristic defines the programmatic functions of the space as the occupants inhabit it as a space for light projections and film art. It enables the inhabitants of the space to pass up and through the space; otherwise they are able to pass under and view the projections and films from below. From below there is a void in the ceiling so the inhabitant can sit in darkness and become aware of what is happening above. This space is elevated above an existing building in the site; the reintroduction of the alleyway is to reintroduce the natural shift in the axis of the site and to anchor the central core.

The Terrace end of the design intervention is where the surrounding buildings and inhabitants have an existing social interaction with each other. The windows and platforms that 
are inhabited allow communication to pass from one to the other; the design intervention echoes these same platforms and windows to allow it to become the new player in the space. There are two types of vocabulary for the social interaction within the space. First, 'natural' platforms already exist in the site. These have created an existing interaction being the local occupants of the surrounding buildings and the occupants of the pedestrian pathway. This interaction occurs through viewing and communicating from existing windows and platforms, from building to building. The second is the new design intervention which mirrors these back into itself. It takes the existing platforms and windows and creates another set to face the existing ones. These windows are then echoed again into the design intervention through to the social pathway; the level of social awareness is deepened.

This mirroring set extends the social interaction to the design intervention and involves the acts of the audience. The occupant both views and is viewed. These social platforms are a mirror image of the real world (the existing site) versus the imaginary world of art (the designed installation). As one moves through the site, one is constantly experiencing the shift through the real world into the world of art as one experiences the change perception of space while inhabiting the designed piece of installation art.

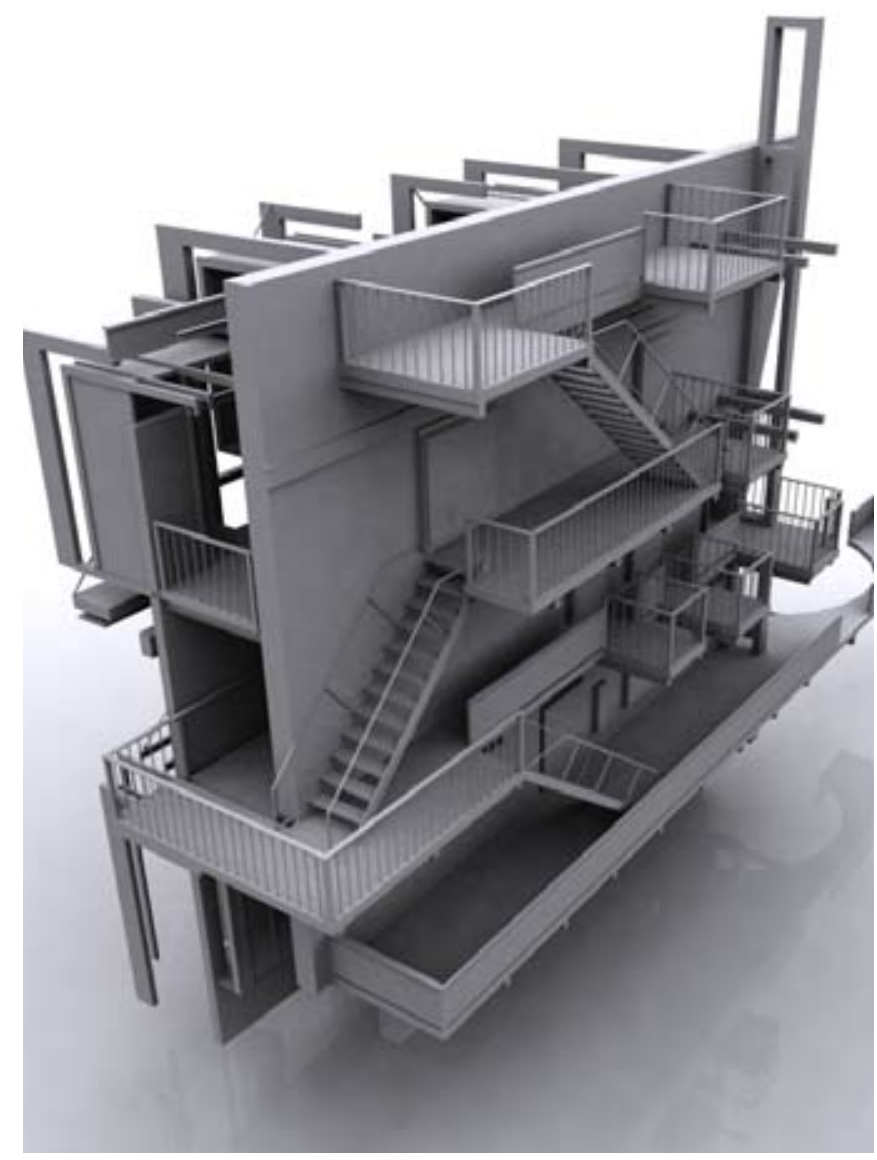




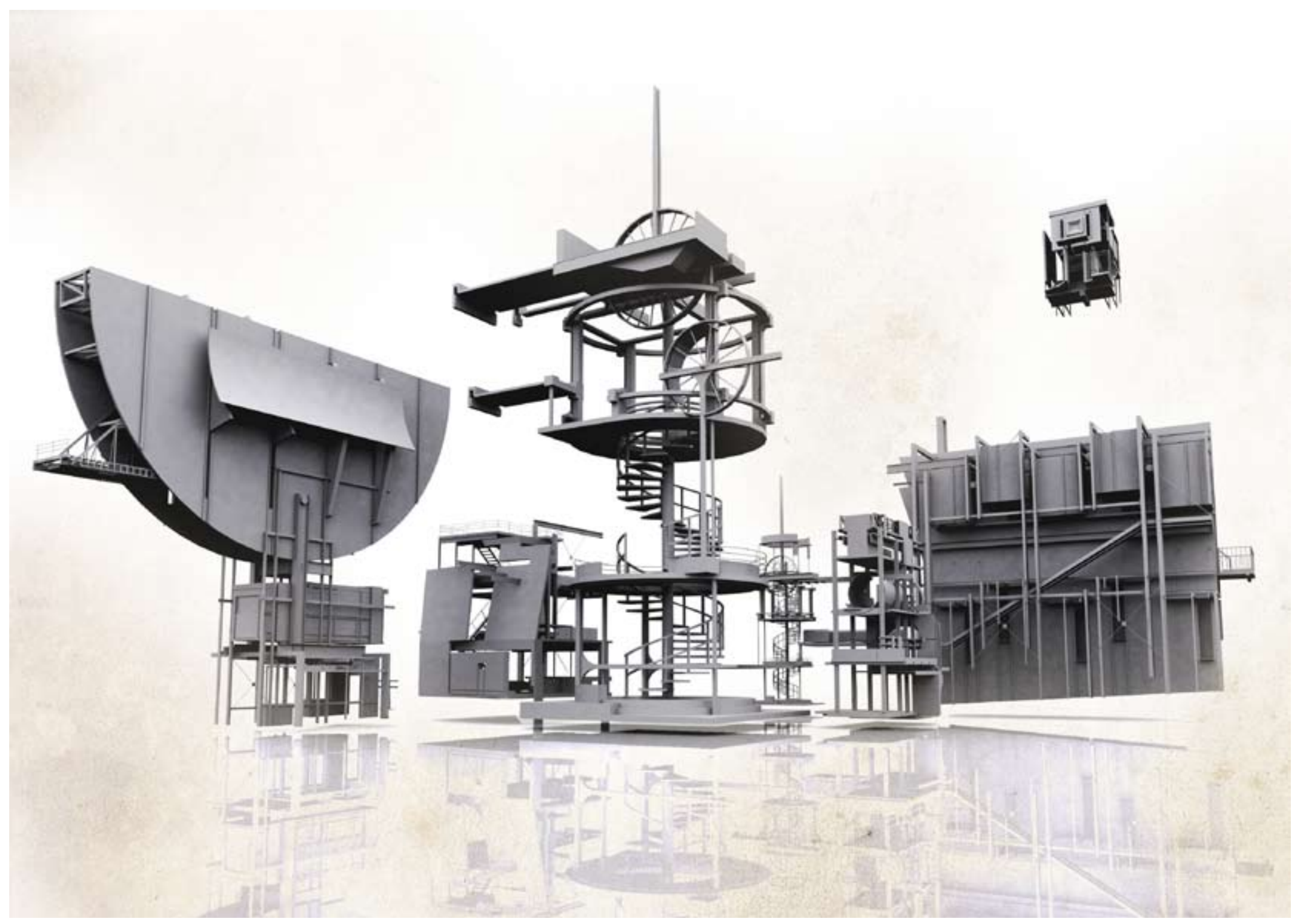




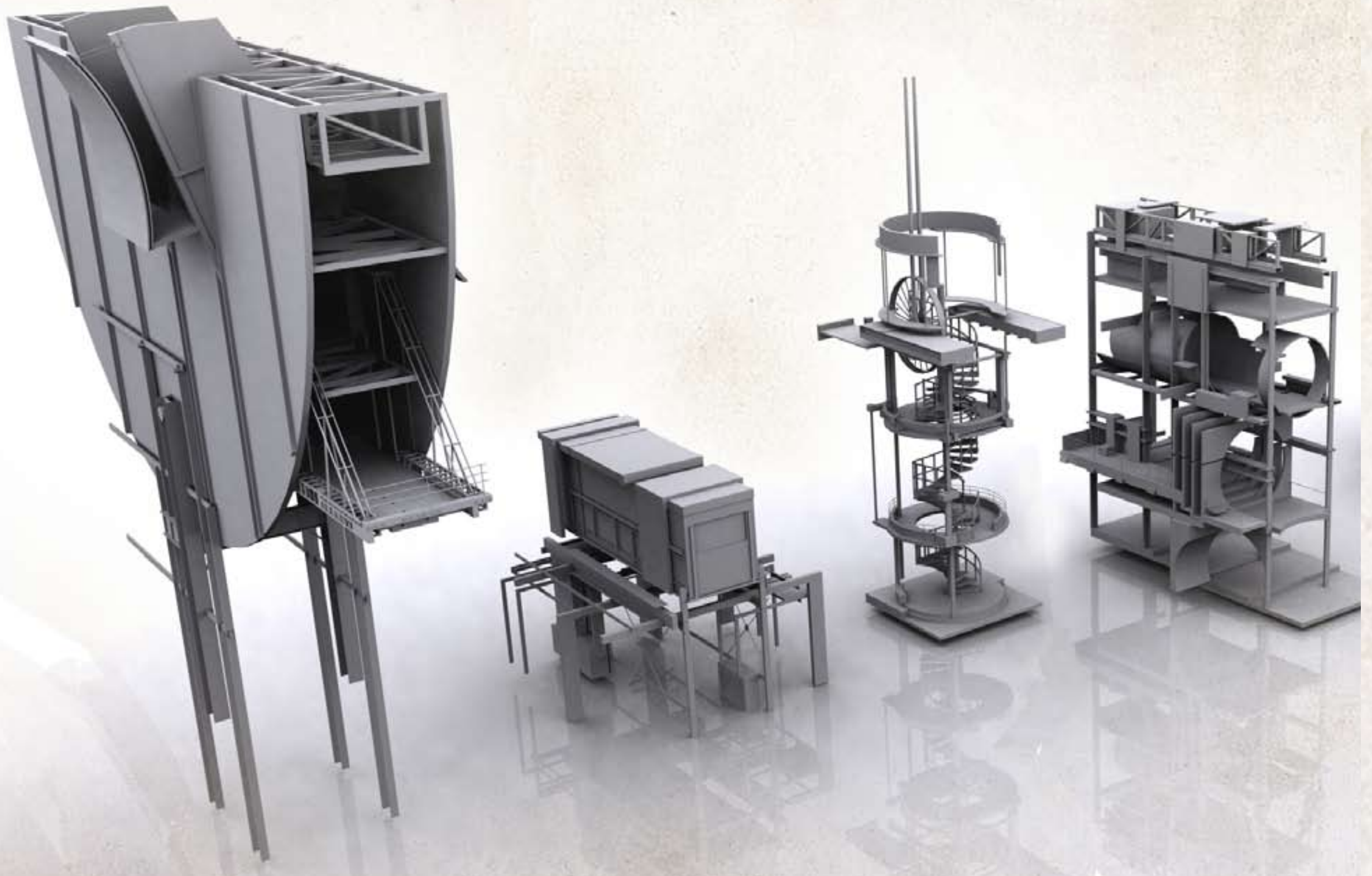




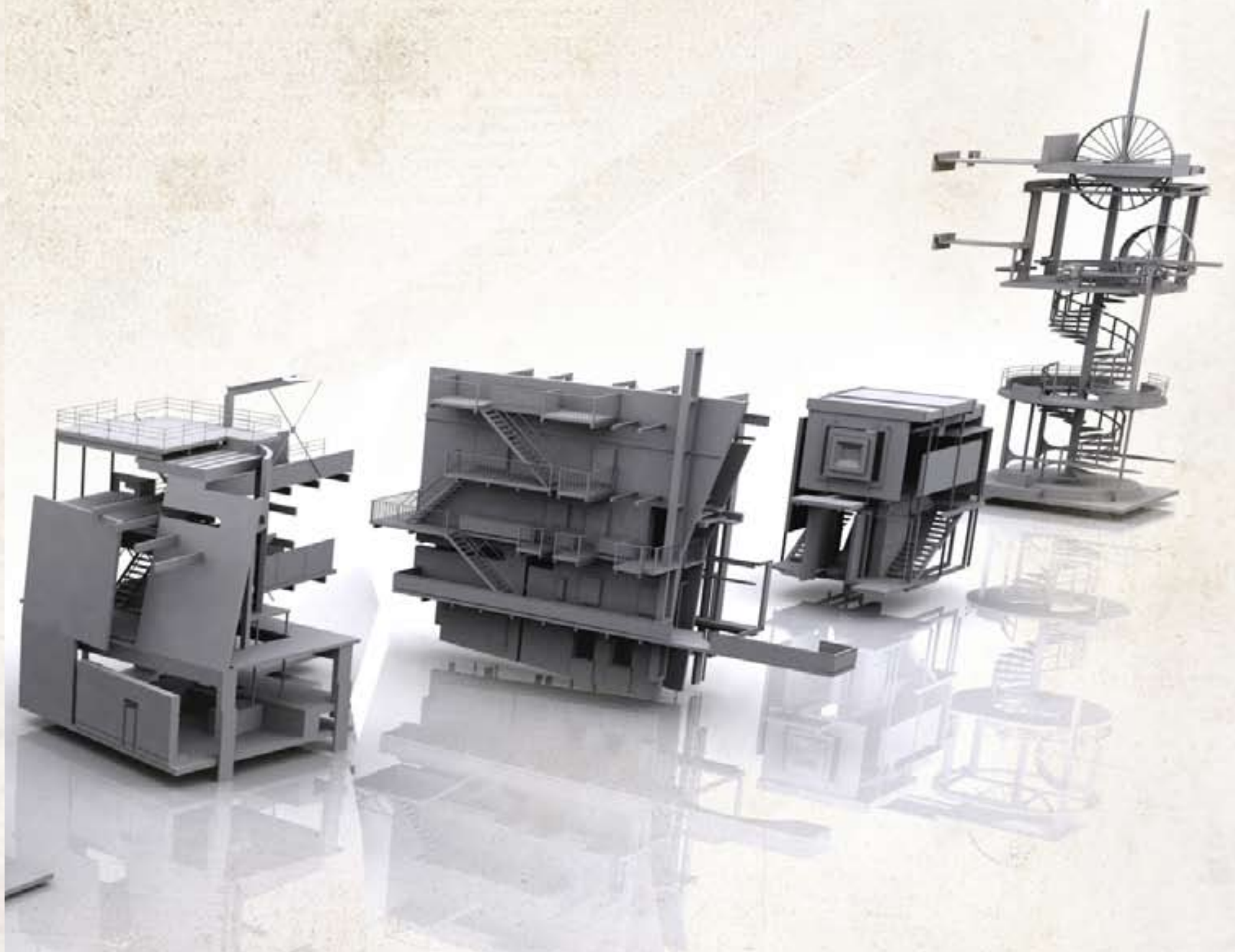



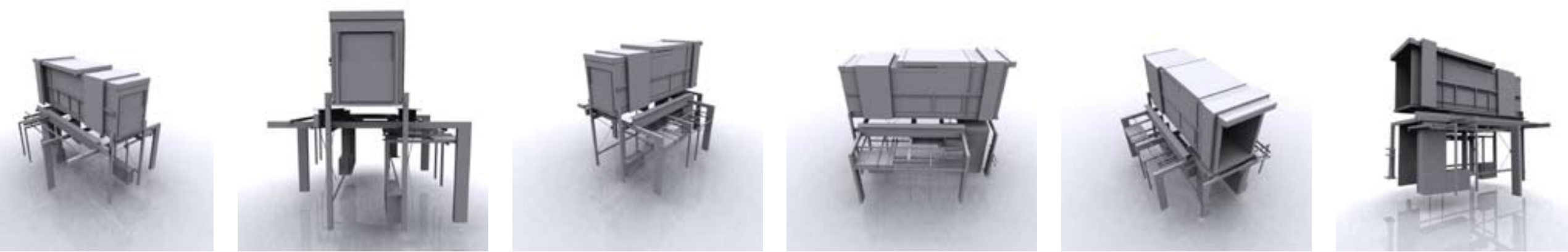

The invention braces itself against the existing surrounding architecture

The shopper from Lambton Quay enters to head home via The Terrace. 


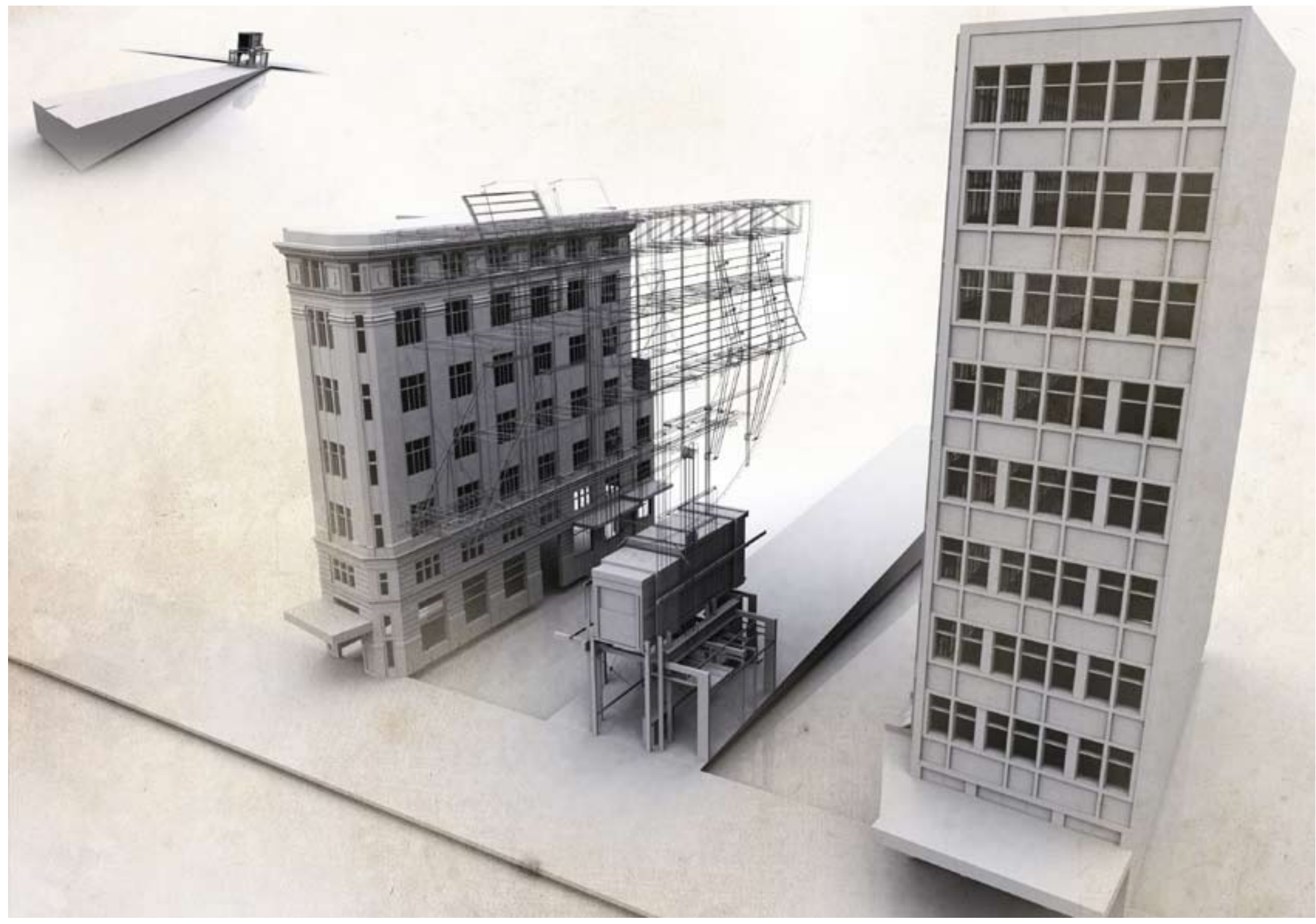



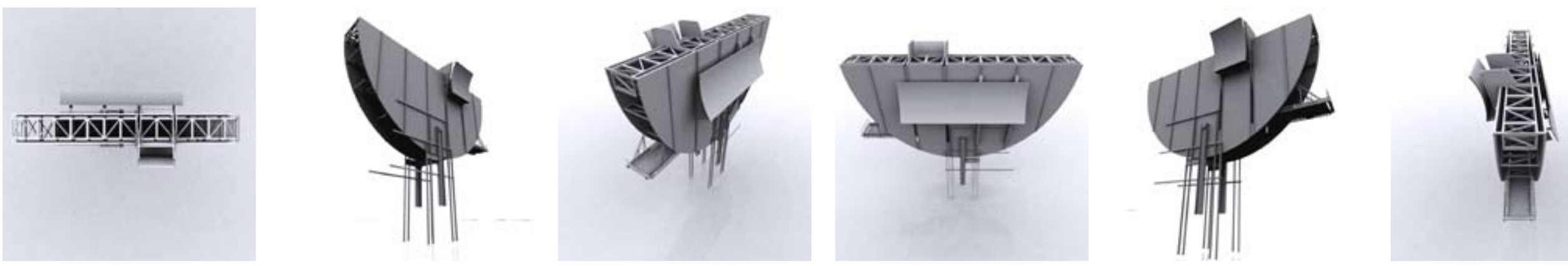

The invention introduces herself to Lambton Quay as her head extrudes from the alleyway to hang over the street.

The old man comes to view the sea and the horizon, a moment of peace in a busy area. 


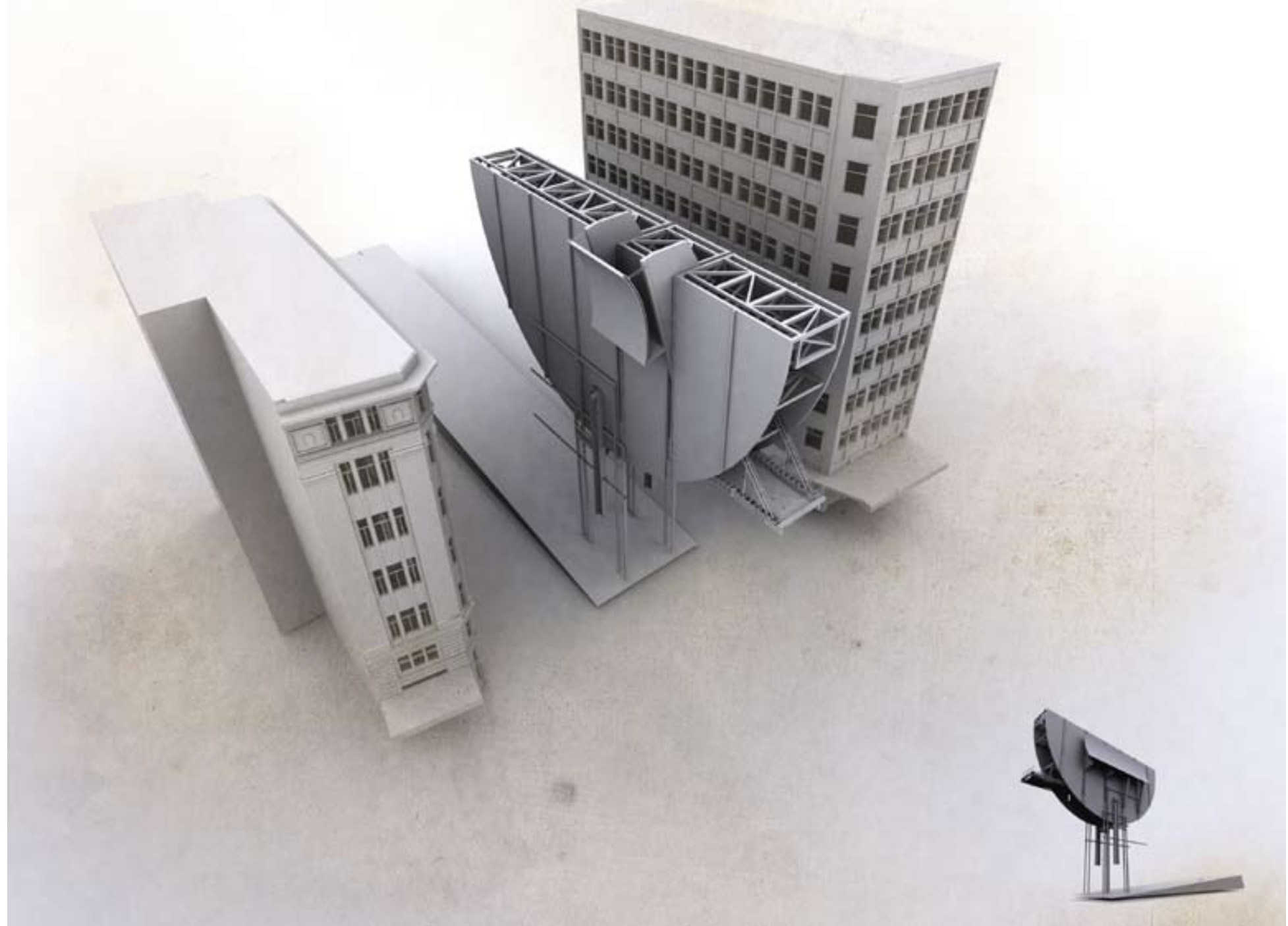



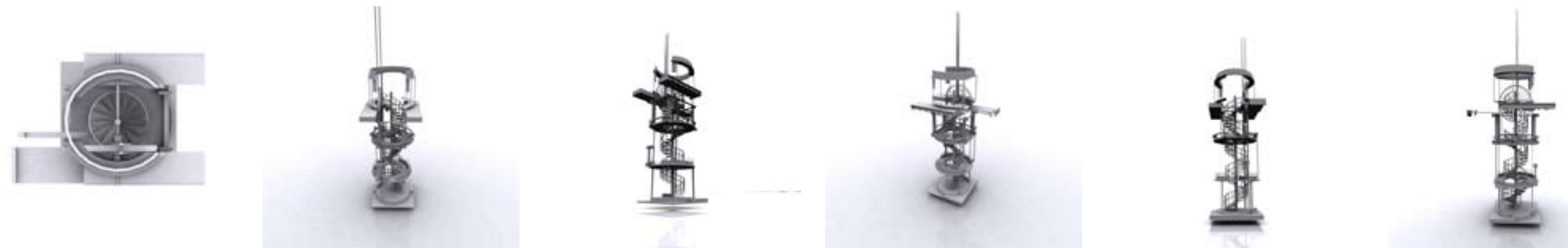

She echoes her sister who sits on the axis point behind her.

The business man climbs to find a quiet spot to read for his lunch break. 


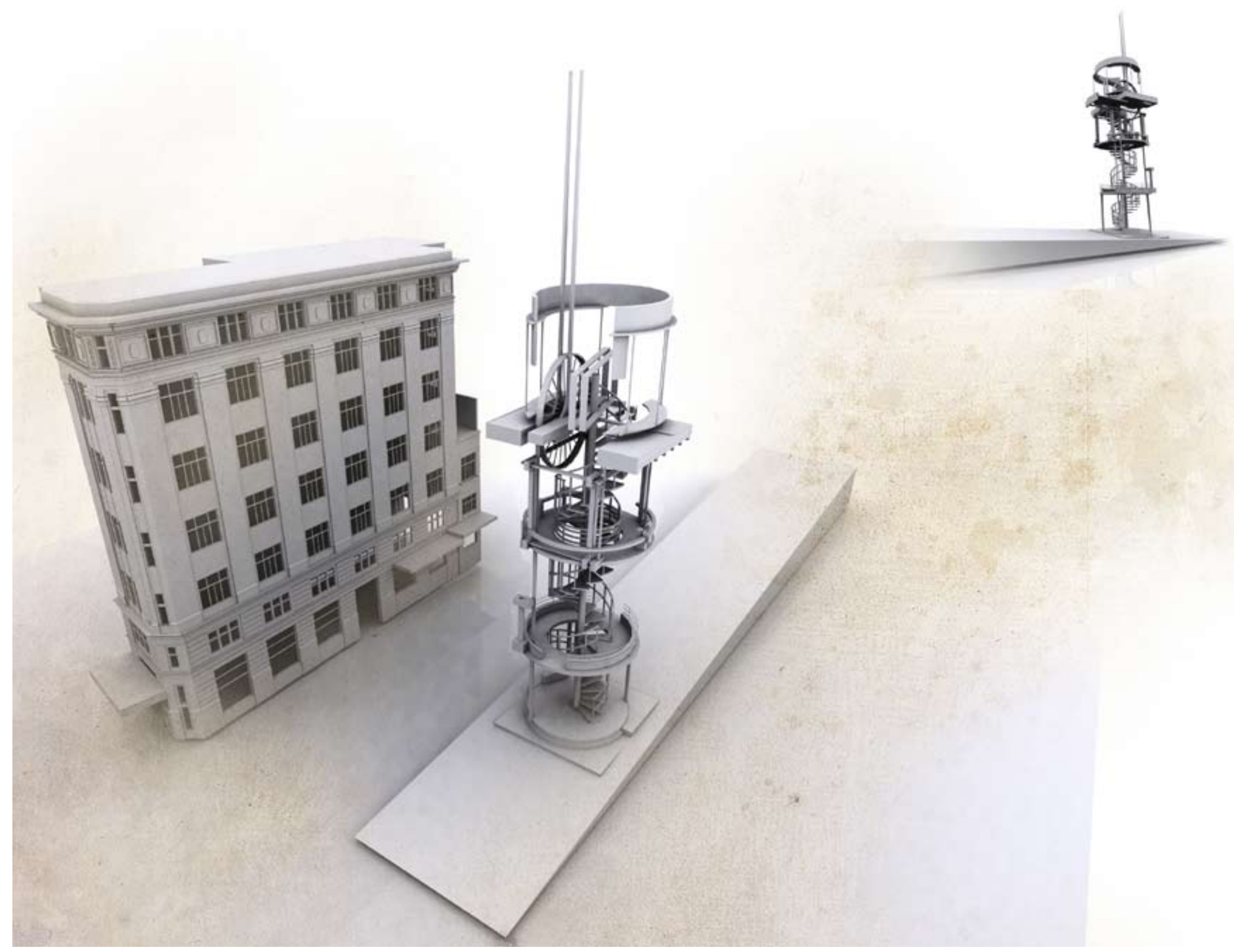



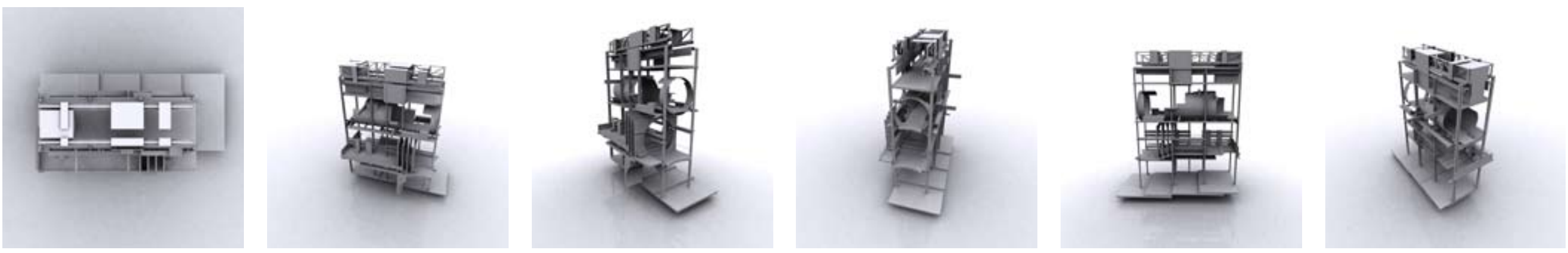

She in the linking bridge of the transition from public to private.

The art curator sets up for an exhibition of small exterior sculptures. 


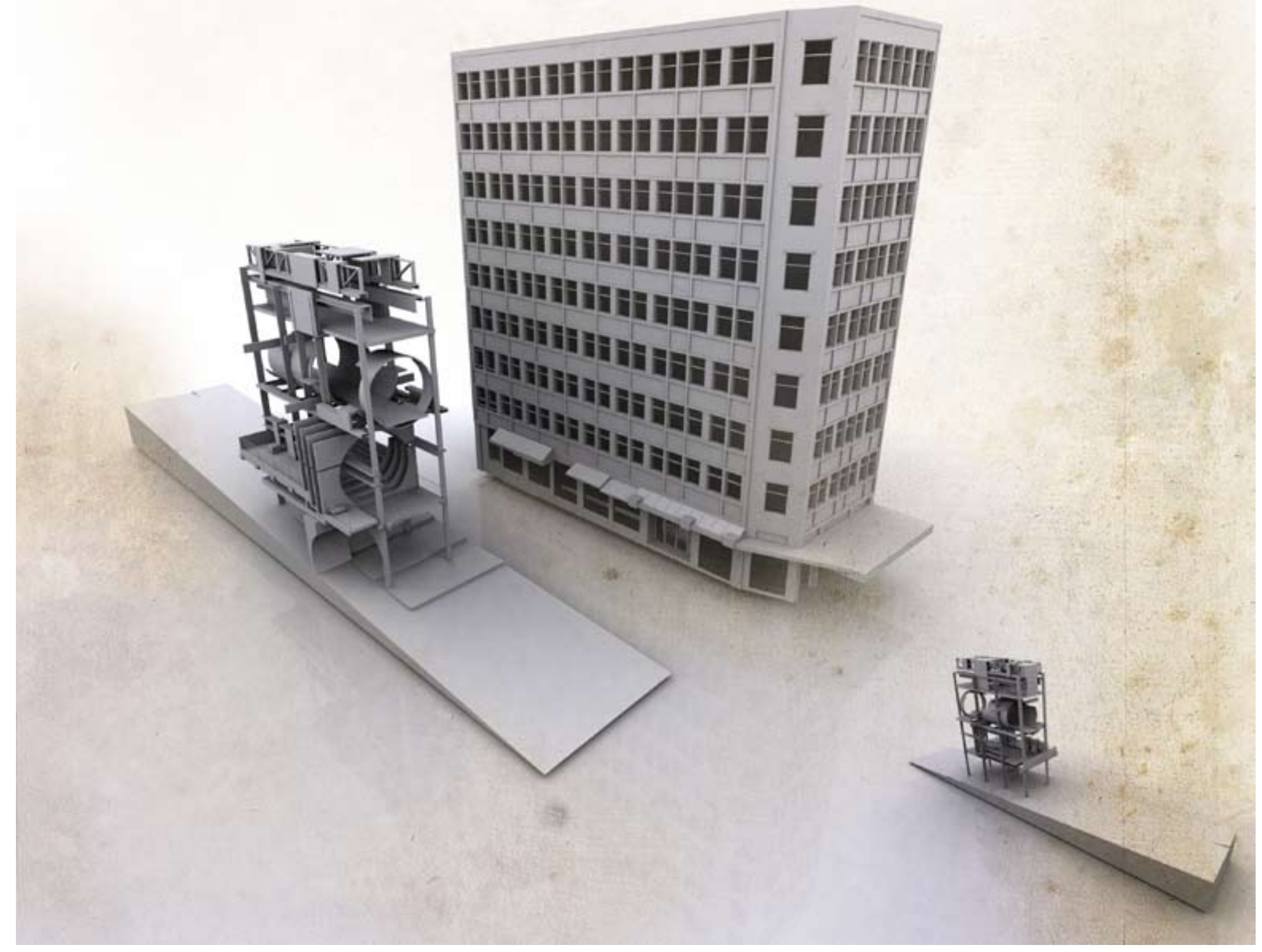



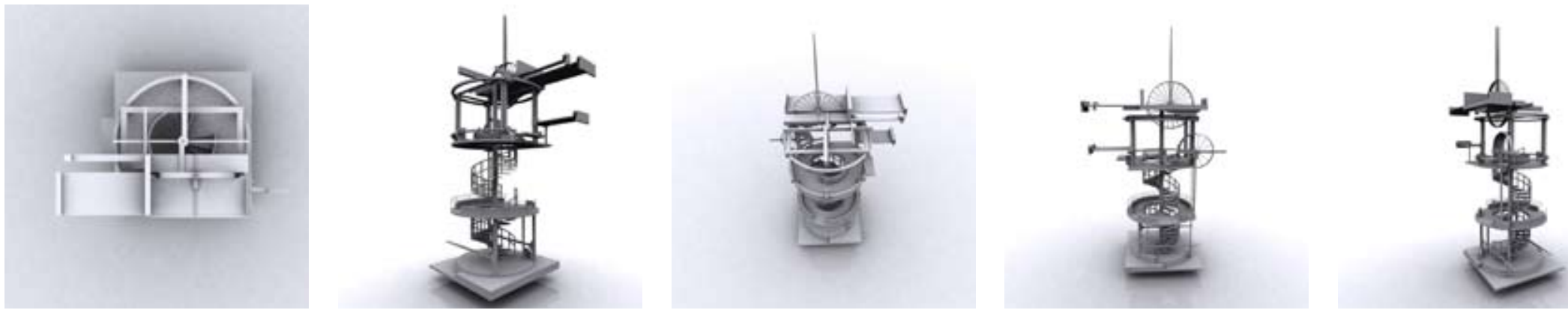

The core punctures through the laterial projection to mark the axis of the site.

The children climb the stair having races on the vertical playground. 


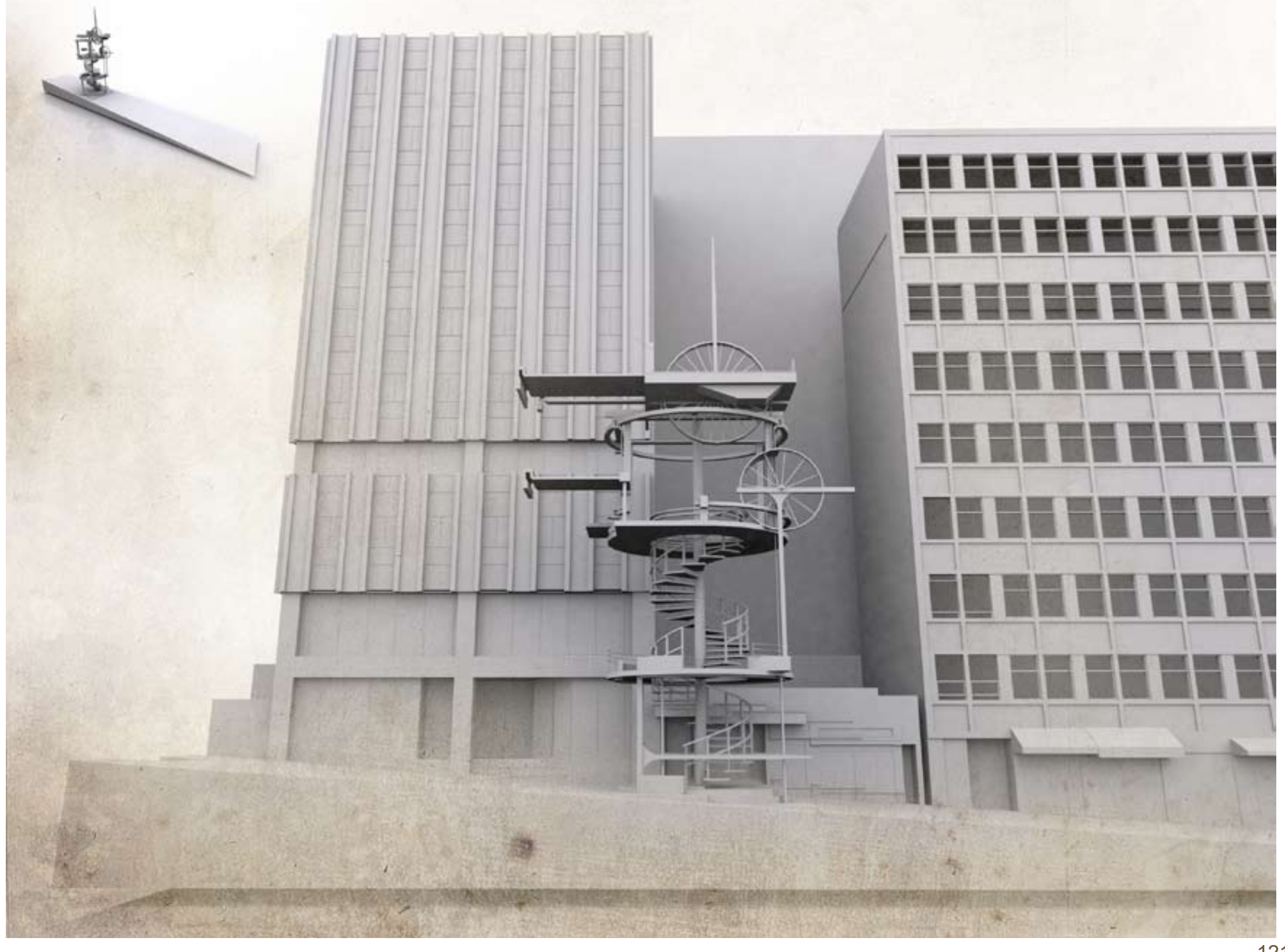



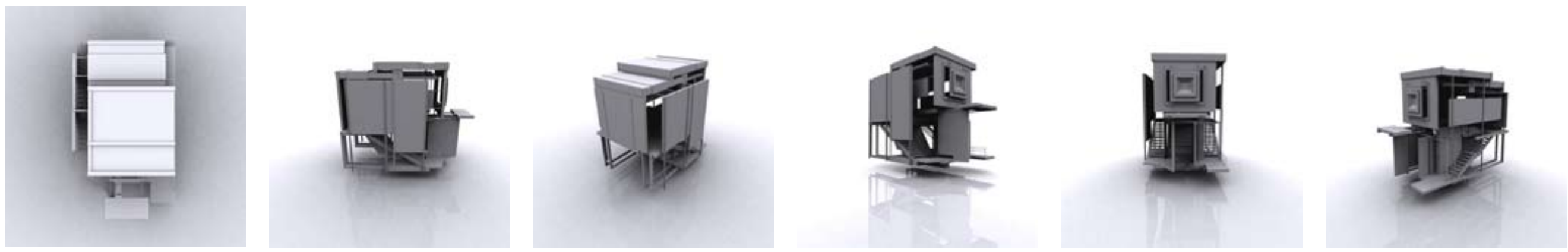

She hides back into the shadows in natural darkness.

The young business man takes a moment to be encased by the light projections of exhibition. 


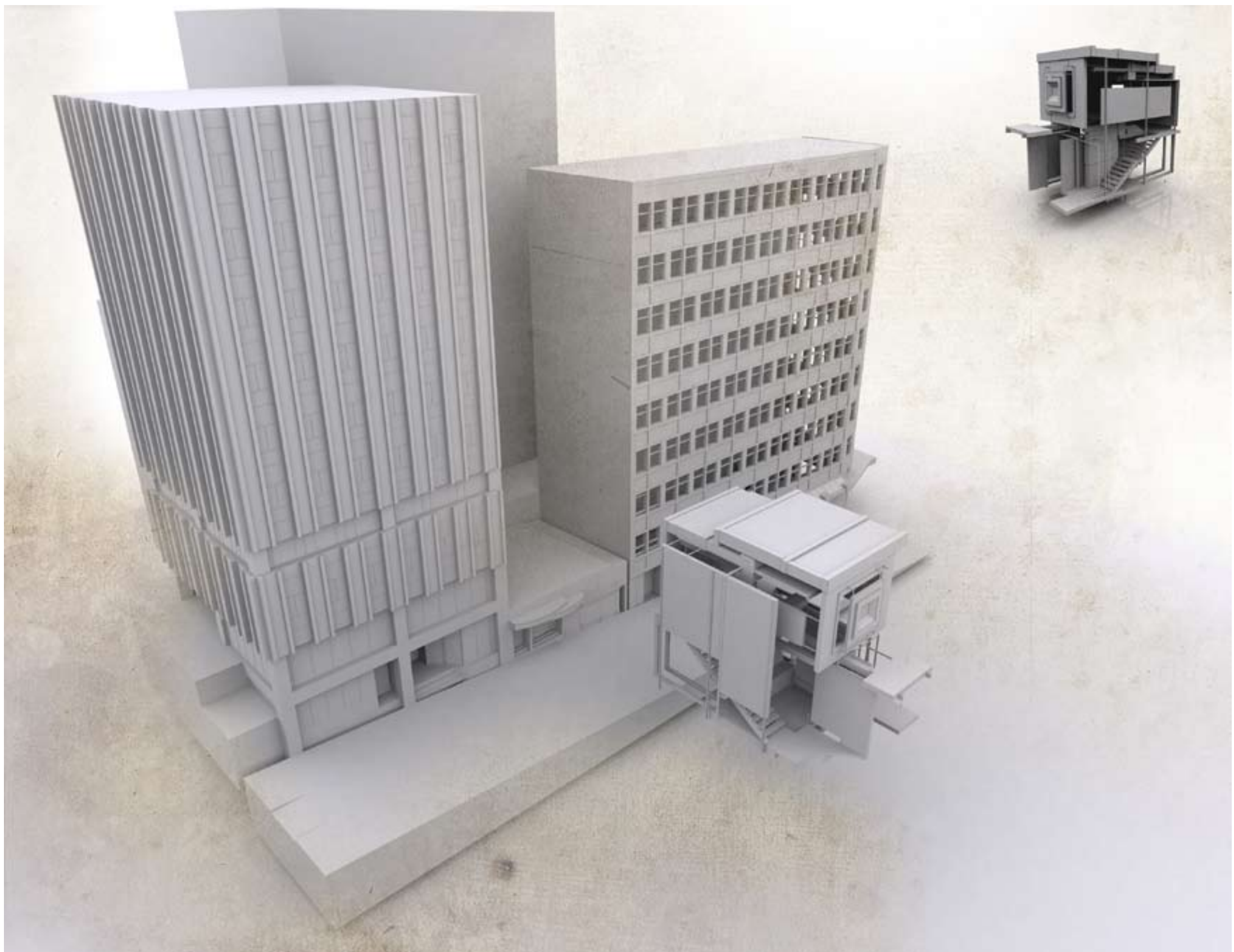



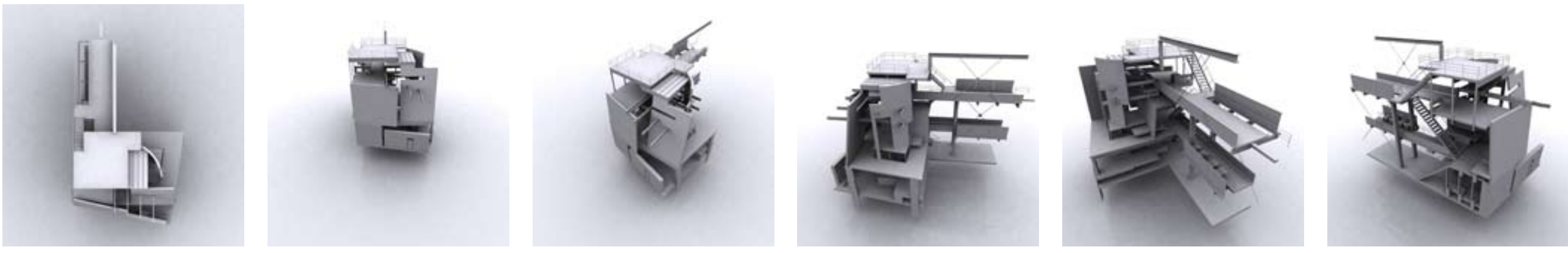

She opens out into the light courtyard opposite her sister on the opposite side.

The highschool students hold a drama play on the open platforms. 


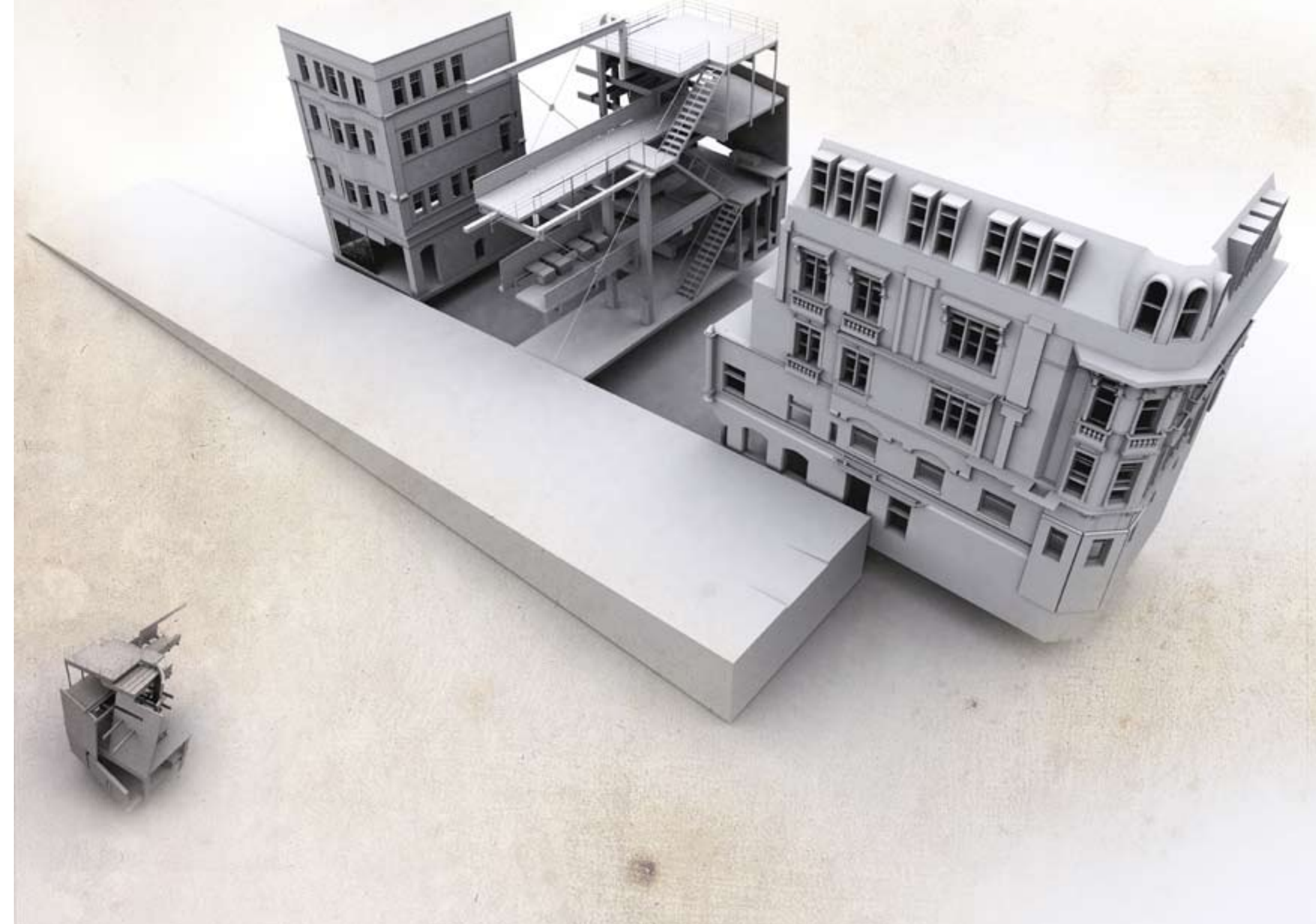



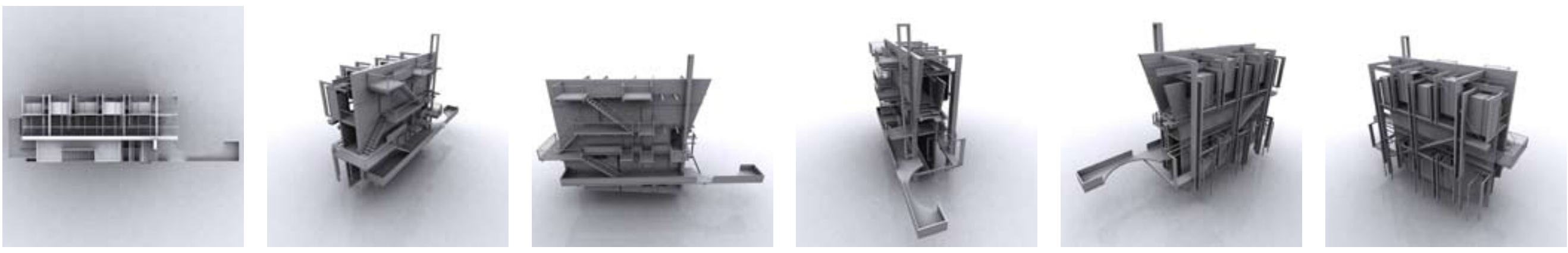

She is an open space of social interaction on one side and enclosed inimate spaces in the opposite.

The young mother finds a quiet place to read to her child. 


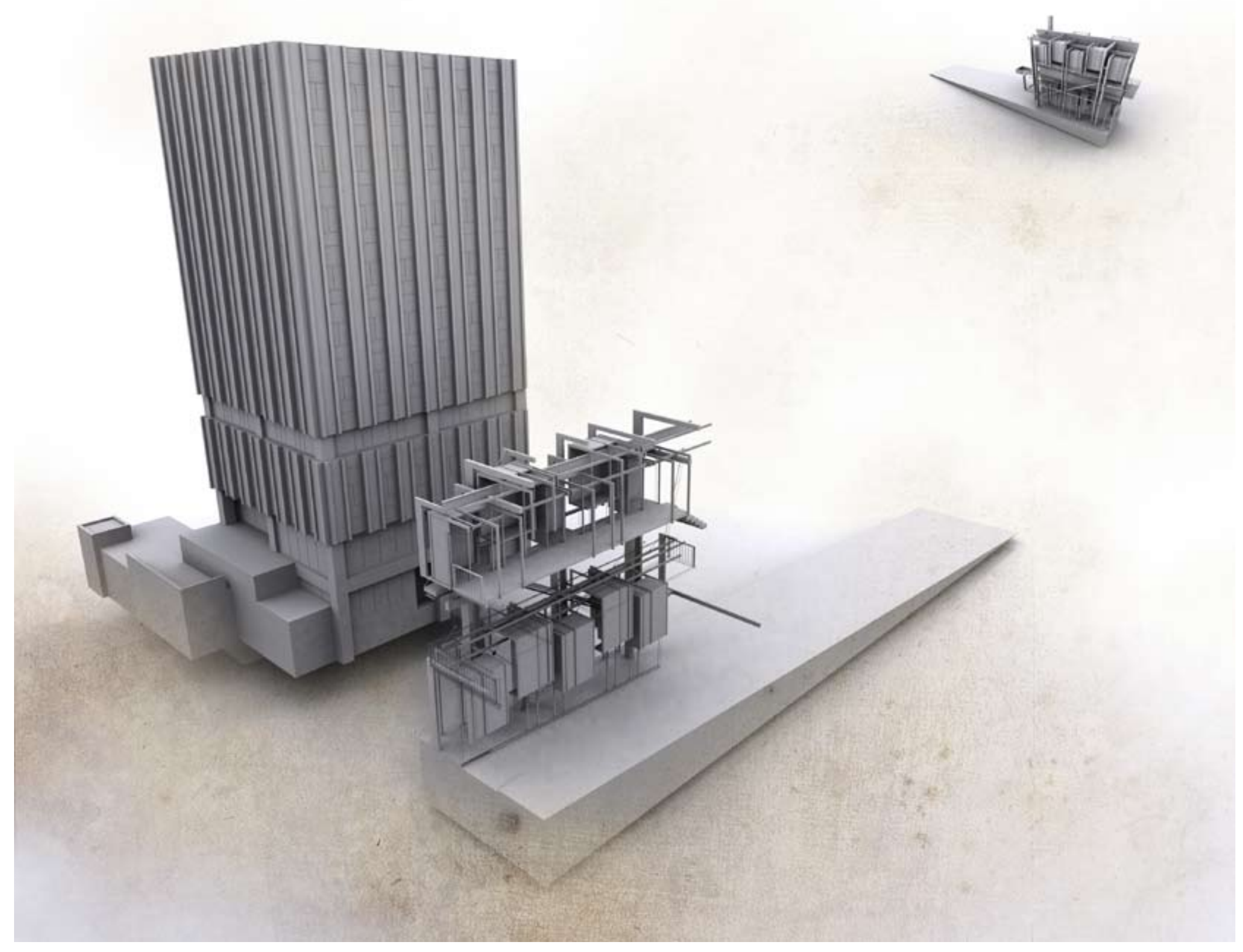




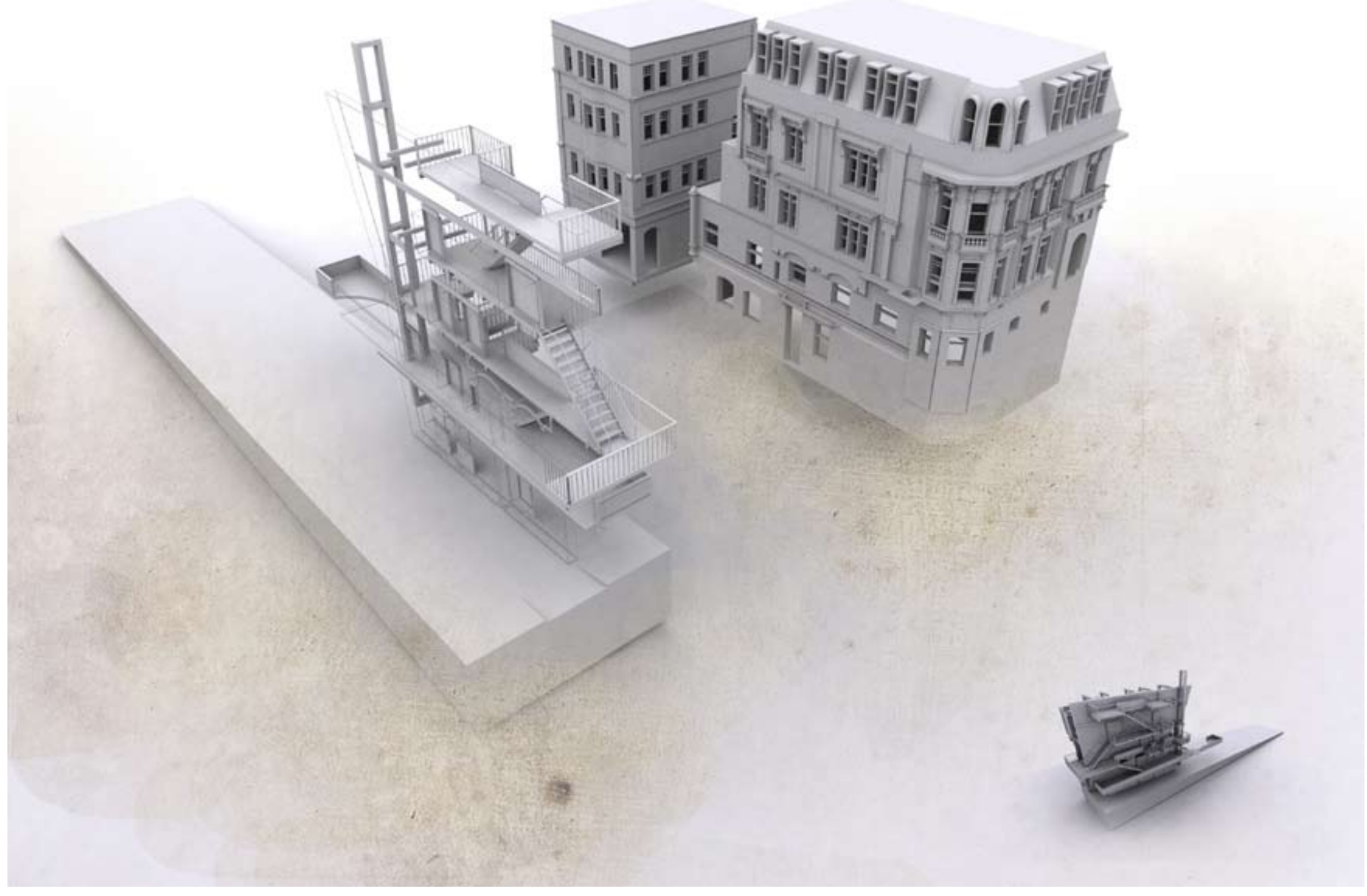




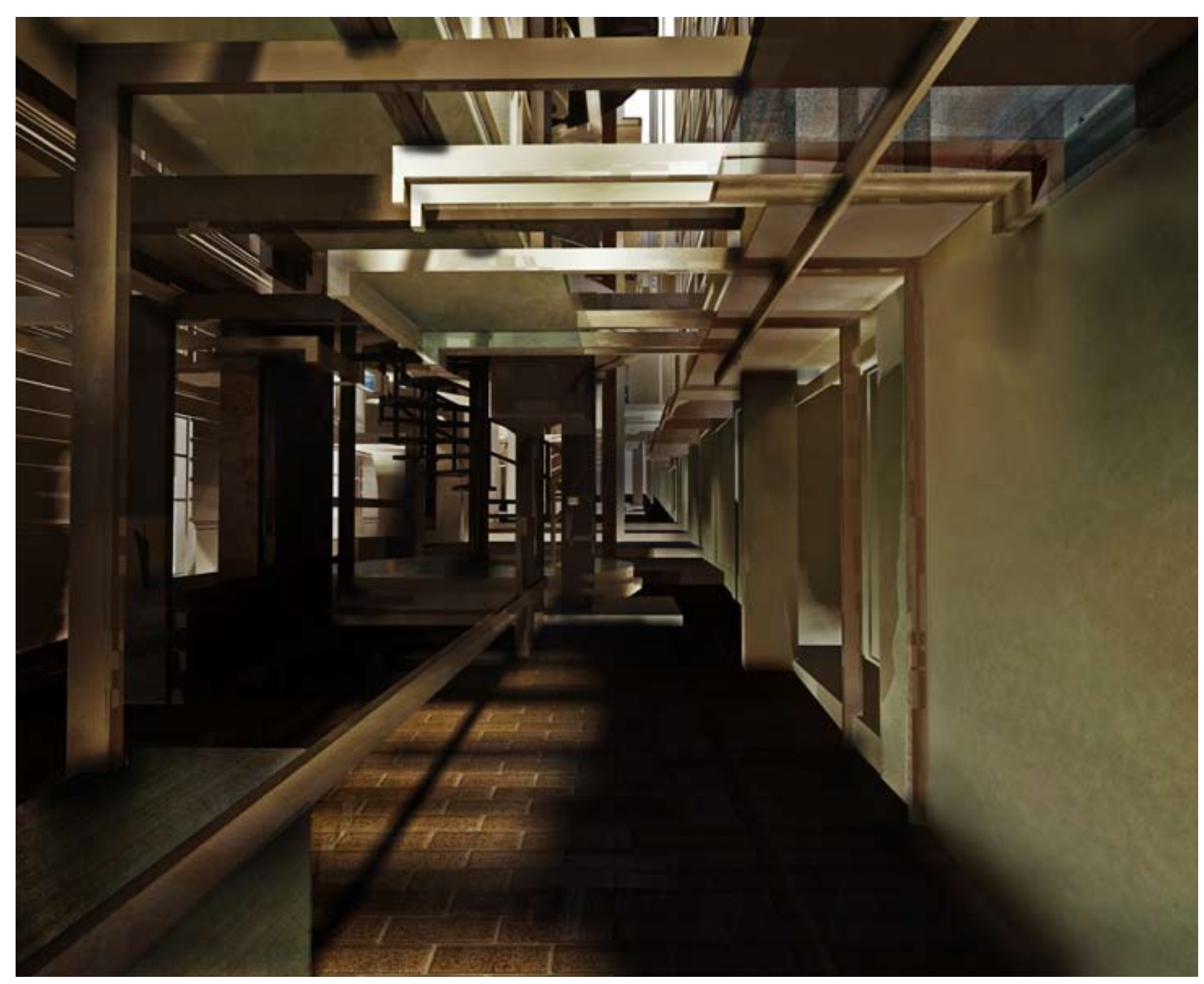

Entry from Lambton Quay 


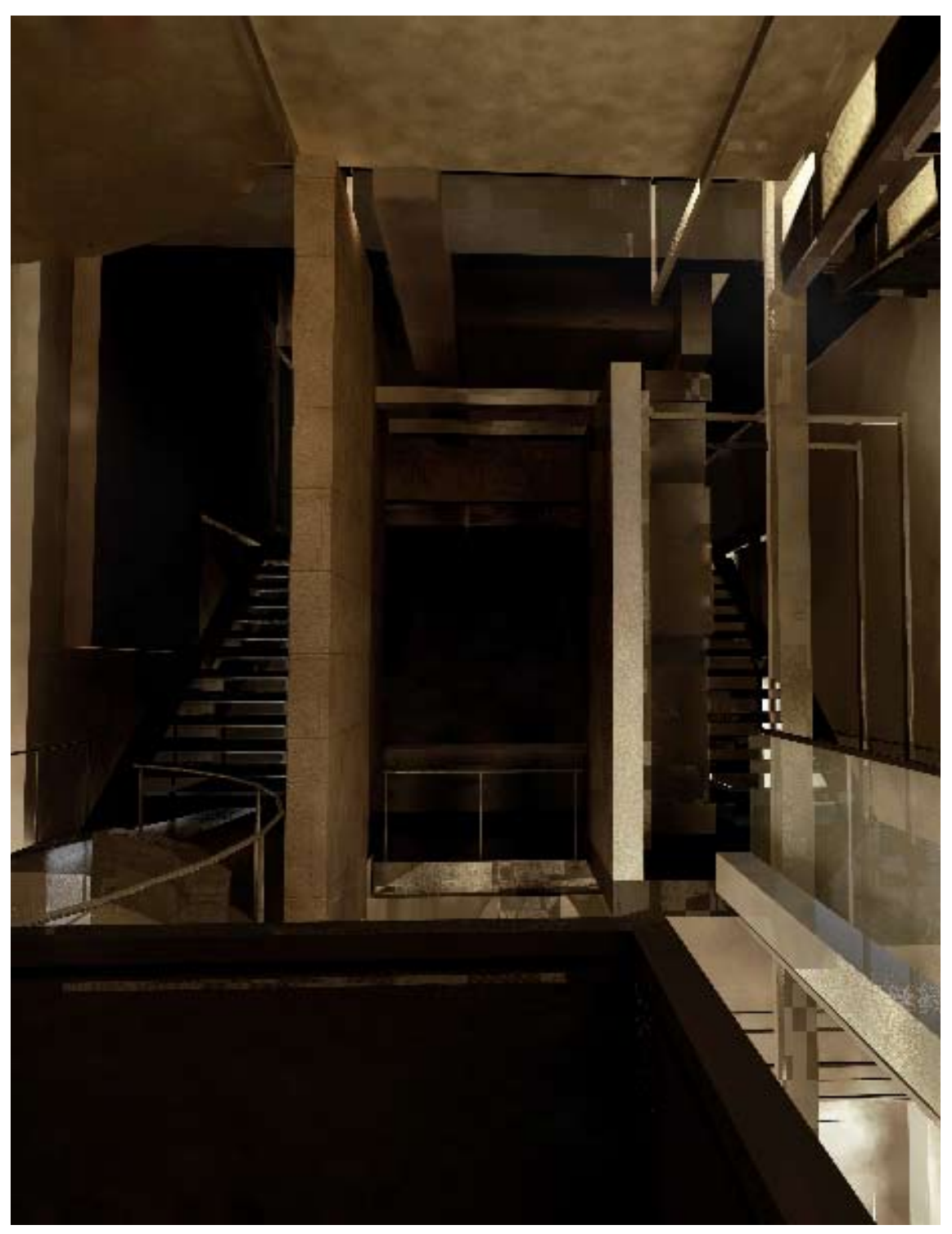

Entry up to the side courtyard for projections and film exhibitions 


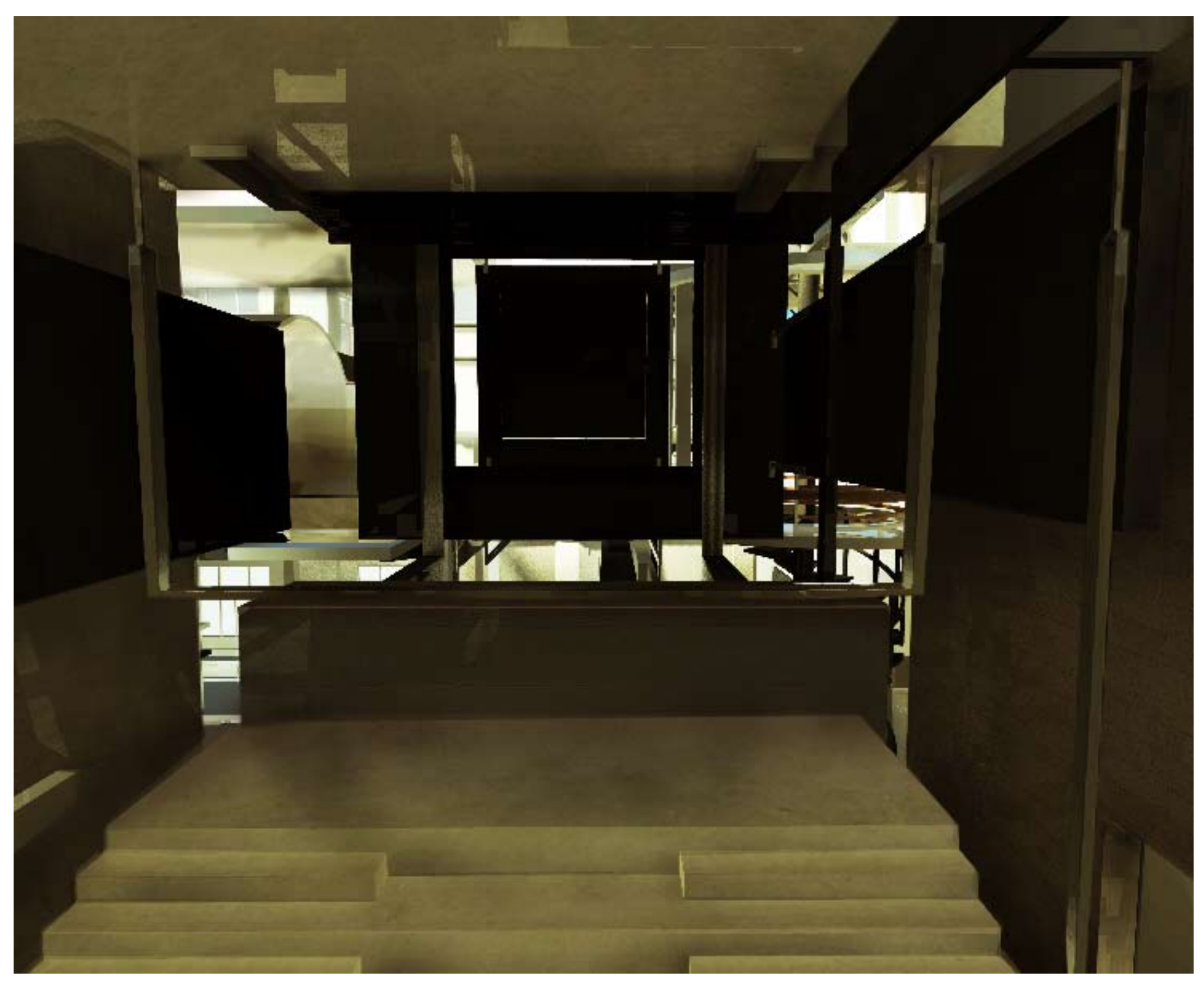

Dark side courtyard for projections and film exhibitions 


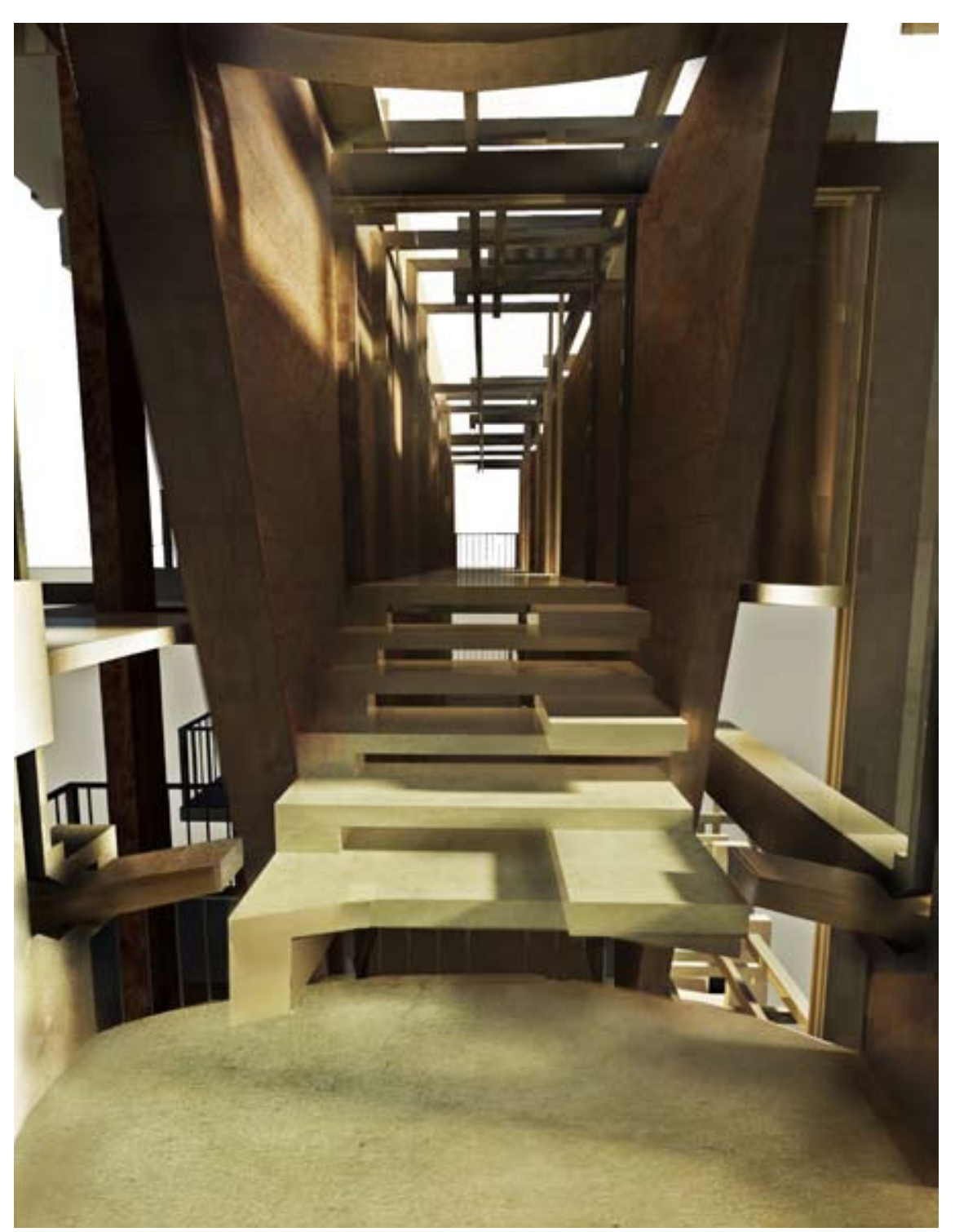

Pathway dividing the exposed and concealed intimate spaces at the Terrace 


\section{DESIGN CONCLUSION}

The research thesis aims to redefine the traditional and presumptive meaning of program, as this design has no set 'program'. It is a piece of architecture that encourages multiple programmatic uses by multiple inhabitants. It can be sequestered for periods by groups who want to take over the whole piece as an art installation or a video installation for a week or a day, or it can be left empty to be filled with the social pedestrians moving through, who wish to engage it on their own personal levels. This design invention is not defined with a set function for the entire space, but rather it enables program to exist and habitation to occur without predetermining what that will be. This engagement of function enables the design to embody the freedom of spatial installation as a medium, together with imperatives of interio architecture. The defining principles of interior architecture, spatial installation art and landscape architecture are all identified in order to create a contemporary multi-functional public work of interior architecture that crosses the boundaries of these disciplines.

The design intervention demonstrates how each inhabitant of the space can defines their own program. The intervention allows for the different populations of each street to combine and define the programme of the spaces at different times of day. Two types of programmatic function are developed, those involving the realm of art (artistic programs such as a city marker, a spatial installation) and those involving the realm of architecture (architectural programs such as a gallery space, a vertical public park). Each programmatic function is designed to enhance the existing conditions of the site, to introduce the intervention as an inhabitant in the space defined by the requirements of the occupant. The occupant experiences the built form as a threshold between art and architecture. As the occupant moves through the intervention, one experiences constant transitions and shifts in habitation from the real (the architectural) to the imaginary (the artistic).

The traditional constraints of interior architecture (that of containment by an architectural shell, and space defined by function and programme inhabited by an occupant) are coupled with the freedom that spatial installation art offers and the ability of the occupant to personally define the experience of space. This design demonstrates a transition between interior architecture and spatial installation art, where the two create a built environment that is both art and architecture with an ability to change according to the needs of the occupant.

The site provides a critical vehicle for investigating the transition between these disciplines, as its outdoor urban nature immediately challenges traditional presumptive boundaries. The design intervention emphasises the existing conditions of the site (the two different populations inhabiting the site from either end, the shift in axis, the shift in hierarchy and scale, and the existing social interactions between the buildings and pathway) to engage the investigation of the nature of program and habitability within a constructed installation space that crosses the boundaries into architecture. 